\title{
THE ASSOCIATION OF PERSON-ENVIRONMENT FIT AND WORK-RELATED ATTITUDES FOR CANADIAN FORCES PERSONNEL
}

by

Michelle Louise Mary MacArthur

A thesis submitted to the Faculty of Graduate and Postdoctoral Affairs in partial fulfillment of the requirements for the degree of

Master of Arts

in

Psychology

Carleton University

Ottawa, Ontario

(C) 2012, Michelle Louise MacArthur 
Library and Archives

Canada

Published Heritage

Branch

395 Wellington Street

Ottawa ON K1A ON4

Canada
Bibliothèque et

Archives Canada

Direction du

Patrimoine de l'édition

395 , rue Wellington

Ottawa ON K1A ON4

Canada
Your file Votre référence

ISBN: 978-0-494-94318-2

Our file Notre référence

ISBN: $978-0-494-94318-2$
NOTICE:

The author has granted a nonexclusive license allowing Library and Archives Canada to reproduce, publish, archive, preserve, conserve, communicate to the public by telecommunication or on the Internet, loan, distrbute and sell theses worldwide, for commercial or noncommercial purposes, in microform, paper, electronic and/or any other formats.

The author retains copyright ownership and moral rights in this thesis. Neither the thesis nor substantial extracts from it may be printed or otherwise reproduced without the author's permission.
AVIS:

L'auteur a accordé une licence non exclusive permettant à la Bibliothèque et Archives Canada de reproduire, publier, archiver, sauvegarder, conserver, transmettre au public par télécommunication ou par l'Internet, prêter, distribuer et vendre des thèses partout dans le monde, à des fins commerciales ou autres, sur support microforme, papier, électronique et/ou autres formats.

L'auteur conserve la propriété du droit d'auteur et des droits moraux qui protege cette thèse. $\mathrm{Ni}$ la thèse ni des extraits substantiels de celle-ci ne doivent être imprimés ou autrement reproduits sans son autorisation.
In compliance with the Canadian Privacy Act some supporting forms may have been removed from this thesis.

While these forms may be included in the document page count, their removal does not represent any loss of content from the thesis.
Conformément à la loi canadienne sur la protection de la vie privée, quelques formulaires secondaires ont été enlevés de cette thèse.

Bien que ces formulaires aient inclus dans la pagination, il n'y aura aucun contenu manquant. 


\begin{abstract}
The current research explored the association between person-environment fit and workplace attitudes for Canadian Forces members. The study explored the unique and combined influences of organization and occupation fit on affective and normative commitment, intention to leave, and psychological withdrawal. In addition, four moderators -- perceived organizational support, continuance commitment, civilian equivalence, and perceived job alternatives -- were evaluated. Hypotheses were tested separately for $(2,952)$ noncommissioned members and $(1,993)$ officers. Results indicated that person-environment fit was positively associated with organizational commitment and negatively associated with organizational withdrawal in an additive manner, but that person-organization fit was the stronger predictor for all outcomes. Continuance commitment buffered the influence of person-organization fit on turnover intention for noncommissioned members, but for officers, continuance commitment buffered the influence of person-occupation fit. The current findings suggest that person-organization and person-occupation fit are both important considerations for effective recruiting, selection, and retention of Canadian Forces members.
\end{abstract}




\section{Acknowledgements}

This work is the culmination of two years of work and stress, and finally a very proud moment in my life. This would not have been possible without the assistance and support of my supervisor, colleagues, friends, and family. I am very indebted to Dr. Janet Mantler for her endless patience. She supported my ideas, encouraged me to explore and learn, but at the same time taught me to be a more focused researcher and a more concise writer (someday I may actually learn where and when to place a comma). I also want to acknowledge the contribution of my prospectus committee members, (Dr. Tzvetanka Dubrovnik and Dr. Bernadette Campbell), for providing their advice and guidance. The administrative staff at Carleton, namely Etelle Bourassa and Jessica Palladin, were invaluable guides in navigating the administrative processes and always answered questions with patience; it was a pleasure to deal with them.

This project would not have been possible without the support of the Canadian Forces and the Personnel Selection Branch who sponsored my Master's studies. In particular, I want to thank Maj Karen Rankin who encouraged me to apply for the Master's program, assisted me in developing a practical project, and provided me with the point of contact to obtain my data. I also want to thank Dr. Irina Goldenberg who was instrumental in obtaining the data for my study.

Finally, I also want to acknowledge the unfailing support of my husband David, my two children Tammy and Timothy, and my friend Charlene who always make me feel like I can accomplish anything I set my mind to and always encourage me to reach for my goals, even when I believe they are unattainable. 


\section{Table of Contents}

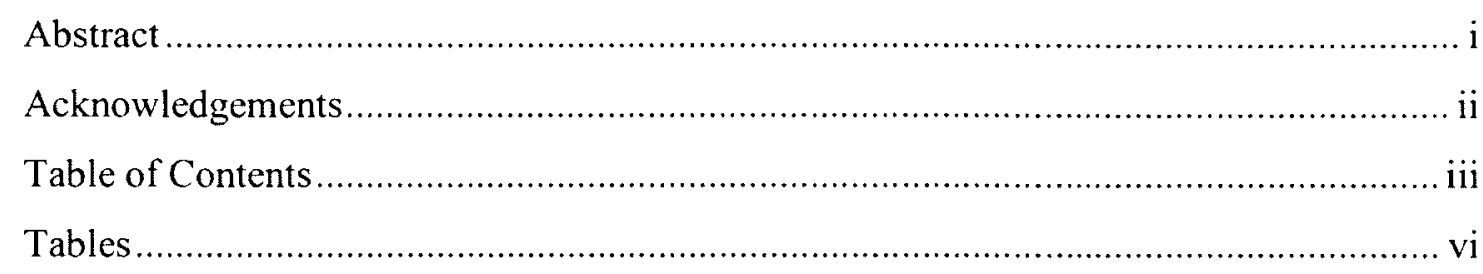

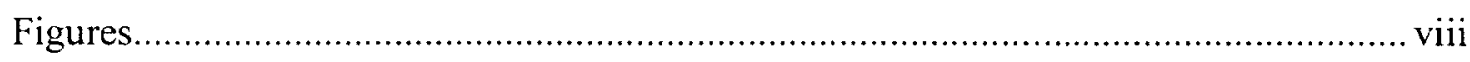

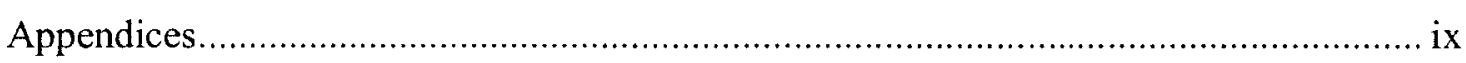

Person-Environment Fit Framework .................................................................. 9

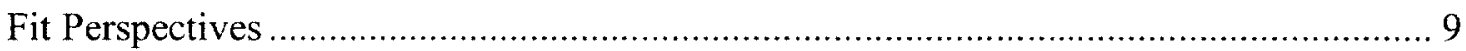

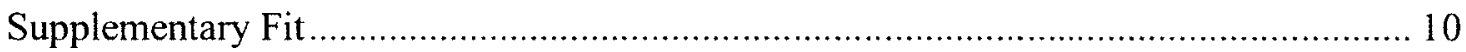

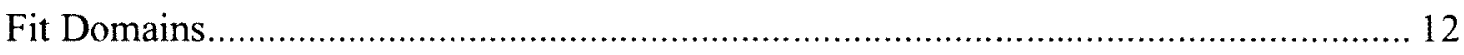

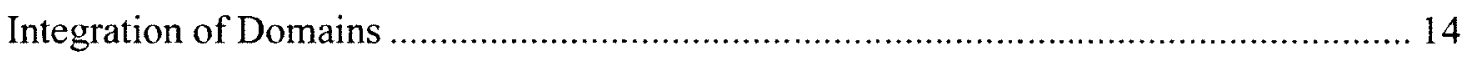

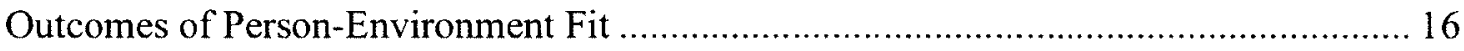

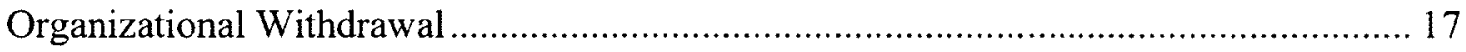

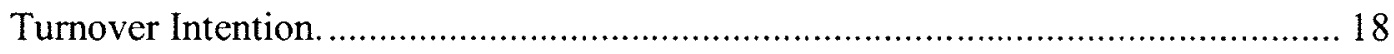

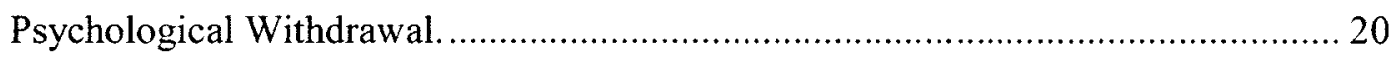

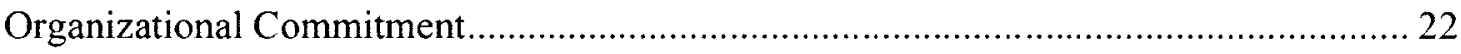

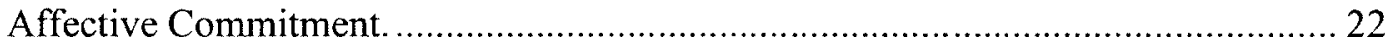

Normative Commitment. ........................................................................ 23

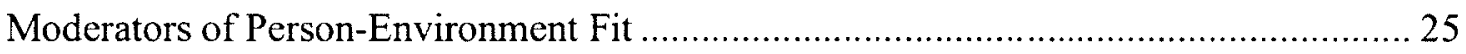

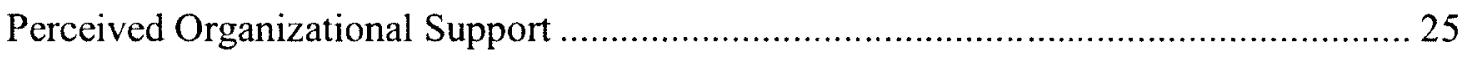

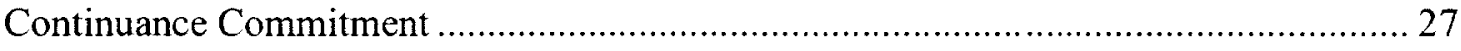

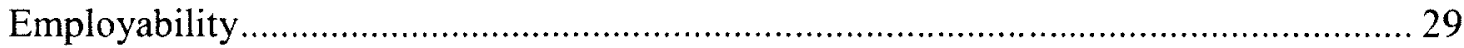

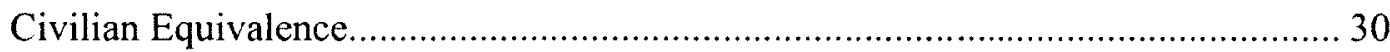

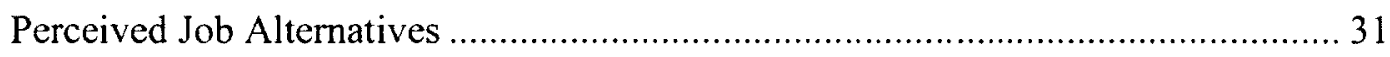

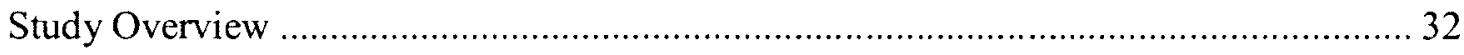

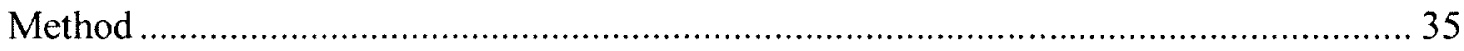

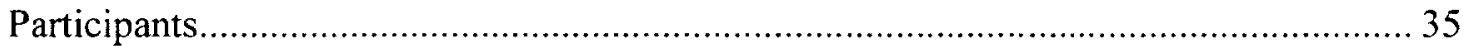

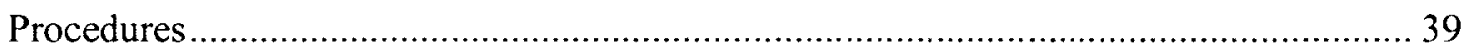


Person-organization fit.

Person-occupation fit.

Organizational Commitment.

Turnover Intention.

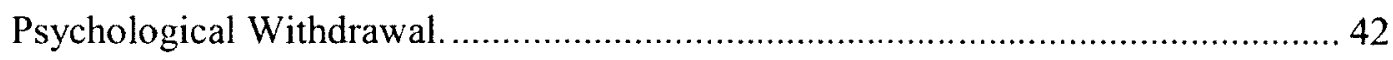

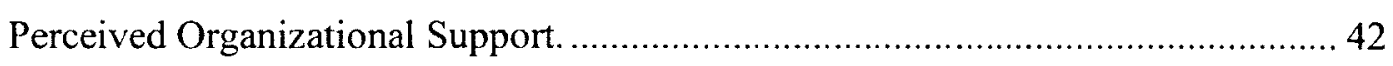

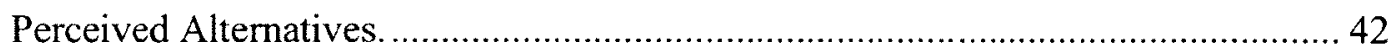

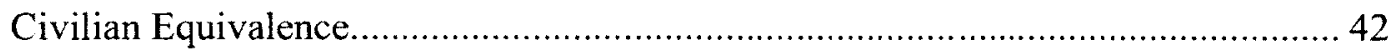

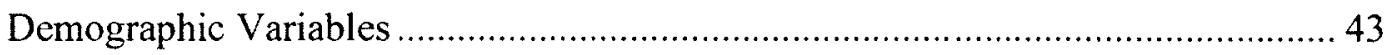

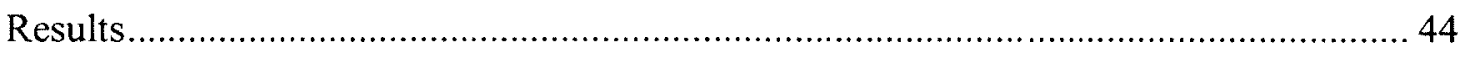

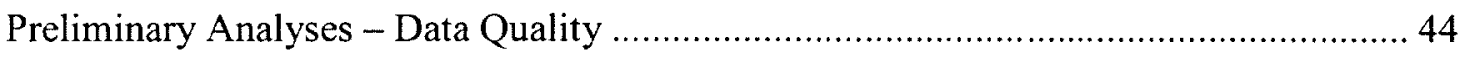

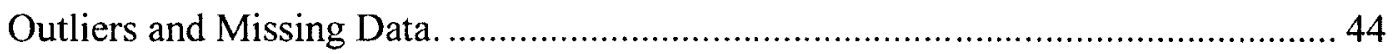

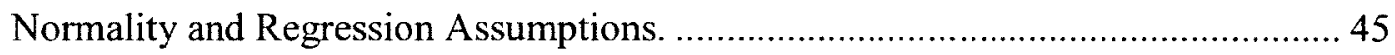

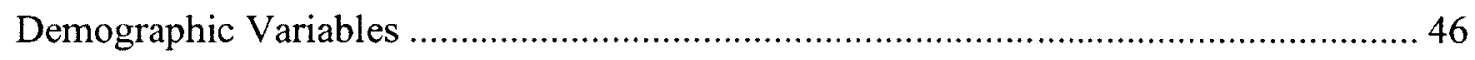

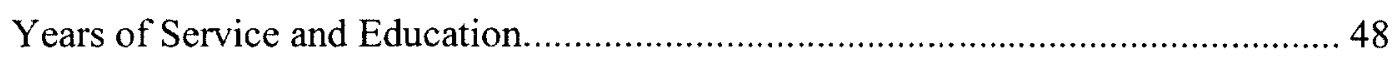

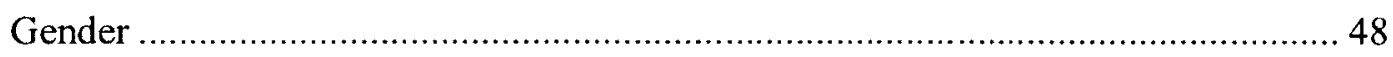

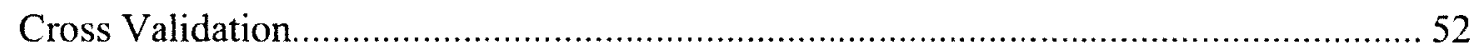

Tests of Person-Environment Fit Conceptual Framework.......................................... 55

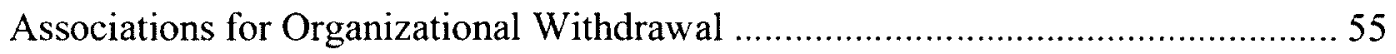

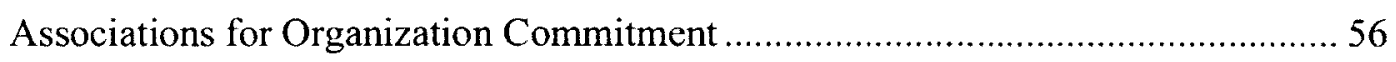

Direct Effects of Person-Environment Fit on Outcomes ........................................... 57

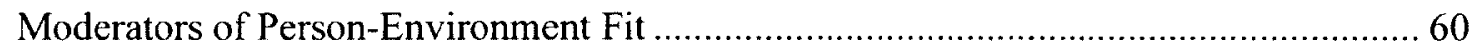

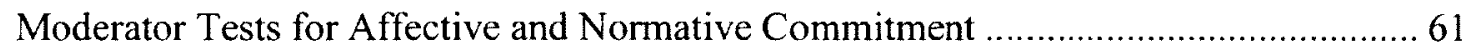

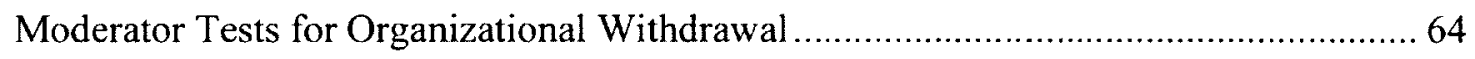

Moderator Effects of Perceived Organizational Support ................................. 64

Moderator Effects of Continuance Commitment. ............................................ 64

Moderator Effects of Civilian Equivalence .................................................. 71

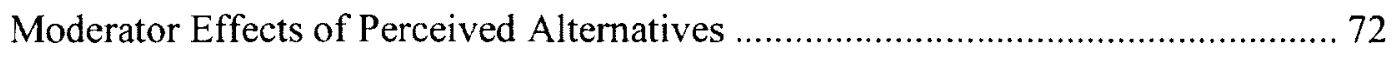

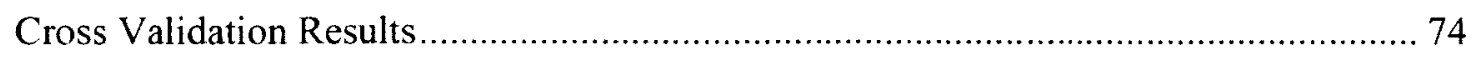




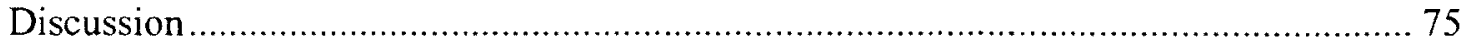

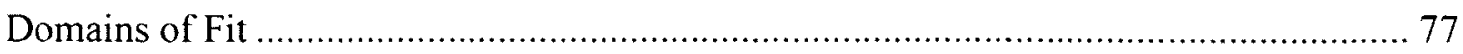

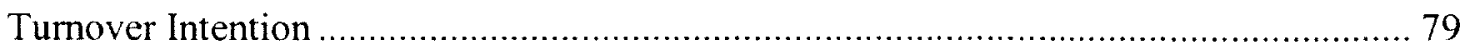

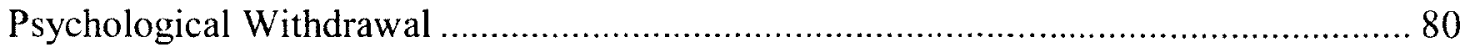

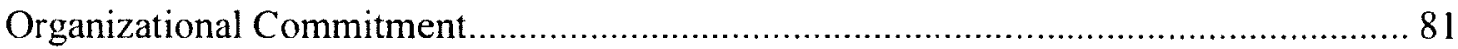

Noncommissioned Members and Officers................................................................ 84

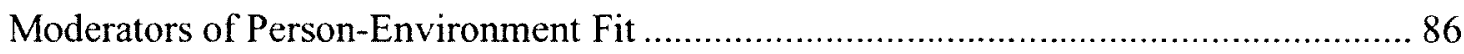

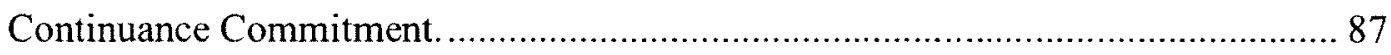

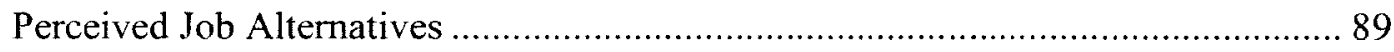

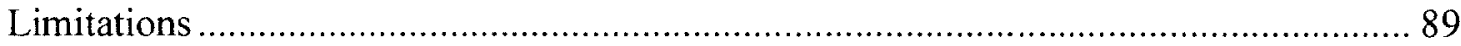

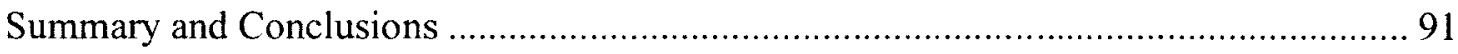

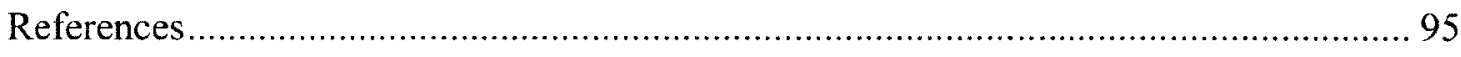

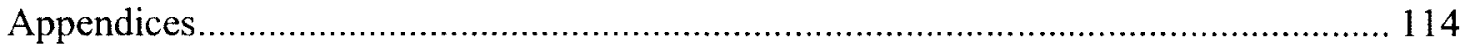

Appendix A List of Surveyed Occupations ................................................. 113

Appendix B Information/Consent Sheet with Ethics Approval............................ 115

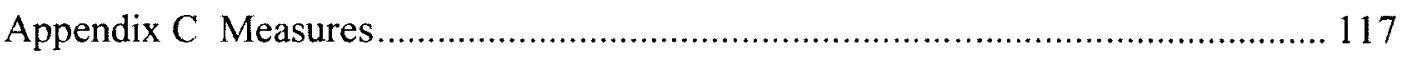

Appendix D Demographic Questions ...................................................... 120

Appendix E Civilian Equivalence Surveyed Occupationsd................................ 122

Appendix F Gender and Occupation Distribution for Officers ........................... 124

Appendix G Gender and Occupation Distribution

for Noncommissioned Members ............................................................ 125

Appendix H Summary Tables for Correlations, Means and Standard Deviations

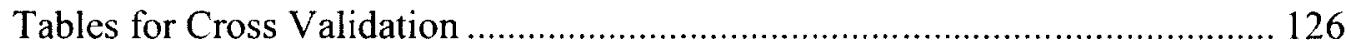

Appendix I Summary Tables for Multiple Regression Analyses

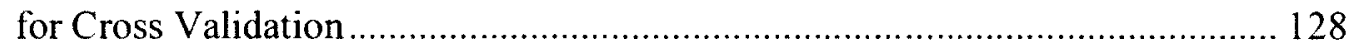

Appendix J Figures for Significant Moderator Effects

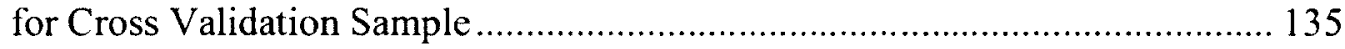




\section{Tables}

Table

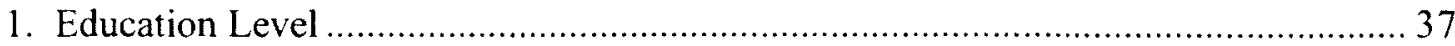

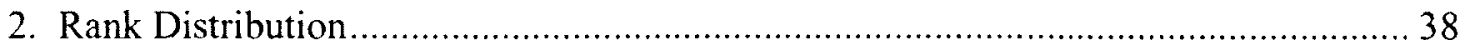

3. Correlations, Means, Standard Deviations, and Reliabilities - Full Sample ............. 47

4. Independent Samples T-tests for Gender Differences .......................................... 50

5. Independent Samples T-tests for Rank Differences........................................ 52

6. Correlations, Means, and Standard Deviations $-80 \%$ Percent Sample of

Noncommissioned Members and Officers

7. Multiple Regression Analysis with Person Occupation and Person Organization Fit $80 \%$ Sample 59

8. Hierarchical Regression Analysis for Moderating Effects of Perceived Organizational Support on Affective Commitment. 62

9. Hierarchical Regression Analysis for Moderating Effects of Perceived Organizational

Support on Normative Commitment. 63

10. Analysis of Moderators on Turnover Intentions for Noncommissioned Members ... 66

11. Analysis of Moderators on Psychological Withdrawal for Noncommissioned

Members

12. Analysis of Moderators on Turnover Intention for Officers 69

13. Analysis of Moderators on Psychological Withdrawal for Officers. 70

14. Correlations, Means, and Standard Deviations - $20 \%$ Sample 126

15. Correlations, Means, and Standard Deviations - $20 \%$ Sample for Noncommissioned Members and Officers 127 
16. Cross Validation of Direct Effects of Person-Environment Fit...

17. Cross Validation of Moderating Effects of Perceived Organizational Support on Affective Commitment

18. Cross Validation of Moderating Effects of Perceived Organizational Support on Normative Commitment

19. Cross Validation of Moderators on Turnover Intentions for Noncommissioned

Members

20. Cross Validation of Moderators on Psychological Withdrawal for Noncommissioned Members 132

21. Cross Validation of Moderators on Turnover Intention for Officers 133

22. Cross Validation of Moderators on Psychological Withdrawal for Officers 134 


\section{Figures}

Figure

1. Conceptual Framework for the Influence of Person-Environment Fit

2. Moderator Effects of Continuance Commitment for Noncommissioned Members ..... 68

3. Moderator Effects of Continuance Commitment for Officers ................................. 71

4. Moderator Effects of Perceived Job Alternatives for Officers ............................... 73

5. Moderator Effects of Perceived Job Alternatives for Officers ................................. 73

6. Moderator Effects of Continuance Commitment on Turnover Intention for Noncommissioned Members.

7. Moderator Effects of Perceived Job Alternatives on Psychological Withdrawal for

Noncommissioned Members 


\section{Appendices}

Appendix

A. List of Surveyed Occupations ...................................... 113

B. Information/Consent Sheet with Ethics Approval......................115

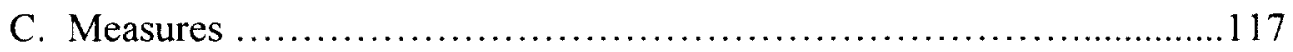

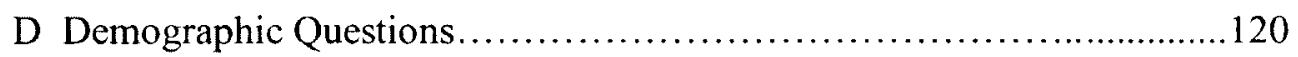

E. Civilian Equivalence for Survey Occupations ….............................122

F. Gender and Occupation Distribution for Officer ...............................124

G. Gender and Occupation Distribution for Noncommissioned Members...125

H. Summary Tables for Correlations, Means and

Standard Deviations for Cross Validation …................................126

I. Tables for Regression Analyses Cross Validation ................................128

J. Figures for Significant Moderator Effects Cross Validation.....................135 
The Association of Person-Environment Fit and Work-Related Attitudes for Canadian Forces Personnel

The Canadian labour market is facing major challenges caused by declining birth rates, an aging population, and immigration programs that have been unable to meet the demand for new skilled workers (Country Commerce, 2008). Although the $2008 / 2009$ recession resulted in a loss of 400,000 jobs, and theoretically a less competitive job market, the Canadian job market appeared to have recovered by January 2011 (Canada Year Book, 2011). The unemployment rate that had peaked at $8.7 \%$ was down to $7.8 \%$ and employment in both full-time and part-time jobs increased by $298,000(1.8 \%)$ in 2010, which was the largest increase since 2007. Although the economy and labour market are subject to fluctuations, overall, the Canadian job market continues to be competitive and labour shortages are once again, being felt in some sectors, particularly for skilled workers (Fisk \& Skattebo, 2010; Sankey, 2012).

In addition to a lack of skilled workers, the other issue faced by employers is the changing demographics of the work force. In terms of labour force participation, work force modeling conducted by Statistics Canada in 2011 projected that by 2031 the labour force participation by population will decrease from $67 \%$ reported in 2010 to between 60 and $63 \%$ in 2031 . This means that there will be less than three employed people for each individual aged 65 or older -- down from the 5:1 ratio in 2010 (Martel, Malenfant, Labelle, Belanger, \& Bastien, 2011). These modeling efforts serve to emphasize the impact employers will feel as an increasing number of baby boomers get set to retire (Wyman, 2011) and the younger demographic groups shrink. 
These labour market challenges are particularly salient for organizations such as the Canadian Forces that target a younger demographic because their recruiting efforts are not focused just on filling jobs but recruiting people for careers that will span 25 years or more. The Department of National Defence and the Canadian Forces combined is the second largest employer in Canada, employing approximately 111,000 people (Park, 2008). Even though the public service component of the Department of National Defense will likely decrease their workforce due to the Canadian government's current fiscal policies, the present goal of the government for the Canadian Forces is to maintain an effective strength of 68,000 regular force personnel (Reports on Plans and Priorities, 2011-2012). In order to meet this goal, the Canadian Forces has to select and successfully train just over 4,500 personnel in over 100 occupations, which, although maintaining status quo, is a substantial number of recruits. This will require significant resources and demand efficient and effective recruiting and selection efforts.

The situation of the Canadian Forces is one example of the future for all Canadian employers as they compete in an increasingly competitive global economy that will require a technologically knowledgeable and adaptable workforce. It is expected that future workers will have several jobs within an organization, and therefore it will be important to hire employees based on not only skills and abilities specific to a job, but for competencies and characteristics that will enable them to meet the future demands of the evolving workforce (Fisk \& Skattebo, 2010; Latham \& SueChan, 1998). This is particularly the case for organizations such as the Canadian Forces or the Royal Canadian Mounted Police as the senior leaders or executives 
within these organizations are grown from within the organization. Unlike civilian organizations, the Canadian Forces cannot simply hire its senior leaders or experienced workers; the skills, competencies, and experience required for the various jobs and positions at all levels of the organization requires years of specialized training and development. Given the realities of the current and future job markets, educated, talented, and productive employees will have many job options; therefore, organizations will also have to ensure that they have policies in place to retain valued employees. Keeping this in mind, it becomes evident that effective recruiting and selection is only half the challenge. Once an individual has been successfully hired, the battle for retention of the most productive and skilled employees begins.

Recruiting, selection, and retention are often studied as separate disciplines; however, there is a growing consensus among researchers that the three processes are inextricably connected and that stronger links must be forged between these three processes (Cable \& Judge 1996; Harrison, 2007; Michaud, 2010; Otis \& Straver, 2008). The primary goal of recruiting is to attract a pool of qualified potential employees, but the secondary goal should also be to improve the chances of selecting applicants who will be a good match for the organization (Cable \& Judge 2004; Catano, Weisner, Hackett, Methot, \& Belcourt, 2005), thus increasing the chances that selected employees will be well adjusted and able to contribute effectively to the organization's effectiveness and stay.

Examining the recruiting and retention dynamic of the Canadian Forces provides a prime example of this relationship. The Canadian Forces have successfully met most of their recruiting targets in recent years, except for some more specialized 
occupations such as technicians, pharmacists, and social workers, but at the same time, they are facing significant challenges with retention, especially in the first year of service. Over the last 20 years, annual attrition for the Canadian Forces averaged approximately $7 \%$, however for the last five years (2006 to 2011 ) it averaged approximately 9\% per year (Backgrounder, 2011; Annual Report on Attrition 2007/08, 2009 ), with the majority of attrition being voluntary (Otis \& Straver, 2008; Syed \& Morrow, 2003). These rates are comparable to North American averages; estimated voluntary attrition in 2003 was approximately 4\% for both the Canadian Forces (Syed \& Morrow, 2003) and Fortune 500 companies (Hom, Roberson, \& Ellis, 2008). The main difference is that for the Canadian Forces there are spikes in attrition at gateways created by the terms of service "contracts"1 that members sign. Although members can request a voluntary release at any time, such release can come with loss of benefits or an obligation to repay the costs of education and salary that makes it less appealing, therefore, the majority of people who want to leave wait until the next gateway (Otis \& Straver, 2008; Syed \& Morrow, 2003).

First year attrition rates are high. In the Canadian Forces, noncommissioned member $^{2}$ attrition has shown a steady increase over the last seven years; for example, in $2007 / 2008$ first year attrition was $26.7 \%$, up from the previous year in which it was 20.9\% (Annual Report on Attrition 2007/08, 2009). For noncommissioned members, the attrition rate spikes again after their period of initial engagement (i.e. first

\footnotetext{
${ }^{1}$ Terms of service contracts are employment agreements that Canadian Forces members sign on enrolment and at specified points in their career that delineate the terms of employment, i.e. length of the employment term and conditions for employment such as agreeing to comply with drug and harassment policies.

? Noncommissioned members are any Canadian Forces members who do not hold a Queen's commission (i.e. not officers); generally, they are front line staff, journeymen, and front line supervisors
} 
employment agreement) has expired (Otis \& Straver, 2008; Syed \& Morrow, 2003). The initial period of employment specified in terms of service contracts varies by occupation. The length of the initial contract depends on the amount of training and development required to complete all the basic military and occupational training necessary for the member to perform their duties independently. Initial engagement periods for officers are much longer than for noncommissioned members because they have distinctly different training requirements and career progression pathways. Officers as the potential future senior leadership of the Canadian Forces and the personnel responsible for the operation of multimillion dollar platforms such as aircraft and ships often require much lengthier and costlier training programs and are also subject to more stringent selection standards. The initial engagement period for noncommissioned members ranges from three to five years. Whereas, the initial engagement period for officers is typically a minimum of nine years, and in some cases longer because officer training will often include provision of an undergraduate degree prior to completion of occupation training. Although the historical attrition rates for officers are typically lower, ranging from 11 to $17 \%$, the cost of losing officer candidates is much higher, making officer attrition just as important a consideration.

In the Canadian Forces, the annual budget for recruiting and initial training of personnel was estimated to be $\$ 1.4$ billion for $2011 / 12$ (Reports on Plans and Priorities 2011-2012) and these costs are only recouped if the personnel hired stay for several years beyond the point where they are fully functional in their occupation (Carrick, 2003). In the US Air Force, basic costs for recruitment and initial training exceed SUS 300 million annually (Holt, Rehg, Lin, \& Miller, 2007). Costs of turnover for civilian 
employers are equally high; economic costs that include profits lost due to lost opportunity costs, costs incurred by having to recruit and train replacement employees, and losses in productivity have been estimated to range from $93 \%$ to $200 \%$ of the leaver's salary. The more valuable the employee is, the higher the cost of leaving is (Griffeth \& Hom, 2001). In addition to the economic costs, there are non-economic costs that involve the potential psychological effects on other employees such as the potential for additional stress, lower morale, and poor work motivation caused by factors such as taking on additional responsibilities and suffering the loss of valued workplace relationships (Koslowksi, Krausz, Sagie, \& Singer, 1997). In the military context, turnover costs also include increased risk to operational capabilities and effectiveness if insufficient numbers of personnel are trained and capable of carrying out assigned missions both domestically and internationally (Holt et al., 2009). Although understanding turnover rates is an important aspect of increasing retention, to truly understand turnover, with an eye to reduction, one must also understand why people choose to leave their jobs. Some turnover occurs for a variety of reasons that are not always under the control of the organization such as family issues and personal goals (Harman, Lee, Mitchell, Felps \& Owens, 2007; Lee, Mitchell, Wise, Fireman, 1996). However, it has also been established that one of the primary drivers of controllable turnover is a low level of job satisfaction that lessens organizational commitment (Griffeth \& Hom 2001; Griffeth et al., 2000; Hom \& Kiniki, 2001; Steel \& Lounsbury, 2009). The question of interest then becomes what causes some people to be satisfied with their jobs and others to be dissatisfied. It is possible that lack of person-environment fit is a key cause of dissatisfaction, resulting 
in attrition. Previous research indicates that employees frequently choose to leave because they believe they have chosen the wrong job or organization, because they do not have a sense of good fit with organizational values and culture, or because their skills and abilities do not meet the job or organization's requirements (Edwards 2008; Hom et al., 2008; Michaud, 2010; Schneider, 1987a, 1987b).

Person-environment fit has been identified as an important factor in the decision-making processes of both organizations and individuals in pre-entry and postentry job decisions and in the creation of job attitudes (Edwards \& Bilberry, 2010; Kristof-Brown, Jansen \& Colbert, 2002; Kristof, 1996; Saks \& Ashforth, 1997), yet there is still much to learn. The majority of person-environment fit research has focused on only one domain (e.g., organization or job) of fit at a time and early research was mostly experimental or involved field studies using college students (Rynes \& Cable, 2003). The selection and recruiting literature has focused primarily on person-job fit perceptions pre-entry as they pertain to organizational attraction and job choice (Cable \& Judge, 1996; Jansen \& Kristof-Brown, 2006; Judge \& Bretz, 1992; Judge \& Cable, 1997). By contrast, researchers interested in turnover and the formation of job attitudes, post-entry, have primarily examined fit with regard to value and culture matches at the organizational level (Chatman, 1991; Pisantenin \& Chapman, 2006; Schneider, Smith, \& Paul, 2001). Research focused on personenvironment fit has most advanced since the 1990s (Ostroff \& Shulte, 2007), but progress has been hampered because of the various different conceptualizations and definitions of fit and disagreement on the number of components and domains involved in fit (Edwards 2008; Harrison, 2007; Jansen \& Kristof-Brown, 2006; 
Kristof-Brown \& Guay 2011; Piasentin \& Chapman, 2006; Uysal-Irak, 2010; Verquer, Beehr \& Wagner, 2003). Leading researchers in the field, such as Kristof (1996), Edwards (2008), Harrison (2007), and Judge (2007), have noted that there is a need for more field research of different components of fit at varying levels of the organization in the same study. They propose that a multidimensional concept of fit will be a better predictor of broad workplace outcomes such as withdrawal behaviours and commitment (Edwards, 2008; Jansen \& Kristof-Brown, 2006).

It has also been suggested that incorporating hiring practices that strive for a better match or person-environment fit between individuals and organizations would have positive outcomes, such as increased employee commitment, decreased withdrawal behaviours, and increased employee well-being (Fisk \& Skattebo, 2010; Karren \& Graves, 1994). However, more research is required to determine how the different domains of fit work together (Catano et al., 2005; Hom et al., 2008; Jansen \& Kristof-Brown, 2006) to influence organizational commitment and withdrawal behaviours and also to determine the practicality and legal defensibility of using person-environment fit measures for selection (Arthur, Bell, Villado, \& Doverspike, 2006; Werbel and Gilland, 1999). Although much attrition is beyond the control of organizations (Harman et al, 2007; Lee et al, 1996), if research can demonstrate that better person-environment fit at the selection stage increases retention, it could provide evidence sufficient for organizations to invest in improving assessment of personenvironment fit in the selection process (Werbel \& Gilliland, 1999; Werbel \& Johnson, 2001). 


\section{Person-Environment Fit Framework}

In broad terms, person-environment fit is defined as the congruence or compatibility between an individual's values, needs, skills, abilities, or interests and his or her environment or the fulfillment of needs in terms of individual or environmental requirements (Edwards 2008; Harrison, 2007; Kristof, 1996; KristofBrown, Zimmerman, \& Johnson, 2005; Muchinsky \& Monahan, 1987). Environments and individuals are both multidimensional (Edwards \& Bilberry, 2010; Edward \& Shipp 2007), and therefore fit is a complex construct that can be conceptualized from multiple perspectives. Most commonly, researchers focus on fit as either a correspondence between workplace and individual characteristics, or a shared set of values, goals and/or interests.

\section{Fit Perspectives}

Person-environment fit research has essentially developed along two distinct but parallel streams -- the complementary and supplementary fit perspectives (Edwards \& Shipp, 2007; Kristof-Brown, 2006; Muchinsky \& Monahan, 1987). These two perspectives have developed independently of each other and there has been little integration until very recently (Cable and Edwards, 2004; Edwards \& Shipp, 2007; Jansen \& Kristof-Brown, 2006). The primary difference between the two perspectives is with regard to the underlying psychological processes that are associated with the creation of these fit perceptions. The basis of complementary fit perceptions are need satisfaction, specifically core psychological needs, such as a need for affiliation or autonomy that individuals have an internal drive to fulfill (Murray, 1938), whereas the basis of supplementary fit is similarity or congruence (Cable \& DeRue 2002; Cable \& 
Edwards, 2004; Edwards \& Shipp, 2007). Given that supplementary fit is better understood and has more predictive power for the outcomes of interest in the current research (Arthur et al., 2006; Verquer et al, 2003), the focus of the current research was from the supplementary fit perspective.

\section{Supplementary Fit}

Supplementary fit occurs when the organization and the individual feel that they share features such as values, goals, culture, and personality (Cable \& Judge 1996; Chatman, 1991; Muchinsky \& Monahan, 1987; Resick, Baltes, \& Shantz, 2007). An important premise of supplementary fit is that employees will be more content working in environments in which what is important to them is also important to the organization because it reinforces their sense of self (Cable \& DeRue, 2002; Cable \& Edwards, 2004; Chatman, 1991; Schneider, 1987a; 1987b). Indeed, the attractionselection-attrition (ASA) framework (Schneider, 1987a, 1987b; Schneider et al., 2001), which is considered one of the primary bases of supplementary fit particularly with regard to person-organization fit (Billsberry, 2007; Cable \& Judge 1996; Judge \& Cable, 1997; Kristof, 1996), proposes that people will be attracted to and be selected by organizations that share their values, personality, and interests. According to the attraction-selection-attrition framework, similarity is important prior to entry in attracting employees to the organization and during the selection process when organizations hire individuals who are perceived to share incumbents' characteristics. Once individuals have joined the organization, they become increasingly aware of their congruence with their organization and if they perceive a misfit, they are more likely to quit (Schneider, 1987a; 1987b; 2001). 
Supplementary fit is most commonly operationalized as values congruence (Carless, 2005; Edwards \& Cable 2009; Jansen \& Kristof-Brown, 2006; Judge \& Cable, 1997; Kristof-Brown, 2000; Piasentin \& Chapman, 2006), which, in keeping with Kristof (1996) and Chatman (1991), is defined as the similarity between the individuals' values and the culture and value systems of the environment. Shared values are considered important to organizational functioning as they guide behaviour, provide clarity and predictability with regard to decision making, and foster understanding of how resources are allocated (Chatman, 1991; Edwards \& Cable, 2009); in other words, it informs the individuals" concept of what is acceptable behaviour and helps with workplace adjustment (Edwards, 2009). Edwards and Cable (2009) proposed that one of the primary benefits of value congruence is the creation of trust, which is the foundation of good communication, builds effective working relationships, and results in employee wellbeing and effective organizational functioning. Further, good supplementary fit results in sense of accomplishment and aligns workers' interests with organizational goals (Vogel \& Feldman, 2009). In studies of job choice, values congruence may be as important to job applicants as pay and benefits (Judge \& Bretz, 1992). It has been suggested that the most important aspects of shared values to selection and retention are that they may create a strong bond with the organization and its members, positively influencing work attitudes and behaviours, increasing organizational citizenship behaviours, and retention (Judge \& Bretz, 1992; Cable \& DeRue, 2002; Chatman, 1991).

In sum, supplementary fit has been found to positively to be positively associated with important workplace outcomes and is most frequently used to ground 
investigations of workplace attitudes and behaviours such as organizational socialization (Cable \& Parsons, 2001), organizational commitment, withdrawal behaviours (Chatman, 1991; Edwards \& Cable 2009), and personnel selection (Holland, 1959; Karren \& Graves, 1994; Kristof, 1996). Moreover, it has demonstrated strong associations with retention, organizational commitment, organizational attraction and job choice (Cable \& Edwards, 2009; Hoffman \& Woher, 2006; Kristof-Brown, et al., 2005; Verquer et al, 2003). The goal of the current research was to explore fit from the supplementary perspective by using an expanded set of outcomes and including potential moderators of fit.

\section{Fit Domains}

Person-environment fit is a global concept that, in addition to the perspectives described above, also encompasses the various domains of the working environment in which fit occurs. Four key domains -- person-vocation, person-job, personorganization, and person-group fit (Carless, 2005; Harrison, 2007; Kristof-Brown, 1996; Kristof-Brown \& Guay 2011; Kristof-Brown, 2000) -- have been identified as important to understanding the various levels of the environment in which employees interact, however the majority of research has focused on person-job and personorganization fit (Kristof-Brown \& Guay 2011; Verquer et al., 2003; Wheeler et al., 2005). Person-vocation fit is fit at the widest bandwidth and involves the compatibility between an individual and his or her chosen vocation/career path, which will often be supra-organizational. Person-job fit is closely related to person-vocation fit, but specifically focuses on the match between the individual and the particular job or position. Person-organization fit refers to fit with the organization as a whole. Person- 
group fit refers to compatibility at the interpersonal level, which could refer to work teams, leaders, subordinates, or clients and customers (Kristof, 1996).

Person-organization and person-job fit have enjoyed the bulk of researchers' attention, usually in isolation from other domains of fit (Carless, 2005; Harrison, 2007; Kristof-Brown et al., 2002; Jansen \& Kristof-Brown, 2006; Lauver \& Kristof-Brown 2001; Piasentin \& Chapman, 2006; Saks \& Ashforth, 1997), consequently, there is a better understanding of these two domains and how they are related to each other. Research that has included both of these domains in the same study has provided evidence of the distinctiveness of person-job and person-organization fit domains (Cable \& DeRue, 2002; Cable \& Judge, 1996; Kristof-Brown \& Guay, 2011; Jansen \& Kristof-Brown, 2006; Ostroff \& Shulte, 2007). Generally, person-organization fit is more strongly associated with organization-level outcomes such as organizational commitment or perceptions of organizational support and turnover (Cable \& Judge, 1996; Verquer et al., 2003). On the other hand, person-job fit has stronger associations with job-level outcomes such as job and career satisfaction, career commitment, and turnover intention (Cable \& DeRue, 2002; Cable \& Judge, 1996; Kristof-Brown, et al., 2002; Kristof-Brown et al., 2005; Lauver \& Kristof-Brown 2001; Saks \& Ashforth 1997; Westerman \& Cyr, 2004).

In the current research the construct of person-job fit was expanded to include elements of person-vocation fit, therefore person-occupation fit was assessed rather than person-job fit. Although at a theoretical level person-job and person-vocation fit are unique domains, in practice it is argued that most people do not distinguish between the concept of job and vocation. Further, people choosing the Canadian 
Forces and perhaps similar organizations such as the Royal Canadian Mounted Police or the Public Service may join these organizations not just for the entry level job, but rather for the expected career path. In effect, some individuals may choose an organization with less concern for the actual job or occupation but because they would like to work for the organization (because of values congruence) as their priority, with a job match being less important (Jansen \& Kristof-Brown, 2006). These individuals may assume that they can find a better job match once they have been hired (Resick et al., 2007). It could be argued that for many Canadian Forces and other military forces' members, their vocation of choice is actually the "profession arms" (Duty with Honour, 2009; Rondeau, 2011) and the occupation they enrol into is their job or role within this vocation. The job itself changes as they develop skills and gain experience and move from position to position within the organization, but their core selfidentification with that role may remain stable. In this sense, the construct of personoccupation fit used in this study was broader than person-job fit but not quite as broad as person-vocation fit.

\section{Integration of Domains}

Within the domains of person-environment fit, it is also important to determine how the various domains integrate and function in combination within the environment. This is particularly important in the context of recruiting and in the development of selection standards and measures. Although some research has been conducted that speaks to the distinctiveness of the various domains of fit (Cable \& DeRue, 2002; Scroggins, 2007), the majority of research has evaluated the influence of the domains on one outcome at a time ((Iplik, Kilic, \& Yalcin, 2011; Halbesleben \& 
Wheeler, 2008). It is only recently that researchers have begun to assess fit domains in combination, assessing the contribution of each domain after controlling for the effects of the others on outcomes such as organizational commitment, turnover, and turnover intention (Scroggins, 2007; Tak, 2011; Wheeler, Gallagher, Brouer, \& Sablynski, 2007).

Jansen and Kristof-Brown (2006) suggested that person-environment fit is an overarching construct that includes the various domains in the sense that each domain is a building block and that they combine in various ways to predict or influence workplace attitudes and behaviours. This holistic framework is hypothesized to have the strongest associations with organizational-level outcomes. In one evaluation of this holistic approach, Kristof-Brown and her colleagues (2005) found that combining person-organization and person-job fit increased effect sizes with regard to predicting organizational commitment and job satisfaction, providing early evidence that it is the combined effect of the fit domains that provide the greatest explanatory power for the creation of workplace attitudes (Cable \& Judge, 1996; Jansen \& Kristof-Brown; 2006; Kristof-Brown \& Guay, 2011; Werbel \& Gilland, 1999).

Nonetheless, a second approach to understanding the dimensionality of fit is to conceive of the different fit components as completely independent. Edwards and Billsberry (2010) found some evidence to support the idea that individuals do not perceive an overarching sense of fit. Employees evaluated fit in relation to the different domains; however, these different perceptions of fit did not build on each other to influence outcomes. Each domain -- the job, the organization, and the work group -- created different perceptions of fit that influenced outcomes independently 
(Edwards \& Billsberry, 2010). However, this line of research is just beginning and there is a possibility that the optimal solution is that some domains of fit build on each other, whereas others are independent. It may also depend on the specific organization or type of organization (i.e. public vs. private) or the outcome of interest (i.e. commitment vs. withdrawal). In sum, it is necessary to examine whether various domains integrate into an overarching sense of person-environment fit, or whether each domain independently influences outcomes (Edwards \& Billsberry, 2010; Jansen \& Kristof-Brown, 2006; Piasentin and Chapman, 2006).

\section{Outcomes of Person-Environment Fit}

Person-environment fit is strongly associated with a variety of positive outcomes (Edwards, 1991; Kristof, 1996) or perhaps more accurately poor personenvironment fit is believed to lead to undesirable work attitudes and behaviours (Edwards \& Bilberry, 2010). The most commonly researched outcomes of personenvironment fit are work attitudes such as organizational commitment, job satisfaction, and turnover intention and work behaviours such as organizational citizenship behaviours and turnover (Edwards, 1991; Chatman, 1991; Kristof-Brown \& Guay, 2011; Verquer, et al., 2003). In response to Jansen and Kristof-Brown's (2006) call for an integrative approach to explain the process of fit, the current research evaluated the pattern of associations between two domains of fit and both organizational withdrawal and organizational commitment. It also explored its ability to predict or influence organizational withdrawal and organizational commitment and evaluated potential moderators of the influence of person-environment fit on organizational commitment and organizational withdrawal. 


\section{Organizational Withdrawal}

Organizational withdrawal is a broad term coined by Hanisch and Hulin (1990) to refer to a wide range of attitudes and behaviours that are indicative of employees reacting to an adverse work environment by avoiding work or removing themselves from their jobs in some fashion (Hanisch \& Hulin, 1990). A recent review of the turnover literature conducted by Steel and Lounsbury (2009) revealed that an adverse work environment is likely to trigger one of three possible responses, leaving the organization, searching for a new job within the organization, or adapting to the circumstances by changing job attitudes and/or behaviours through psychological or behavioural withdrawal. Steel and Lounsbury's (2009) review found over 24 models of the turnover process and identified job search behaviours and turnover intention as the most proximal withdrawal mechanisms. Their review also revealed a consensus that job dissatisfaction and organizational commitment are the two main job attitudes that consistently predict organizational withdrawal; however they also conceded that more research is required to better understand the antecedents of these work attitudes with regard to their influence on organizational withdrawal.

Person-environment fit has emerged as a major underlying mechanism in understanding turnover and it has been suggested that it should be included in turnover process models as an antecedent (Cable \& DeRue, 2002; Hom et al., 2008; KristofBrown \& Guay, 2011; Scroggins, 2007). Consistent with the attraction-selectionattrition framework, poorer person-environment fit, particularly person-organization fit, is thought to increase the likelihood that an individual will be less satisfied with their working environment, less committed to the organization, and therefore less 
likely to remain (Chatman, 1991; Kristof-Brown et al., 2005; Verquer et al, 2003). The unique associations between person-job and person-organization fit on turnover, turnover intention, and affective organizational commitment have been fairly well established (Cable \& DeRue, 2002; Kristof-Brown \& Guay, 2011; Lauver \& KristofBrown, 2001; Scroggins, 2007), however, there is virtually no research that has examined psychological withdrawal as a potential outcome of poor personenvironment fit. Psychological withdrawal may be a factor for those who are unhappy with the work environment, but who feel they cannot leave. The current research, therefore, assessed the influence of two domains of fit -- person-organization and person-occupation on two forms of organizational withdrawal -- turnover intention and psychological withdrawal.

Turnover Intention. The theory of reasoned action (Ajzen, 2000; Ajzen \& Fishbein, 1980), which essentially purports that the best predictor of behaviour is forming the intention to carry out said behaviour, grounds the construct of turnover intention. Turnover research indicates that turnover intention is the strongest, most direct predictor of turnover (Griffeth et al., 2000; Jaros, 1997; Steel \& Lounsbury, 2009). Although this association only averages corrected correlations of 34 (Griffeth et al., 2000), understanding the antecedents, moderators, mediators and correlates of turnover intention can provide insight into the more distal influences on turnover, which can assist organizations in improving retention.

Turnover research has demonstrated that the turnover process is very similar for both civilian and military populations (Steel \& Lounsbury, 2009), however it has also found that the structure of military turnover intentions differ from the structure of 
civilian intentions (Fuller, Hester, Dickson, Allison, \& Birdseye, 1996; Griffeth et al., 2000; Hom, Carinakas-Walker, Prussia, \& Griffeth, 1992). In the most recent metaanalysis (Griffeth et al., 2000), the corrected correlations between turnover intention and turnover were $\rho=.40$ for military populations versus $\rho=.34$ for civilian populations, which suggests that turnover decisions are more stable for military members than they are for civilian employees (Fuller et al., 1996; Hom et al., 1992). One of the reasons hypothesized for this difference is the terms of service contracts that military personnel sign when enrolling or extending periods of service. It has been proposed that thoughts about leaving are preprogrammed or scripted by virtue of signing terms of service contracts; when terms of service expire, individuals leave (Holt et al., 2007; Hom et al., 1992). In fact, Canadian military turnover research has established that members are most likely to leave at or shortly after the expiry of an engagement period (Otis \& Straver, 2008), although in reality they could request release from that period of engagement anytime they chose.

The associations of person-organization and person-job fit on turnover and turnover intention vary considerably in terms of the magnitude of the correlations (Tak, 2011) however the majority of research has demonstrated that person-job fit is the stronger predictor of turnover intention (Kristof-Brown \& Guay, 2011; KristofBrown et al, 2005). However, there has been very little research that has examined the combined influences of fit domains on turnover intention (Wheeler et al., 2005). In the one study that evaluated the combined influence of person-organization and personjob fit on turnover intention, person-organization fit did not increase the explained variance in turnover intentions over and above the effect of person-job fit, suggesting 
that the combination of these two domains are not additive in their influence on turnover intention (Scoggins, 2007). Based on this research it was hypothesized that:

H1. Person-occupation and person-organization fit would both be negatively associated with turnover intention, but person-occupation fit would exert its influence on turnover intention over and above the influence of personorganization fit.

Psychological Withdrawal. The construct of psychological withdrawal refers to attitudinal and behavioural strategies enacted by individuals, consciously or unconsciously that are intended to put psychological distance between an individual and the work environment in response to an aversive work environment (Rosse \& Hulin, 1985; Sagie et al., 2002). The type of behaviours manifested includes lowered performance, disengagement, and increased social loafing (Hanisch \&, Hulin 1990; Hom \& Kiniki, 2001). There is disagreement as to the role of psychological withdrawal in turnover (Hanisch \& Hulin, 1990; 1991; Hom \& Kiniki, 2001; Kammeyer-Mueller, Wanberg, Glomb \& Ahlburg 2005; Koslowsky, 2009; Rosse \& Hulin, 1985). It is most commonly thought of as the mildest form of turnover behaviour and as a precursor to turnover (Griffeth et al., 2000), but there is some research evidence that indicates psychological withdrawal may also be an alternative to turnover (Hanisch \& Hulin, 1990), particularly for those individuals who feel constrained to stay (Halbesleben \& Wheeler, 2008; Wheeler, et al., 2005).

Psychologically withdrawn employees incur costs not only with regard to lost productivity and inefficient work practices but also with regard to the influence these employees may have on the morale and productivity of other employees (Sagie, Birati, 
\& Tziner, 2002). Psychological withdrawal is an important organizational behaviour to understand, not only because of its hypothesized relationship to turnover, which has fairly easily determinable economic costs, but because it is necessary to gain a better understanding of how it affects employee attitudes, job performance, organizational functioning, and employee health. Psychological withdrawal is normally more highly related to turnover intention than it is to turnover (Kammeyer-Mueller et al., 2005), but little research has tested whether employees who are more likely to withdraw psychologically are similar to those who intend to quit in terms of lack of perceived fit with their job and their organization.

Early person-environment fit research found that lack of fit was associated with stress and strain in the working environment (Edwards, 1996; Edwards \& Shipp, 2007; Kristof-Brown \& Guay, 2011). Stress or strain was thought to occur when the environment failed to meet the needs of the worker or when the demands of the environment exceeded the abilities of the person or the employee's abilities exceeded the demands of the environment (Edwards et al., 1998; Edwards \& Harrison, 1993). Feelings of stress and strain could logically result in job avoidance or psychological withdrawal (Hanisch \& Hulin, 1990; 1991), especially if the workers believe they have no option but to stay. The current research investigated the association between supplementary fit at the person-organization and person-occupation level with regard to psychological withdrawal and offered the following hypothesis:

H2. Person-organization and person-occupation fit would be negatively associated with psychological withdrawal such that individuals who perceived better fit would report lower levels of psychological withdrawal. 


\section{Organizational Commitment}

Organizational commitment, in essence, is the psychological link that develops between an employee and employer. Meyer (2009) defines organizational commitment as "an internal force (mindset) that binds an individual to a target (social or nonsocial) and/or to a course of action of relevance to that target" (p. 40). Organizational commitment is a principal topic of interest with regard to effective organizational functioning (Griffeth et al., 2000; Kristof-Brown et al., 2005; Hoffman \& Woher, 2006; Verquer et al., 2003). There is strong evidence that committed employees will be strong performers (Kim, Mueller, \& Watson, 1996), carry out extrarole behaviours (Gellatly, Meyer, \& Luchak, 2006; Popper \& Lipshitz, 1992), and retain organizational membership (Allen \& Meyer, 1996; Griffeth et al., 2000). The current research used the three-component model of commitment, which includes affective, normative, and continuance commitment (Meyer \& Maltin, 2010). Each of these components is important to overall commitment, but because they reflect different circumstances for person-environment fit, the components expected to be important outcomes are affective and normative commitment.

Affective Commitment. Affective commitment is an emotional attachment to the organization and is the "mindset of desire" or the "want to" component of commitment. Individuals who exhibit this type of commitment genuinely like being a member of the organization and identify strongly with the organization (Allen \& Meyer, 1996; Meyer, Allen, \& Smith, 1993; Meyer \& Parfyonova, 2010).

Theoretically, the link between affective commitment and person-environment fit is primarily through values congruence, which leads to the fulfillment of the needs for 
competence, autonomy, and affiliation (Arthur, et al., 2006; Edwards \& Shipp, 2007; Randall \& O`Driscoll, 1997). The satisfaction of these needs is believed to result in favourable attitudes towards the organization, a desire to accomplish organizational goals and a desire to maintain organizational membership (Chatman, 1991; Edwards \& Shipp 2007; Kristof, 1996; Meyer \& Maltin, 2010). The influence of personorganization fit on affective commitment has been found to increase with longer tenure (Kristof-Brown \& Guay, 2011), and affective commitment has been found to be one of the strongest correlates and outcomes of person-organization fit (Cable \& Judge, 1996; Greguras \& Diefendorff, 2009: Kristof-Brown et al., 2005; Meyer, 2009). However, it has also shown weaker but positive associations with person-job and person-vocation fit (Cable \& DeRue, 2002; Kristof-Brown et al., 2005; Vogel \& Feldman, 2009). Moreover, early evidence is emerging that combining domains of fit has an additive effect on affective commitment and results in larger effects. For example, Scroggins (2007) found that person-organization fit and two types of personjob fit combined predicted $46 \%$ of the variance in affective commitment. Thus, it was predicted that:

H3. Both person-organization and person-occupation fit would be positively associated with affective commitment in an additive manner, but personorganization fit would account for a higher proportion of the variance in affective commitment relative to person-occupation fit.

Normative Commitment. Normative commitment is the "mindset of obligation" or the "ought to" component of commitment (Allen \& Meyer, 1990; Meyer \& Parfyonova, 2010). The foundation for normative commitment is a sense of 
duty or obligation to the organization, developed through pre-entry early socialization within the family and culture and post-entry socialization (Allen \& Meyer, 1990). Edwards and Shipp (2007) suggested that normative commitment is associated with person-environment fit in terms of needs satisfaction. They hypothesize that organizations that demand loyalty from their incumbents create a need for the employee to reciprocate, which employees then internalize as a role demand and respond to by remaining with the organization.

Normative and affective commitment are normally highly correlated (Allen \& Meyer, 1996; Meyer et al., 1993; Meyer, Stanley, Herscovitch \& Topolyntsky, 2002), but research has also shown that they also have unique associations with other workplace variables, indicating that although they are similar, they are separate components (Meyer et al., 2002; Meyer \& Parfyonova, 2010). For example, normative commitment is normally positively correlated with continuance commitment, whereas affective commitment is negatively associated or not correlated with continuance commitment at all (Brown, 1996; Jaros, 1997; Meyer et al., 2002). Research investigating normative commitment has been conducted infrequently and often results are inconsistent with previous research, which may be a factor in why it is not been researched more often. Further, affective commitment generally has the strongest associations with outcomes of interest to organizations (Meyer \& Maltin, 2010). Nonetheless, research indicates that normative commitment decreases withdrawal behaviours (Meyer, et al., 2002) albeit at a lower rate than does affective commitment. Moreover, there is evidence that it may be one of the more important components of commitment when studying military or paramilitary organizations (Popper \& Lipshitz, 
1992). Griffeth and his colleagues (2000) hypothesized that some may see military service as a calling, creating a moral obligation to serve. Therefore, it was important to include normative commitment in the current study. Furthermore, its relationship with person-environment fit has never been evaluated and therefore the following hypothesis was tested:

H4: Person-occupation and person-organization fit would both be positively associated with normative commitment in an additive fashion; however, person-organization fit would contribute more variance to normative commitment than would person-occupation fit.

\section{Moderators of Person-Environment Fit}

The majority of research conducted to date has only examined the direct influence of person-environment fit perceptions on outcomes (Wheeler et al., 2005), but given the weak to moderate correlations and effect sizes reported in recent metaanalyses (Kristof-Brown \& Guay, 2011), it is likely that the association between person-environment fit and organizational attitudes is mitigated or bolstered by intervening variables. The current research evaluated the moderating effects of perceived organizational support on the associations between person-environment fit organizational commitment and organizational withdrawal. It also proposed a moderating role for continuance commitment and individual employability on the association between person-environment fit and organizational withdrawal.

\section{Perceived Organizational Support}

Perceived organizational support is a belief held by individuals that an organization values their contributions and cares about their well-being. It is based on 
the norm of reciprocity from social exchange theory (Blau, 1964), wherein the basic tenet of social relationships is that if individuals receive favourable treatment from another party, they are obligated to respond by reciprocating that favourable treatment (Eisenberger, Huntington, Hutchinson, \& Sowa, 1986; Lynch, Eisenberger, \& Armeli, 1999). Perceived organizational support has been found to affect the creation of commitment attitudes (Eisenberger, Stinglhamber, Vandenberghe, Sucharski, \& Rhoades, 2002; Hom, Tsui, Wu, Lee, Zhang, Fu, \& Li, 2009; Otis \& Straver, 2008) in that the more supported employees feel, the more committed they are to their organizations. Perceived organizational support may be especially relevant in the creation of normative commitment because it is thought to be created through a sense of obligation and a need to satisfy a demand for loyalty (Meyer \& Parfyonova, 2010) however, to date there is little empirical evidence for this relationship. Given that perceived organizational support contributes to affective commitment (Eisenberger et al., 2002; Wayne, Shore, Bommer \& Tetrick, 2002) and normative commitment (Meyer, Stanley, Herscovitch, \& Topolnytsky, 2002) and is strongly associated with positive perceptions of person-organization fit (Cable \& DeRue, 2002), the present study explored perceived organizational support as a moderator of perceptions of person-organization fit on organizational commitment and organizational withdrawal. It was expected that perceived organizational support would add to the positive effects of person-environment fit perceptions for commitment and mitigate the negative effects of low environment fit for withdrawal. Specifically it was hypothesized that: H5a. Perceived organizational support would act as a moderator of the association between person-organization and person-occupation fit and 
affective and normative commitment. It was expected that individuals' poor perceptions of fit would be mitigated by high perceived organizational support; and

H5b. Perceived organizational support would act as a moderator of the association between person-organization and person-occupation fit and organization withdrawal, such that the negative association on poor fit with organizational withdrawal would be mitigated by higher perceived organizational support.

\section{Continuance Commitment}

The basis of continuance commitment is less of an emotional attachment to an organization and more of an awareness of the financial benefits or work investments that would be lost by leaving. It is the "have to" component of commitment or the "mindset of fear of loss" (Meyer \& Allen, 1996; Meyer \& Maltin, 2010). Individuals who show evidence of continuance commitment appear to feel constrained to stay with the organization because they feel they have too few alternatives to leave or that it would cost them too much to leave because of what they have invested into the organization (Allen \& Meyer, 1990; Meyer, Becker, \& Vandenberghe, 2004; Halbesleben \& Wheeler, 2008). For military members a very real loss of investment would be a reduction of pension benefits if they decided to leave prior to completing the specified years of service required to retire with an unreduced pension. Further, there is a potential for loss in terms of the effort expended to gain skills and competencies in their occupation, which may not be easily transferable to another organization (Griffeth et al., 2000). Similar to the other two forms of commitment, 
continuance commitment has a negative association with turnover intention (Meyer et al., 2002), although the association is generally weaker (Gellatly et al., 2006). Meyer and Allen (1990) argued that continuance commitment also binds individuals to an organization and therefore is not necessarily a negative outcome. Nonetheless, Meyer and colleagues (2002) meta-analysis found that the direction of correlations between continuance commitment and other work experience variables such as organizational support and organizational justice was always the opposite of affective commitment, suggesting that it may not be the most desired type of commitment. Indeed, Gellatly, Meyer, and Luchak (2006) proposed that individuals whose primary attachment to the organization is through continuance commitment may be less likely to be strong performers and may in fact be motivated to reduce work effort (become disengaged) due to feelings of resentment caused by feeling constrained to stay with the organization.

The attraction-selection-attrition framework suggests that individuals with poor person-environment fit should choose to leave the organization (Schneider 1987a; 1987b) however, not everyone who perceives poor fit actually leaves, as evidenced by the low to moderate effect sizes reported by Kristof-Brown and Guay's (2011) metaanalysis. Wheeler and colleagues (2005) proposed that the reason for low effect sizes is the existence of intervening variables that may be moderating or mediating the influence of fit on turnover intention, therefore the current research evaluated whether continuance commitment moderated the effect of poor person-organization fit on both forms of organization withdrawal used in this study. Accordingly, it was hypothesized that: 
H6. Continuance commitment would moderate the association between person-organization and person-occupation fit on organizational withdrawal such that the association of poor person-environment fit with organizational commitment would be mitigated by continuance commitment.

\section{Employability}

The Canadian government's Labour Force Development Board defined employability as "the relative capacity of an individual to achieve meaningful employment given the interaction of personal circumstances and the labour market" (Canadian Labour Force Development Board, 1994, p. viii). Essentially, employability in this context evaluates the ability of individuals to participate in the job market, given a range of factors such as skills, experience, and barriers to employment (e.g., need for childcare, geographical location; Fugate, Kiniki, \& Ashforth, 2004).

Following from its roots in the economic literature, employability emerged in the psychological literature as an individual difference construct referring to an individual's perceptions of their employability (McQuaid \& Lindsay, 2005). From an organizational perspective, employability refers to workers' ability to effectively adapt to changing environments through continuous learning to ensure they possess the skills and competencies needed to effectively function in light of rapidly developing technology and the need to develop new products and services to maintain competitiveness (Nauta, Vianen, Heijden, Dam, \& Willemsen, 2009). Concern about the employability of workers has resulted in a move by organizations to provide retraining and development opportunities or to encourage employees to pursue career development activities on their own to enable employees to meet the demands of the 
changing workplace (Ito \& Brotheridge, 2005; Nauta et al., 2009). However, these practices have also raised a dilemma for organizations, in that some research has found that highly employable workers are more likely to seek out new job opportunities (Ito \& Brotheridge, 2005). However, more recent research indicates that this may only be true for workers who are already dissatisfied with the workplace (Maurer \& Lippstreu, 2008; Nauta et al., 2009). Maurer and Lippstreu's (2008) research results supported the attraction-selection-attrition framework and suggested that for workers with good person-environment fit (goal congruence), opportunities for development improved workers' sense of competence, increased commitment, and improved retention. On the other hand, it has also been suggested that workers who perceived they are less employable may remain even when they were dissatisfied with their current workplace, affecting their performance and organizational effectiveness (De Cuyper, Mauno, Kinnunen \& Mäkikangas, 2011), in other words, psychologically withdrawing from the workplace.

Civilian Equivalence. A lack of skill transferability is a potential issue that has been identified in the turnover research, particularly for military members (Griffeth et al., 2000). A very real factor in turnover decisions may be a real or perceived lack of employability and a corresponding perception of a lack of viable alternatives that use the member's current inventory of skills and competencies, particularly given that many military occupations do not have a directly equivalent civilian occupation (Griffeth et al., 2000). In order to gain a clearer idea of why individuals may stay in the Canadian Forces despite perceptions of poor fit, one of the factors the current research sought to explore was the perceived employability of Canadian Forces 
personnel. Military members are likely looking to civilian jobs as an alternative to service; employability in this context must take into account whether the military members believe they would find a similar job in the civilian workforce for which they would be qualified. Therefore, it was important to examine the concept of civilian equivalence, which refers to how closely a military occupation is aligned with civilian occupations, as a factor that could influence perceptions of employability. Individuals employed in an occupation that does not have a direct civilian equivalent may perceive themselves to be less employable and remain with the organization despite poor fit and adjust to feeling a lack of fit or an adverse environment by adopting work avoidance behaviours, such as psychological withdrawal (Steel \& Lounsbury, 2009). Therefore, an individual's employability (civilian equivalence) might have a moderating influence on withdrawal. The following hypothesis tested this idea:

H7: Civilian equivalence would moderate the influence of person-organization and person-occupation fit on organizational withdrawal such that for those individuals who perceived poor fit, a lack of civilian equivalence would associated with greater psychological withdrawal but not with turnover intentions.

Perceived Job Alternatives. A closely related concept to perceived employability is perceived job alternatives. This concept refers to workers' perceptions of viable job alternatives (Griffeth, Steel, Allen \& Bryan, 2005; Steel \& Griffeth, 1989). Perceived job alternatives have an important, albeit modest, link (Griffeth et al., 2000 ) in the turnover process. In essence, the perception of job alternatives may motivate dissatisfied workers to seek alternative employment and be the first step in 
the search for alternative employment (Griffeth et al., 2005; Steel \& Griffeth, 1989). In the current research, a link was drawn between "employability" and perceived job alternatives in that they both relate to worker's perceptions of viable work alternatives. Although these two concepts are somewhat different, they are really two sides of the same coin; from the worker's perspective, employability speaks to an ability to supply skills to the workplace, whereas, perceived job alternatives speaks to the job market's ability to supply suitable employment (McQuaid \& Lindsay, 2005). Hence, an individual's perception of employability is strongly linked to his or her perceptions of alternatives (Cuyper et al., 2011; Griffeth et al., 2005). Logically, workers who perceive viable job alternatives should be less likely to feel constrained to stay in an organization where they perceive a misfit. Therefore, the following hypothesis was tested:

H8: Perceived job alternatives would moderate the influence of poor personorganization and person-occupation fit on organizational withdrawal such that the perception of job alternatives would be associated with lower psychological withdrawal and greater turnover intention.

\section{Study Overview}

Employee attrition is a significant issue for organizations (Hom et al., 2008;

Otis \& Straver, 2008), particularly for organizations such as the Canadian Forces that aim to attract, select, and retain employees for a 25-30 year career. Although not all turnover is controllable (Lee et al., 1996) and the turnover process is fairly well understood (Steel \& Lounsbury, 2009), questions still remain with regard to what organizations can do to reduce turnover. Practitioners and researchers agree that one 
promising avenue is to draw clearer links between recruiting, selection, and attrition (Barrick \& Zimmerman, 2009; Karren \& Graves, 1994; Sekiguchi, 2007; Werbel \& Johnson, 2001). The current study proposed that one way to forge clearer links between recruiting, selection, and attrition is through the framework of personenvironment fit. Person-environment fit has been strongly associated with positive workplace outcomes, and there is a substantial body of research that supports the idea that effectively matching employees to organizations can have a positive influence on the recruiting and selection of personnel, the creation of positive workplace attitudes, and the retention of employees (Cable \& DeRue, 2002; Cable \& Judge, 1996;

Edwards, 2009; Kristof-Brown \& Guay, 2011; Kristof-Brown et al., 2002; Verquer et al., 2003).

The current study answered the call for more research that examines multiple types of fit and multiple outcomes in the same study by using data collected in the 2010 Canadian Forces retention survey. Its overall aim was to explore employee perceptions of organization and occupation fit and how these perceptions were related to affective and normative commitment, intention to leave, and psychological withdrawal. The current research examined the unique and combined effects of the fit domains on the above outcomes. In addition, the current research explored the buffering effects of perceptions of organizational support on person-environment fit perceptions, proposing that strong perceptions of perceived organizational support would bolster organizational commitment and buffer the influence of poor fit on organizational withdrawal attitudes. Further, continuance commitment was explored as a moderator of the associations between perceptions of fit and organizational 
withdrawal. It was hypothesized that continuance commitment would mitigate the influence of poor fit on organizational withdrawal and result in a decrease in psychological withdrawal and turnover intention. Finally the study explored whether a member's employability (equivalence of the individual's occupation to a civilian occupation and perception of alternatives) would increase psychological withdrawal, but decrease turnover intention based on the theory that individuals who perceive that their options for employment in another organization are limited would feel constrained to stay with the organization, despite poor fit. The ultimate goal of this research was to form a clearer picture of the role person-environment fit plays in effective organizational functioning and retention. The conceptual framework for the current research is depicted in Figure 1. 
Figure 1

Conceptual Framework for the Influence of Person-Environment Fit

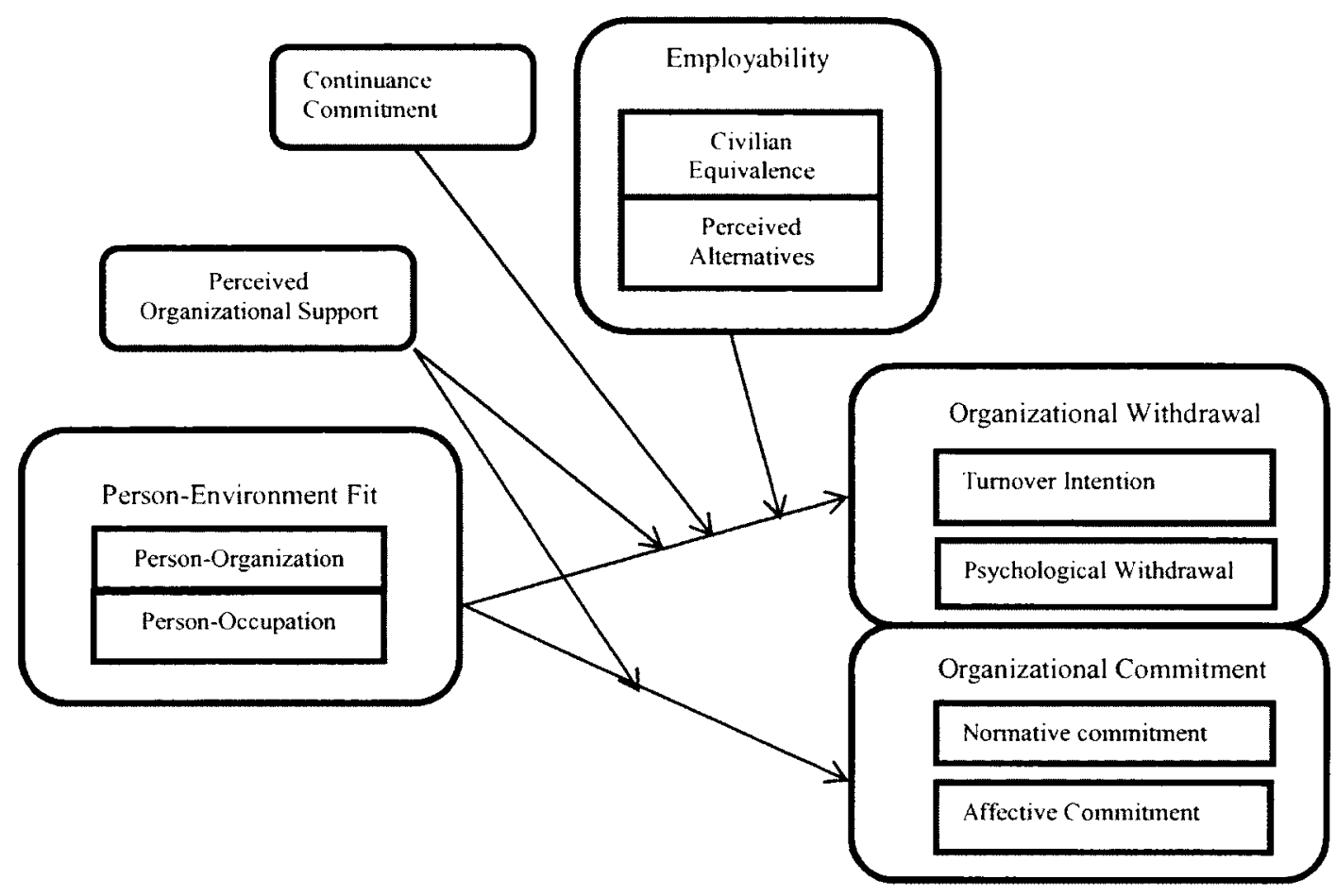

Figure 1. Conceptual framework for the influence of person-environment fit perceptions on organizational commitment and organizational withdrawal.

\section{Method}

\section{Participants}

The current study used archival data collected by the Director General Military

Personnel Research and Analysis (DGMPRA) in the administration of the 2010

Canadian Forces Retention Survey. The survey was administered to all members of 47

select occupations (Appendix A), who could be contacted through the Canadian

Forces internal email system. In total, 25,642 personnel were invited to complete the survey and 6,503 members responded, resulting in a $25.4 \%$ response rate. The final 
sample was not necessarily representative of the Canadian Forces. Personnel were under-represented in the younger age groups, particularly for the junior noncommissioned rank personnel (Private to Master Corporal). Participants with 0 to 4 and 5 to 14 years of service were also underrepresented (Goldenberg, 2011). After data screening, the final data set consisted of 6,181 participants.

Most of the participants 4,815 (77.9\%) were male. Although only 1,342 $(21.8 \%)$ of the participants were female, they were still overrepresented in this sample, because women in the Canadian Forces actually comprise approximately $13 \%$ of the total population of the Canadian Forces (Park, 2008). The higher percentage of females in the sample can be attributed to the fact that although women are employed in every occupation in the Canadian Forces, they still tend to work in the more traditional support occupations, such as medical, dental, clerical, logistics, and supply (Park, 2008), which forms a large proportion of the occupations surveyed for this study. For example, the resource management support occupation (essentially a clerical occupation), which traditionally has a large female population, had a ratio of 45:54 males to females. Similarly, for nurses, also a traditionally female occupation, the ratio was $24 \%$ males as compared to $74 \%$ females. Appendices $F$ and $G$ provide a detailed summary of both the number of participants in each occupation and the gender distribution of participants in each occupation surveyed.

The average age of the participants was 40 years old $(S D=8.2)$. Most participants, 4,754 (76.9\%), were married or common-law, 857 (13.9\%) were single, $529(8.6 \%)$ were separated or divorced and $19(.3 \%)$ were widowed. English was reported as the first official language for $4,609(74.6 \%)$, whereas $1,518(24.6 \%)$ 
reported French as their first official language. Table 1 provides a summary of the education level of participants. Of note, the majority of participants possessed at minimum a high school education with only 281 (4.5\%) participants indicating they had not completed high school even though the minimum entry standard for some occupations is Grade 10. It is also notable that almost $21 \%$ of the participants possessed an undergraduate degree.

The participants served across Canada with an average length of service of 18 years $(S D=9.0)$. Table 2 provides a detailed summary of the rank breakdown of the participants. One thousand, one hundred and three participants were in the Navy $(17.8 \%), 3,439(55.6 \%)$ were in the Army and 1,621 (26.2\%) were in the Air Force.

\section{Table 1}

Education Level

\begin{tabular}{lcc}
\hline \multicolumn{1}{c}{ Education Level } & $\mathrm{N}$ & $\%$ \\
\hline Some high school & 281 & 4.5 \\
High school graduate (including GED) & 1590 & 25.7 \\
Some college (including CEGEP) & 780 & 12.6 \\
College graduate (including CEGEP) & 713 & 11.5 \\
Some university & 614 & 9.9 \\
Undergraduate degree & 1292 & 20.9 \\
Graduate degree courses & 234 & 3.8 \\
Graduate degree & 663 & 10.7 \\
\hline
\end{tabular}


Table 2

\section{Rank Distribution}

\begin{tabular}{|c|c|c|}
\hline Noncommissioned Members & $\mathrm{N}$ & $\%$ \\
\hline Private/Able Seaman ${ }^{3}$ & 257 & $\overline{4.2}$ \\
\hline Corporal/Leading Seaman & 804 & 13.0 \\
\hline Master Corporal/Master Seaman & 788 & 12.7 \\
\hline Sergeant/Petty Officer Second Class & 841 & 13.6 \\
\hline Warrant Officer/Petty Officer First Class & 601 & 9.7 \\
\hline Master Warrant Officer /Chief Petty Officer Second Class & 378 & 6.1 \\
\hline Chief Warrant Officer/Chief Petty Officer First Class & 113 & 1.8 \\
\hline Total Noncommissioned Members & 3680 & 59.5 \\
\hline Officers & $\mathrm{N}$ & $\%$ \\
\hline Second Lieutenant/Acting Sub Lieutenant & 77 & $\overline{1.2}$ \\
\hline Lieutenant /Sub Lieutenant & 216 & 3.5 \\
\hline Captain/Lieutenant (Navy) & 950 & 15.4 \\
\hline Major/Lieutenant Commander & 795 & 12.9 \\
\hline Lieutenant Colonel/Commander & 297 & 4.8 \\
\hline Colonel/Captain(Navy) & 64 & 1.0 \\
\hline Total Officers & 2501 & 40.5 \\
\hline
\end{tabular}

Note: Ranks are listed in ascending order, from junior to most senior

${ }^{3}$ Ranks on the right are the Royal Canadian Navy equivalents to the Canadian Army and the Royal Canadian Air Force rank designations listed on the left. 


\section{Procedures}

The Canadian Forces retention survey is a cross-sectional web-based electronic questionnaire aimed at exploring factors that contribute to the retention decisions of its members. It is a bi-annual survey directed at occupations that have not maintained effective staffing levels, either because of high attrition or because insufficient personnel have been recruited into these occupations. The Social Science Research Review Board (ethics committee) of the Canadian Forces cleared the Retention Survey for administration to Canadian Forces personnel; the authorization number is shown in Appendix B. The Carleton University Research Ethics Board approved the current research.

The survey was administered between February and July 2010. Members received an e-mail through the internal e-mail system to solicit their participation in the survey. The email provided the participants with instructions on how to access the survey, complete it, and submit the completed questionnaire. Respondents were instructed to click on the hyperlink and follow the on-screen instructions. When the participants opened the survey, the first page they opened was the survey cover page (see Appendix B). The cover page of the survey provided the details necessary for informed consent, the purpose of the study, assurances that their participation was voluntary, and that they were free to not answer any question they did not wish to answer. Participants were also guaranteed that their responses would be kept strictly confidential and anonymous under the Access to Information Act. Finally, the cover page provided information regarding the appropriate persons to contact in the event participants had any questions. The survey and instructions were available in both 
official languages and respondents received two reminders during the survey administration while the link was still active. The survey in its entirety took approximately 40 to 50 minutes to complete.

Completed surveys were sent electronically to a database in the information technology section of Director General Military Personnel Research and Analysis section. All unique identifiers were removed from the data prior to being provided to the researcher. The data for the current research was provided by the Director General Military Personnel Research and Analysis section of National Defence Headquarters.

\section{Measures}

Appendix C contains the portions of Canadian Forces Retention Survey that are relevant to this research. The majority of the measures used was available in the public domain and adapted for the Canadian Forces (CF) population by replacing terms that referred to the "organization" with "the CF" where appropriate. The personenvironment fit measures described below were developed for the retention survey.

Person-organization fit. Person-organization fit was measured with a threeitem scale assessing participants' perceptions of the congruence between their values and the Canadian Force's values and culture. A sample item was "I fit with the CF's culture." Items were scored on 6-point scales ranging from 1 (strongly disagree) to 6 (strongly agree). Higher scores indicate higher levels of person-organization fit. Cronbach's alpha for the three-item scale was .77 .

Person-occupation fit. The person-occupation fit measure was a three-item scale constructed by combining items from two different scales in the original survey. The first item essentially measuring job fit asked "My job is a good fit with my skills 
and interests." The other two items assessed fit with their occupation: "I feel my occupation is still a good fit for me" and "I would leave my occupation if given the opportunity to transfer to a new one" (reverse scored). Participants were asked to indicate their level of agreement with the item with responses on 5-point scales, ranging from 1 (strongly disagree) to 5 (strongly agree). Higher scores indicate higher levels of person-occupation fit. The reliability of the scale was .67 .

Organizational Commitment. Organizational commitment was assessed with 17 items from Meyer, Allen, and Smith's (1993) three-component organizational commitment scale. Items were scored on 6-point scales with responses ranging from 1 (strongly disagree) to 6 (strongly agree). Affective commitment consisted of six items; a sample item was "I would be happy to spend the rest of my career in the CF." The normative commitment scale also consisted of six items with a sample item being "I owe a great deal to the CF." Continuance commitment was assessed with five items; a sample item was "I feel that I have too few options to consider leaving the CF." Individuals received a separate score for affective, continuance, and normative commitment. Past reported reliabilities averaged across studies were $.83, .76$, and .80 for affective, normative, and continuance commitment respectively (Allen \& Meyer, 1996). For the present research, the affective commitment scale had an alpha coefficient of .83 , normative commitment had an alpha coefficient of .82 and continuance commitment's alpha coefficient was .77.

Turnover Intention. Turnover intention was assessed by a single item that asked "Do you intend to leave the CF within a year?" This item was scored on a 5 point scale with 1 (definitely not) to 5 (definitely yes). 
Psychological Withdrawal. Psychological withdrawal was measured using a 6- item scale created by Mantler (2006). A sample item was "My body goes to work; my mind does not." Items were scored on six-point scales ranging from 1 (strongly disagree) to 6 (strongly agree). Higher scores indicate higher levels of psychological withdrawal. Previous research using this scale reported a Cronbach's alpha of .92 (Koundakjian \& Michaud, 2011); the scale reliability for the present sample was .93.

Perceived Organizational Support. Perceived organizational support was assessed using nine items adapted from Eisenberger, Huntington, Hutchinson, and Sowa's (1986) perceived organizational support scale. Participants responded to items such as "The Canadian Forces really cares about my well-being." Scale anchors ranged from 1 (strongly disagree) to 6 (strongly agree). Reported reliabilities ranged from .90 to .95 (Shore \& Tetrick, 1991). Reliability for the 9-item perceived organizational support scale used for this study was .86 .

Perceived Alternatives. Perceived alternatives was measured with one item "How easy would it be for you to find a good job with another employer?" Participants indicated the level of difficulty they believed they would have on a 4point scale with responses ranging from 1 (very difficult) to 4 (very easy).

Civilian Equivalence. Civilian equivalence refers to the correspondence of a military occupation to a civilian equivalent. Scores were derived by consulting the occupations fact sheets available on the Canadian Forces Recruiting web site http://www.forces.ca. If the fact sheet listed related civilian occupations for the occupation, it was coded with a 2 and if there were no related civilian occupations listed that occupation was coded with a 1 . A complete list of all occupations in the 
study and how they were coded is attached as Appendix E. Overall, 3,962 (64.1\%) of participants worked in an occupation that had no related civilian occupations listed and $2,219(35.9 \%)$ of participants belonged to an occupation that had one or more related civilian occupations listed. A larger proportion of noncommissioned members, 3,246 $(85.8 \%)$, were employed in occupations with no related civilian occupations than in occupations with related civilian occupations $536(14.2 \%)$. Conversely, $716(29.8 \%)$ of officers were employed in occupations that did not list related civilian occupations whereas $1,683(70.2 \%)$ were employed in occupations that had related civilian occupations.

Demographic Variables. Demographic information was collected for rank, occupation, environment (Air Force, Navy, or Army), age, gender, marital status, education level, and years of service. Demographic questions are attached as Appendix D. Based on previous research (Griffeth et al., 2000; Kristof-Brown \& Guay, 2011) it was expected that years of service would significantly influence the outcomes and therefore be an important covariate to control in analyses related to turnover intention and commitment. Education level was another variable of particular interest with regard to evaluating the influence of perceived alternatives, continuance commitment, and turnover intentions given that it is logical to assume that individuals with higher levels of education are more likely to perceive that they are more employable and have more job alternatives (Griffeth et al, 2000; Trevor, 2001). 


\section{Results}

\section{Preliminary Analyses - Data Quality}

In accordance with the guidelines provided by Tabachnick and Fidell (2007) and supplemented by Field (2009), prior to conducting main analyses, the data were screened for accuracy of input, missing data, univariate and multivariate outliers, and tested to ensure they met the assumptions for the planned multivariate analyses. Following the guidelines provided by Cohen (1991), both effect sizes and $p$ values were reported and because the data set was large, the alpha level was set to $p<01$.

Outliers and Missing Data. All of the values fell into plausible ranges and were consistent with expected minimum and maximum values. Univariate outliers were identified by creating standard scores for both individual items and computed variables. As can be expected in a large data set (Tabachnick \&Fidell, 2007), there were univariate outliers, identified as values that exceeded a $z$ score value of \pm 3.29 , however these comprised less than $1 \%$ (95 cases) of the data set. To retain the information from the variables but reduce the negative influence on normality (Field, 2009), the scores on computed variables were brought into range by altering scores to bring them as close to the cut-off of 3.29 as possible without altering the rank order of the responses. The presence of multivariate outliers was assessed with Malahanobis and Cook's distance; 99 multivariate outliers were identified using a critical value of $X^{2}(12)=32.91, p<.001$. A series of stepwise regressions, followed by frequency analyses, were conducted using dummy-coded outliers to ensure there were no variables that were consistently separating the multivariate outliers from the other cases; no systematic variations were found. Cook’s distance was .003 for 
noncommissioned members and .005 for officers, providing further confirmation that no single case was having an undue influence on the other variables. Given that there were no concerns with regard to having sufficient power, all 99 cases were deleted.

Two additional cases were deleted because the participants did not respond to the items relevant to the current research, and a further 221 cases were deleted because they were identified as belonging to participants whose turnover intentions were not voluntary. In total, 322 cases were deleted from the dataset, leaving a final sample of 6,181 cases.

Missing data analysis indicated that there were less than $5 \%$ missing values and Little's MCAR test was significant $X^{2}=1741.33(190), p<.0001$, therefore missing values were judged to be missing completely at random (MCAR). Missing data were dealt with by using listwise deletion.

Normality and Regression Assumptions. Data were explored with Q-Q plots, box plots, and stem and leaf plots to determine whether there were departures from normality. Although Kolmogorov-Smirnov was significant at $p<.001$ for all measured variables, given the sensitivity of this test with large data sets (Tabachnick \& Fidell, 2007), $z$ scores were calculated to determine the significance of the skewness and kurtosis. Results indicated that all of the measured variables except normative commitment exceeded $z$ scores of \pm 3.29 ; skewness values ranged from -31.19 for person-organization fit to 43.61 for turnover intention and kurtosis ranged from -10.32 for continuance commitment and 16.63 for person-organization fit. Even so, no transformations of the data were constructed because such transformations would have complicated the interpretation of results and because with the large data set available 
the results should remain robust despite of the departures from normality (Tabachnick \& Fidell, 2007).

Examination of pairwise bivariate scatter plots and the partials plots of the residuals indicated there were good linear relationships between the predictors and outcomes and that data were homoscedastic. The assumption of independence was met as variables were dispersed consistently around the mean with only mild deviations. Independence of errors was assessed with the Durbin-Watson coefficient, which was 1.34 for noncommissioned members and 1.61 for officers, well within the acceptable range of between 1 and 3 (Field, 2009). Examination of the tolerance statistic indicated all tolerance values were well above $.1 / .2$, therefore neither multicollinearity nor singularity were an issue with this data set.

\section{Demographic Variables}

Prior to proceeding with hypothesis testing of study variables, the data were explored though their correlations (see Table 3). A select set of demographic variables were included in the correlation analysis to identify demographic factors that might influence the outcomes and need to be taken into account prior to conducting the regression analyses. Given the large data set, associations with $p$ values greater than .01 were not considered significant. In addition, the significance of the findings was evaluated using the standards set by Cohen (1992.), for example $r=.10$ is a small effect, $r=.50$ is a medium effect, and $r=.80$ is a large effect. 


\section{Table 3}

\section{Correlations, Means, Standard Deviations, and Reliabilities - Full Sample}

\begin{tabular}{|c|c|c|c|c|c|c|c|c|c|c|c|c|}
\hline & 1 & 2 & 3 & 4 & 5 & 6 & 7 & 8 & 9 & 10 & 11 & 12 \\
\hline \multicolumn{13}{|l|}{1 Gender $^{a}$} \\
\hline 2 Years of Service & $-.19^{* *}$ & & & & & & & & & & & \\
\hline 3 Education & $.05^{* *}$ & $-.08^{* *}$ & & & & & & & & & & \\
\hline 4 Affective Commitment & -.01 & $.11^{* *}$ & $.04 * *$ & $(.83)$ & & & & & & & & \\
\hline 5 Continuance Commitment & $.06 * *$ & $-.09 * *$ & $-.13 * *$ & .02 & $(.77)$ & & & & & & & \\
\hline 6 Normative Commitment & $.04^{*}$ & .01 & .00 & $.64^{* *}$ & $.21^{* *}$ & $(.82)$ & & & & & & \\
\hline 7 Organizational Support & -.01 & $.08^{* *}$ & .02 & $.59^{* *}$ & $-.05^{* *}$ & $.53^{* *}$ & $(.86)$ & & & & & \\
\hline 8 Psychological Withdrawal & -.01 & $-.07^{* *}$ & $-.08^{* *}$ & $-.63^{* *}$ & $.14^{* *}$ & $-.50^{* *}$ & $-.60^{* *}$ & $(.93)$ & & & & \\
\hline 9 Person-Organization Fit & -.01 & $.12^{* *}$ & .01 & $.70^{* *}$ & -.03 & $.53^{* *}$ & $.55^{* *}$ & $-.57^{* *}$ & $(.77)$ & & & \\
\hline 10 Person-Occupation Fit & $.03^{*}$ & $.11^{* *}$ & $.08^{* *}$ & $.45^{* *}$ & $-.08^{* *}$ & $.37^{* *}$ & $.42^{* *}$ & $-.54^{* *}$ & $.42^{* *}$ & $(.67)$ & & \\
\hline 11 Turnover Intention & $-.05^{* *}$ & $.23^{* *}$ & $-.10^{* *}$ & $-.32^{* *}$ & $-.25^{* *}$ & $-.35^{* *}$ & $-.25^{* *}$ & $.31^{* *}$ & $-.24^{* *}$ & $-.22^{* *}$ & & \\
\hline 12 Perceived Alternatives & $.06^{* *}$ & .01 & .00 & $.05^{* *}$ & $-.08^{* *}$ & $.06^{* *}$ & $.05^{* *}$ & $-.08^{* *}$ & $.06^{* *}$ & $.07^{* \bullet}$ & -.03 & \\
\hline 13 Civilian Equivalence ${ }^{b}$ & & $.05^{* *}$ & $.39^{* *}$ & $.06^{* *}$ & $-.04^{*}$ & .00 & .03 & $-.04^{*}$ & $.04^{*}$ & -.03 & $-.05^{* \bullet}$ & $-.04^{*}$ \\
\hline $14 \operatorname{Rank}^{\circ}$ & & .03 & $.77^{* *}$ & $.07^{* *}$ & $-.14^{* *}$ & .01 & $.05^{* *}$ & $-.10^{* *}$ & .03 & $.09^{* *}$ & $-.08^{* *}$ & .00 \\
\hline Mean & & 18.0 & 4.29 & 4.38 & 3.37 & 3.48 & 3.88 & 2.66 & 4.72 & 3.72 & 1.80 & 3.67 \\
\hline $\mathrm{SD}$ & & 9.0 & 2.12 & .95 & 1.09 & 1.05 & .92 & 1.26 & 0.92 & 0.96 & 1.10 & 0.97 \\
\hline
\end{tabular}

Note: $N$ ranges from 6,181 to 6,110 . Reliabilities for measured variable are in parenthesis on the diagonal

${ }^{a}$ Gender $($ Males $=0$, Females $=1){ }^{b}$ Civilian Equivalence (no equivalence $=0$, equivalence $=1$ ) ${ }^{c}$ ank $($ Noncommissioned member $=0$, Officer $=1$ ) ${ }^{*} p<.01, * * p<.0001$ 
Years of Service and Education. As evidenced in Table 3, more years of service was significantly associated with better person-environment fit, greater affective commitment, stronger perceptions of organizational support, and higher turnover intentions. Moreover, years of service was also significantly associated with lower continuance commitment and lower psychological withdrawal. Surprisingly, years of service was not associated with normative commitment.

Level of education was positively associated with affective commitment, and interestingly, not associated with normative commitment. As would be expected, higher education was positively associated with civilian equivalence and rank, given that officers were more likely to work in an occupation that had a civilian equivalent and that many officer occupations require a degree. In addition, level of education was negatively associated with psychological withdrawal, continuance commitment, and turnover intention. Interestingly, members with fewer years of service were more likely to have higher levels of education. In summary, consistent with previous literature (Griffeth et al., 2000; Kristof-Brown \& Guay, 2011; Trevor, 2001) correlation results confirm that years of service and education both have a significant association with variables of interest in the study and therefore these two variables were added in the first step of subsequent regression analyses as control variables.

Gender. Independent samples t-tests were conducted to determine whether the small but significant gender differences evident in the correlation analyses (see Table 3 ) would necessitate including gender as a control in regression analyses. As evidenced in Table 4, there were notable gender differences, although the effects were generally small. On average, women were significantly more highly educated than were the men, and 
believed they had more job alternatives. At the same time, women reported significantly higher continuance commitment and lower turnover intentions. The largest gender difference was that, on average, females had fewer years of service than did the males. Moreover, women were also employed in significantly more occupations that did not have a related civilian occupation $X^{2}(1)=79.92, p=.0003, \varphi=.11$ and were more likely to be noncommissioned members than they were to be officers, $X^{2}(1)=7.346, p=.007$, $\varphi=.04$. In short, gender was significantly associated with many study variables, and although for the most part the effect sizes are small, they were considered meaningful enough to potentially influence regression analyses, particularly in relation to turnover intention and perceived alternatives. Therefore, gender was added to Step 1 of the regression analyses as a control variable. 
Table 4

Independent Samples t-tests for Gender Differences

\begin{tabular}{|c|c|c|c|c|c|c|}
\hline \multirow[b]{2}{*}{ Variables } & \multicolumn{2}{|c|}{$M(S D)$} & \multirow[b]{2}{*}{$t$} & \multirow[b]{2}{*}{$d$} & \multicolumn{2}{|c|}{$\begin{array}{l}99 \% \text { Confidence } \\
\text { Interval }\end{array}$} \\
\hline & Males & Females & & & Lower & Upper \\
\hline Years of Service & $19.01(9.0)$ & $14.81(8.41)$ & $15.33^{*}$ & 0.48 & 3.50 & 4.91 \\
\hline Education & $4.23(2.15)$ & $4.48(1.98)$ & $-3.94 *$ & -0.12 & -0.41 & -0.09 \\
\hline Affective Commitment & $4.40(0.96)$ & $4.38(0.90)$ & 0.38 & 0.01 & -0.06 & 0.09 \\
\hline Continuance Commitment & $3.34(1.19)$ & $3.50(1.09)$ & $-4.56^{*}$ & -0.14 & -0.24 & -0.07 \\
\hline Normative Commitment & $3.47(1.05)$ & $3.56(1.01)$ & -2.90 & -0.09 & -0.02 & -0.01 \\
\hline Person-Organization Fit & $4.73(0.91)$ & $4.71(0.90)$ & 0.53 & 0.02 & -0.06 & 0.09 \\
\hline Person-Occupation Fit & $3.70(0.95)$ & $3.79(1.10)$ & -2.70 & -0.09 & -0.16 & -0.00 \\
\hline $\begin{array}{l}\text { Perceived Organizational } \\
\text { Support }\end{array}$ & $3.89(0.92)$ & $3.89(0.91)$ & -0.14 & 0.00 & -0.00 & 0.02 \\
\hline Psychological Withdrawal & $2.66(1.24)$ & $2.64(1.29)$ & 0.38 & 0.01 & 0.01 & 0.04 \\
\hline Turnover Intention & $1.81(1.14)$ & $1.68(1.08)$ & $3.72 *$ & 0.12 & 1.30 & 0.04 \\
\hline Perceived Alternatives & $3.63(0.95)$ & $3.78(1.01)$ & $-4.90 *$ & -0.16 & -0.23 & -0.07 \\
\hline
\end{tabular}

Note. $N=$ males 4,791, females 1,332 .

${ }^{*} p<.0009$ with Bonferroni correction applied 


\section{Noncommissioned Member and Officer Characteristics}

Independent samples t-tests were run to determine whether noncommissioned members and officers differed from each other; the results of these analyses are presented in Table 5. Corroborating the correlation results (Table 3), the t-tests show that officers possessed significantly higher levels education relative to noncommissioned members and that these differences are meaningfully significant. Further, officers were employed in significantly more occupations with related civilian equivalencies relative to noncommissioned members, $X^{2}(1)=1999.09, p=.0008, \varphi=.57$. This is not surprising, however, as the Canadian Forces is working toward ensuring all officers have a degree and many officer occupations require a degree (e.g., doctor, nurse, etc.). Aside from this expected difference, the t-tests (see Table 5) also demonstrated that officers and noncommissioned members differed significantly on continuance commitment, personoccupation fit, psychological withdrawal, and turnover intention and therefore it was determined that these two groups should be analyzed separately.

Subsequently, the data set was split by rank into two subsets of data, one for noncommissioned members and one for officers. Table 6 shows the correlations, means, and standard deviations of study variables for the two groups. In addition to the significant differences noted in Table 5, it was also interesting to note differences in the patterns of correlations between the two groups (see Table 6). Specifically, civilian equivalence was associated with person-occupation fit for noncommissioned members, but not for officers. Conversely, civilian equivalence was not associated with personorganization or person-occupation fit for officers. Further, the association between gender and turnover intention applied to noncommissioned members and not to officers. 


\section{Table 5}

Independent Samples t-tests for Rank Differences

\begin{tabular}{lcccccc}
\hline & \multicolumn{2}{c}{$M(S D)$} & & \multicolumn{2}{c}{$99 \% C I$} \\
\cline { 2 - 3 } \cline { 6 - 7 } & NCMS & Officers & $t$ & $d$ & Lower & Upper \\
\hline Years of Service & $17.88(8.98)$ & $18.45(9.14)$ & -2.43 & -0.06 & -1.18 & .03 \\
Education & $2.98(1.32)$ & $6.33(1.39)$ & $-94.72^{*}$ & -2.48 & -3.44 & -3.26 \\
Affective Commitment & $4.33(0.97)$ & $4.47(0.91)$ & $-5.52^{*}$ & -.014 & -0.20 & -0.07 \\
Continuance Commitment & $3.49(1.09)$ & $3.17(1.06)$ & $11.52^{*}$ & 0.30 & 0.25 & 0.39 \\
Normative Commitment & $3.48(1.07)$ & $3.50(1.00)$ & -0.58 & -0.02 & -0.84 & 0.05 \\
Person-Organization Fit & $4.70(0.92)$ & $4.76(0.89)$ & -2.59 & -0.07 & -0.12 & -0.00 \\
Person-Occupation Fit & $3.65(0.96)$ & $3.83(0.95)$ & $-6.97^{*}$ & -0.18 & -0.24 & -0.11 \\
Perceived Organizational & $3.85(0.94)$ & $3.95(0.87)$ & $-4.31^{*}$ & -0.11 & -0.16 & -0.04 \\
$\begin{array}{l}\text { Support } \\
\text { Psychological Withdrawal }\end{array}$ & $2.76(1.26)$ & $2.51(1.20)$ & $7.46^{*}$ & 0.15 & 0.16 & 0.33 \\
Turnover Intention & $1.86(1.16)$ & $1.68(1.09)$ & $6.30^{*}$ & 0.16 & 0.11 & 0.26 \\
Perceived Job Alternatives & $3.66(1.02)$ & $3.67(.88)$ & -0.26 & -0.01 & -0.07 & 0.06 \\
\hline
\end{tabular}

Notes $-N=3,782$ (Noncommissioned members) $N=2,399$ (Officers)

$* p<.0009$ Bonferroni correction applied.

\section{Cross Validation}

To increase the generalizability of the results of the current research, a simple cross-validation was conducted by further splitting the sample using an $80 / 20$ split (Tabachnick \& Fidell, 2007) and testing the conceptual framework depicted in Figure 1 separately on each subset, which resulted in four subsets of data. The first dataset comprised $2,952(80 \%)$ of the noncommissioned members and the second set comprised $1,993(80 \%)$ of the officer participants. The third and fourth datasets encompassed the remaining 20\% groups so that there were 771 noncommissioned members and 499 
officers respectively. To ensure sufficient power would be available to conduct the planned analyses, an online power calculator available at http:/www.danielsoper.com/statcalc3 (Cohen, Cohen, West, \& Aiken, 2003; Soper, 2012), was used to determine the minimum sample size required to detect an effect at $80 \%$ power. Based on previous research it was expected the effect sizes for the multiple $R$ would be small to moderate ranging from .01 to .47 (Kristof Brown \& Guay, 2011). Keeping a stringent alpha of .01, and assuming an effect size of .05 , with 17 independent variables (for the full moderator model), the minimum sample size required was 548 participants; adjusting the alpha to .05 , minimum sample size required was 408 participants. Given these parameters, alpha was adjusted to .05 for the $20 \%$ officer group only. 


\section{Table 6}

\section{Correlations, Means, and Standard Deviations - 80\% Percent Sample of Noncommissioned Members and Officers}

\begin{tabular}{|c|c|c|c|c|c|c|c|c|c|c|c|c|c|c|c|c|c|}
\hline Variables & $M$ & $\mathrm{SD}$ & 1 & 2 & 3 & 4 & 5 & 6 & 7 & 8 & 9 & 10 & 11 & 12 & 13 & $\mathrm{M}$ & $\mathrm{SD}$ \\
\hline I Gender & 1.23 & 0.42 & & $-.16^{* *}$ & $.06^{*}$ & $-.07^{*}$ & .02 & -.02 & $-.05^{*}$ & .05 & $-.05^{*}$ & -.04 & -.03 & $.08^{* t}$ & & 1.20 & 0.40 \\
\hline 2 YOS & 17.94 & 8.99 & $-.20^{* *}$ & & $-.06^{* *}$ & $.07^{*}$ & $-.06^{* *}$ & -.03 & -.02 & -.01 & $.09^{* *}$ & $.07^{+}$ & $24^{* *}$ & -.01 & $12^{* *} 1$ & 18.39 & 9.15 \\
\hline 3 Education & 2.97 & 1.31 & $.15^{* *}$ & $-.23^{* *}$ & & .01 & $-.08^{* *}$ & .01 & .00 & $-.08 * *$ & .00 & $.11^{* *}$ & -.03 & .02 & $-.07^{* *}$ & 6.19 & 1.56 \\
\hline 4 Affective Commitment & 4.33 & 0.97 & .03 & $.12^{* *}$ & -.05 & & .01 & $.64^{* *}$ & $.59^{* *}$ & $-.62^{* *}$ & $.71^{*}$ & $.45^{* *}$ & $-.31^{* *}$ & $.06^{*}$ & .03 & 4.46 & 0.92 \\
\hline 5 Continuance Commitment & 3.48 & 1.08 & $.09^{* *}$ & $-.11^{* *}$ & .01 & .02 & & $.19^{* *}$ & -.05 & $.15^{* *}$ & -.03 & $-.12^{* *}$ & $-.27^{* *}$ & $-.09^{* *}$ & $.08^{*}$ & 3.21 & 1.06 \\
\hline 6 Normative Commitment & 3.48 & 1.07 & $.07^{* *}$ & .02 & -.03 & $.64^{* *}$ & $.22^{* *}$ & & $.53^{* *}$ & $-.48^{* *}$ & $.51^{* *}$ & $.37^{* *}$ & $-.32^{* *}$ & $.07^{*}$ & -.01 & 3.51 & 1.01 \\
\hline 7 Organizational Support & 3.86 & 0.93 & .04 & $.13^{* *}$ & $-.05^{*}$ & $.61^{* *}$ & $-.03^{*}$ & $.54^{* *}$ & & $-.58 * *$ & $.55^{* *}$ & $.41^{* *}$ & $-.24^{* *}$ & $.06^{*}$ & .04 & 3.94 & 0.88 \\
\hline 8 Psychological Withdrawal & 2.76 & 1.29 & -.04 & $-.11^{* *}$ & .01 & $-.64^{* *}$ & $.13^{* *}$ & $-.51^{* *}$ & $-.60^{* *}$ & & $-.56^{* *}$ & $-.55^{* *}$ & $.27^{* *}$ & $-.07^{*}$ & .00 & 2.51 & 1.20 \\
\hline 9 Person-Organization Fit & 4.70 & 0.92 & .02 & $.14^{* *}$ & $-.05^{*}$ & $.70^{* *}$ & -.05 & $.53^{* *}$ & $.56^{* *}$ & $-.58^{* *}$ & & $.43^{* *}$ & $-.24^{* *}$ & $.08^{*}$ & .05 & 4.76 & 0.90 \\
\hline 10 Person-Occupation Fit & 3.64 & 0.96 & $.08^{* *}$ & $.13^{* *}$ & -.04 & $.45^{* *}$ & $-.05^{*}$ & $.36^{* *}$ & $.42^{* *}$ & $-.53^{* *}$ & $.42^{* *}$ & & $-.21^{* *}$ & $.06^{\circ}$ & -.04 & 3.82 & 0.95 \\
\hline 11 Turnover Intention & 1.87 & 1.15 & $-.06^{* *}$ & $.22^{* *}$ & $-.08^{* *}$ & $-.34^{* *}$ & $-.26^{* *}$ & $-.38^{* *}$ & $-.24^{* *}$ & $.33^{* *}$ & $-.26^{* *}$ & $-.23^{* *}$ & & -.05 & -.00 & 1.67 & 1.07 \\
\hline 12 Perceived Alternatives & 3.67 & 1.02 & $.06^{* *}$ & .01 & -.03 & $.06^{*}$ & $-.09^{* *}$ & $.06^{* *}$ & $.07^{* *}$ & $-.09^{* *}$ & $.07^{* *}$ & $.07^{* *}$ & -.02 & & -.04 & 3.68 & 0.89 \\
\hline 13 Civilian Equivalency & 1.13 & 0.34 & & -.01 & $-.20^{* *}$ & .01 & .00 & -.01 & -.03 & .02 & .02 & $-.13^{* *}$ & .01 & -.04 & & 1.70 & 0.46 \\
\hline
\end{tabular}

Notes: $N^{\prime}=2,952$ Nonconmissioned members values shown below the diagonal. $N=2.009$ Officers values shown above the diagonal. Means and standard deviations for noncommissioned members are shown on the left side of the table and officer values are shown on the right. $*_{p}<.01,{ }^{* *} p<.0001$ 


\section{Tests of Person-Environment Fit Conceptual Framework}

The conceptual framework depicted in Figure 1 was primarily tested with multiple regression analyses. Correlations were examined to explore the simple associations between the conceptual variables, followed by an examination of the direct effects of person-environment fit on the outcomes through standard regression analyses. The association of the proposed moderators were evaluated using hierarchical moderator regression following the guidelines set out by Frazier and colleagues (2004).

Associations for Organizational Withdrawal. In short, the person-environment fit variables had a pattern of associations that is similar to what has been reported in the extant literature. The moderate positive correlation between person-organization and person-occupation fit, $r=.42, p<.0001$ (Table 3 ), suggested that participants distinguished between both domains of fit. The negative correlations between turnover intention and person-occupation fit, $r=-.22, p$ $<.0001$ and person-organization fit $r=.24, p<.0001$, were consistent with results reported in previous research for perceived fit, (Kristof-Brown et al,. 2005; Kristof-Brown \& Guay; Scroggins, 2007; Wheeler et al., 2005, Verquer et al., 2003), except that, for the most part, person-job (occupation) fit, $\rho=-.46$, is generally a slightly stronger predictor of turnover intention than is person-organization fit, with corrected correlations ranging from -.31 to -.21 , (Kristof-Brown \& Guay, 2011). Psychological withdrawal was negatively associated with both person-occupation, $r=-.54, p<.0001$, and person-organization fit, $r=-.57, p<.0001$, suggesting that the lower fit an individual perceives, the more he or she will be psychologically withdrawn. Contrary to expectations and previous research (Griffeth et al., 2000) turnover intention was not associated with perceived job alternatives, $r=-.03, p=.014$. 
Associations for Organization Commitment. Consistent with a recent meta-analysis conducted by Kristof-Brown and Guay (2011), which reported corrected correlations ranging from .59 to .77 for the association between person-organization fit and organizational commitment, affective commitment was positively correlated with person-organization fit, $r=$ $.70, p<.0001$. The results for the association between person-occupation fit and affective commitment, $r=.45, p<.0001$, were stronger in this study than those reported in same metaanalysis for the association between person-job fit and affective commitment $\rho=.19$ (KristofBrown \& Guay, 2011). As expected person-organization fit, $r=53, p<.0001$, and personoccupation fit, $r=.37, p<.0001$, were positively associated with normative commitment. Interestingly, continuance commitment was not associated with person-organization fit and was only weakly associated with person-occupation fit, $r=-.08, p<.0001$, for the total sample. However, the pattern of associations changed when the results were examined for the two groups (officers and noncommissioned members, see Table 6) in that continuance commitment was weakly associated with both person-organization and person-occupation fit for noncommissioned members, $r=-.05, p<.01$, for both domains. Conversely, similar to the effects for the total sample, continuance commitment was not significantly associated with person-organization fit for officers, but was associated with person-occupation fit, $r=-12, p<$ .0001 . Finally, consistent with results previously reported by Cable and DeRue (2002), perceived organizational support was positively associated with person-organization fit, $r=.55$, $p<.0001$, and person-occupation fit, $r=.42, \mathrm{p}<.0001$. 


\section{Direct Effects of Person-Environment Fit on Outcomes}

Multiple regression analyses were conducted to explore the direct and additive effects of person-organization and person-occupation fit on affective and normative commitment, turnover intention, and psychological withdrawal, thus testing Hypotheses $\mathrm{H} 1, \mathrm{H} 2, \mathrm{H} 3$, and H4. Results of these analyses are presented in Table 7, which includes the unique association $\left(s r^{2}\right)$ for each variable and the effect sizes $\left(f^{2}\right)$ for the $R^{2}$, calculated as recommended by Cohen (1991). Years of service, gender, and education were included as control variables.

Hypothesis HI was partially supported in that person-organization and person-occupation fit were both negatively associated with turnover intention, however contrary to expectations, person-organization fit was a stronger predictor of turnover intention particularly for officers. Further, examination of the squared semi-partial correlations indicated that years of service explained a greater unique portion of the variability in turnover intention than did either personorganization or person-occupation fit. Scroggins' (2007) results indicated that personorganization fit did not add additional variance to turnover intention over and above person-job fit, however the results from the present study indicated that while there is common variance between the domains of fit, person-organization fit and person-occupation fit, both contributed uniquely to the variance in turnover intention.

Hypothesis $\mathrm{H} 2$ was supported in that person-environment fit had a moderate and negative association with psychological withdrawal. Person-organization fit contributed a higher proportion of variance relative to person-occupation fit for both noncommissioned members and officers, but both domains contributed to the overall variance suggesting that both domains are important and that they build on each other. Of note, however, examination of the 
unstandardized regression coefficients and squared semi-partial correlations suggests that for non-commissioned members, person-organization fit has a stronger association with psychological withdrawal (see Table 7). Even so, $\mathrm{H} 2$ was supported in that both domains of fit were negatively related to psychological withdrawal, suggesting that lower perceptions of both domains of fit are uniquely associated with increased psychological withdrawal.

As predicted in Hypotheses $\mathrm{H} 3$ and $\mathrm{H} 4$, affective and normative commitments were each positively associated with both person-organization and person-occupation fit, for both officers and noncommissioned members, over and above the association of the control variables. In addition, the combined effects of both domains accounted for more variance for both forms of commitment than did each domain individually, however, particularly for noncommissioned members, person-organization fit contributed the largest unique proportion of variance $s r^{2}=.31$ and .18 for affective and normative commitment respectively. Intriguingly, years of service also contributed to the overall variability for normative commitment, albeit weakly, despite the lack of correlation between years of service and normative commitment. As years of service increased, the association with normative commitment decreased. Conversely, years of service had no unique association with affective commitment once the person-environment fit variables were taken into account. 


\section{Table 7}

Multiple Regression Analysis with Person Occupation and Person Organization Fit - 80\% Sample

\begin{tabular}{|c|c|c|c|c|c|c|c|c|c|c|c|c|}
\hline & \multicolumn{6}{|c|}{ Noncommissioned Members } & \multicolumn{6}{|c|}{ Officers } \\
\hline & $B$ & $S E B$ & $\beta$ & $s r^{2}$ & $R^{2}$ & $f^{2}$ & $B$ & $S E B$ & $B$ & $s r^{2}$ & $R^{2}$ & $f^{2}$ \\
\hline Turnover Intention & & & & & $.16^{* *}$ & .19 & & & & & $14^{* *}$ & .16 \\
\hline Years of Service & $.03^{* *}$ & .00 & .27 & .06 & & & $.03^{* *}$ & .00 & .27 & .07 & & \\
\hline Gender & .04 & .05 & .01 & .00 & & & .04 & .06 & .01 & .00 & & \\
\hline Education & -.03 & .02 & -.04 & .00 & & & -.00 & .02 & -.00 & .00 & & \\
\hline P-Org & $-.29 * *$ & .02 & -.23 & .04 & & & $-.24 * *$ & .03 & -.20 & .03 & & \\
\hline $\mathrm{P}-\mathrm{Occ}$ & $-.20^{* *}$ & .02 & -.17 & .02 & & & $-.15^{* *}$ & .03 & -.14 & .01 & & \\
\hline Psychological Withdrawal & & & & & $.44^{* *}$ & .79 & & & & & $44^{* *}$ & .79 \\
\hline Years of Service & -.00 & .00 & -.01 & .00 & & & $.01^{*}$ & .00 & .06 & .00 & & \\
\hline Gender & -.01 & .04 & -.00 & .00 & & & .08 & .05 & .03 & .00 & & \\
\hline Education & -.03 & .01 & -.03 & .00 & & & -.03 & .01 & -.03 & .00 & & \\
\hline P-Org & $-.62^{* *}$ & .02 & -.44 & .16 & & & $-.54 * *$ & .03 & -.40 & .13 & & \\
\hline $\mathrm{P}-\mathrm{OCc}$ & $-.46^{* *}$ & .02 & -.34 & .10 & & & $-.48 * *$ & .02 & -.38 & .11 & & \\
\hline Affective Conmitment & & & & & $.52^{* *}$ & 1.08 & & & & & $.53^{* *}$ & 1.13 \\
\hline Years of Service & .00 & .00 & .01 & .00 & & & .00 & .00 & .00 & .00 & & \\
\hline Gender & .01 & .03 & .00 & .00 & & & -.06 & .04 & -.03 & .00 & & \\
\hline Education & -.00 & .01 & -.01 & .00 & & & -.01 & .01 & -.01 & .00 & & \\
\hline P-Org & $.66^{* *}$ & .02 & .62 & .31 & & & $.64^{* *}$ & .02 & .63 & .32 & & \\
\hline $\mathrm{P}-\mathrm{Occ}$ & $.18 * *$ & .01 & .18 & .03 & & & $.17^{* *}$ & .02 & .18 & .03 & & \\
\hline Normative Commitment & & & & & $.32^{* *}$ & .47 & & & & & $.29 * *$ & .37 \\
\hline Years of Service & $-.01^{* *}$ & .00 & -.06 & .00 & & & $-.01^{* *}$ & .00 & -.08 & .00 & & \\
\hline Gender & .11 & .04 & $.05^{*}$ & .00 & & & -.01 & .05 & -.01 & .00 & & \\
\hline Education & -.02 & .01 & -.02 & .00 & & & -.01 & .01 & -.02 & .00 & & \\
\hline P-Org & $.55^{* *}$ & .02 & .47 & .18 & & & $.48^{* *}$ & .02 & .43 & .15 & & \\
\hline $\mathrm{P}-\mathrm{Occ}$ & $.19^{* *}$ & .02 & .17 & .02 & & & $.20^{* *}$ & .02 & .19 & .03 & & \\
\hline
\end{tabular}




\section{Moderators of Person-Environment Fit}

The conceptual framework depicted in Figure 1 proposed that the association between person-occupation and person-organization fit would be moderated by perceived organizational support, continuance commitment, and employability (civilian equivalence and perceived job alternatives). Specifically it was proposed that perceived organizational support would moderate the association of person-environment fit with both organizational commitment and organizational withdrawal, whereas the other three moderators were expected to moderate the association of fit with organizational withdrawal.

Following the procedures for testing moderating variables discussed in Frazier, Tix, and Baron (2004), a series of hierarchical linear regression analyses were conducted to test the conceptual framework. To reduce potential multicollinearity between the interaction terms and their component variables, which may skew the results of the regression analyses centering transformations were executed for each continuous predictor and moderator (Cohen, Cohen, West, \& Aiken, 2003). Dichotomous variables were coded as dummy variables, which was used instead of effects or contrast coding because it was more important to the current research to evaluate which groups were related (i.e., those with civilian equivalence versus those without civilian equivalence) than in evaluating the conditional effects of these variables (Frazier et al., 2004). The control variables -- gender, years of service, and education -- were entered in the first step, the centered predictors and moderators were entered in the second step, and finally the interaction terms (predictor $\mathrm{x}$ moderator) were entered in the third step. All significant interactions were interpreted by graphing the interactions with the assistance of the online 
interaction utilities provided at http://www.quantpsy.org by Preacher, Curran, and Bauer (2006).

\section{Moderator Tests for Affective and Normative Commitment}

The first series of regressions tested $\mathrm{H} 5 \mathrm{a}$ to evaluate the moderating effect of perceived organizational support on affective and normative commitment for each group. These results are summarized in Tables 8 and 9. Contrary to predictions, perceived organizational support did not moderate the effects of person-organization or personoccupation fit on either component of organizational commitment. However, there were moderate conditional effects of perceived organizational support for both noncommissioned members, $B=.29 S E .02, p<.0001$ and for officers, $B=.20, S E=.02$, $p<.0001$. The combined effects of both domains of fit and perceived organizational support explained $57 \%$ of the variance in affective commitment over and above the influence of years of service for noncommissioned members, $f^{2}=1.23$. The results are similar for normative commitment in that perceived organizational support made a moderate contribution to the overall variance for both noncommissioned members, $B=$ $.37, S E=.02, p<.0001$ and officers $B=.37, S E=.03 p<.0001$. An interesting difference for normative commitment is that years of service had a negative effect on turnover intention for both groups, but this effect was only seen after person-environment fit and perceived organizational support were added to the regression equation suggesting the existence of a suppressor relationship between normative commitment and years of service (Cohen et al., 2003). 


\section{Table 8}

\section{Hierarchical Regression Analysis for Moderating Effects of Perceived Organizational Support on Affective Commitment}

\begin{tabular}{|c|c|c|c|c|c|c|c|c|c|c|c|c|c|c|}
\hline \multirow[b]{3}{*}{ Step and Variable } & \multicolumn{7}{|c|}{ Noncommissioned Members } & \multicolumn{7}{|c|}{ Officers } \\
\hline & \multicolumn{6}{|c|}{$99 \% \mathrm{Cl}$ for $\mathrm{B}$} & \multirow[b]{2}{*}{$f^{2}$} & \multicolumn{7}{|c|}{$99 \% \mathrm{CI}$ for $B$} \\
\hline & $B$ & $S E B$ & $L L$ & $U L$ & $R^{2}$ & $\Delta R^{2}$ & & $B$ & $S E B$ & $L L$ & $U L$ & $R^{2}$ & $\Delta R^{2}$ & $f^{2}$ \\
\hline Step 1 & & & & & $.02 * *$ & & .02 & & & & & $.01^{*}$ & & .01 \\
\hline Years of Service & $.01^{* *}$ & .00 & .01 & .02 & & & & .01 & .00 & .00 & .01 & & & \\
\hline Gender & $.12^{*}$ & .04 & .01 & .23 & & & & -.12 & .05 & -.25 & .02 & & & \\
\hline Education & -.02 & .01 & -.05 & .02 & & & & .01 & .01 & -.02 & .05 & & & \\
\hline Step 2 & & & & & $.57^{* *}$ & $.55^{* *}$ & 1.23 & & & & & $.57^{* *}$ & $.57^{* *}$ & 1.30 \\
\hline Years of Service & .00 & .00 & -.00 & .00 & & & & .00 & .00 & -.00 & .00 & & & \\
\hline Gender & -.01 & .03 & -.08 & .07 & & & & -.04 & .03 & -.13 & .05 & & & \\
\hline Education & -.00 & .01 & -.03 & .02 & & & & -.00 & .01 & -.02 & .02 & & & \\
\hline P-Org & $.52 * *$ & .02 & .48 & .57 & & & & $.52^{* *}$ & .02 & .47 & .57 & & & \\
\hline $\mathrm{P}-\mathrm{Occ}$ & $.13^{* *}$ & .01 & .09 & .16 & & & & $.12 * *$ & .02 & .08 & .16 & & & \\
\hline POS & $.28^{* *}$ & .02 & .24 & .32 & & & & $.27^{* *}$ & .02 & .22 & .32 & & & \\
\hline Step 3 & & & & & .57 & .00 & .00 & & & & & .57 & .00 & .00 \\
\hline Years of Service & .00 & .00 & -.00 & .00 & & & & $.00^{*}$ & .00 & -.00 & .00 & & & \\
\hline Gender & -.01 & .03 & -.08 & .07 & & & & -.04 & .03 & -.13 & .05 & & & \\
\hline Education & -.00 & .00 & -.03 & .02 & & & & -.00 & .00 & -.02 & .02 & & & \\
\hline P-Org & $.52^{* *}$ & .02 & .48 & .57 & & & & $.52^{*}$ & .02 & .47 & .57 & & & \\
\hline $\mathrm{P}-\mathrm{Occ}$ & $.13^{* *}$ & .01 & .09 & .16 & & & & $.12^{*}$ & .02 & .08 & .16 & & & \\
\hline POS & $.28^{* *}$ & .02 & .24 & .32 & & & & $.27^{*}$ & .02 & .22 & .32 & & & \\
\hline P-Org Fit X POS & -.00 & .01 & -.04 & .03 & & & & -.01 & .02 & -.05 & .03 & & & \\
\hline P-Occ Fit X POS & .00 & .02 & -.03 & .04 & & & & .00 & .02 & -.04 & .05 & & & \\
\hline
\end{tabular}

Notes: $N=2,921$ noncommissioned members, 1,993 Officers POS = Perceived Organizational Support, P-Org =Person-Organization Fit, P-Occ Fit - Person = Occupation fit $f^{2}$ shown in steps 2 and 3 are the effect sizes for $\Delta R^{2} * p<.0 I,{ }^{* *} p<.0001$. 


\section{Table 9}

\section{Hierarchical Regression Analysis for Moderating Effects of Perceived Organizational Support on Normative Commitment}

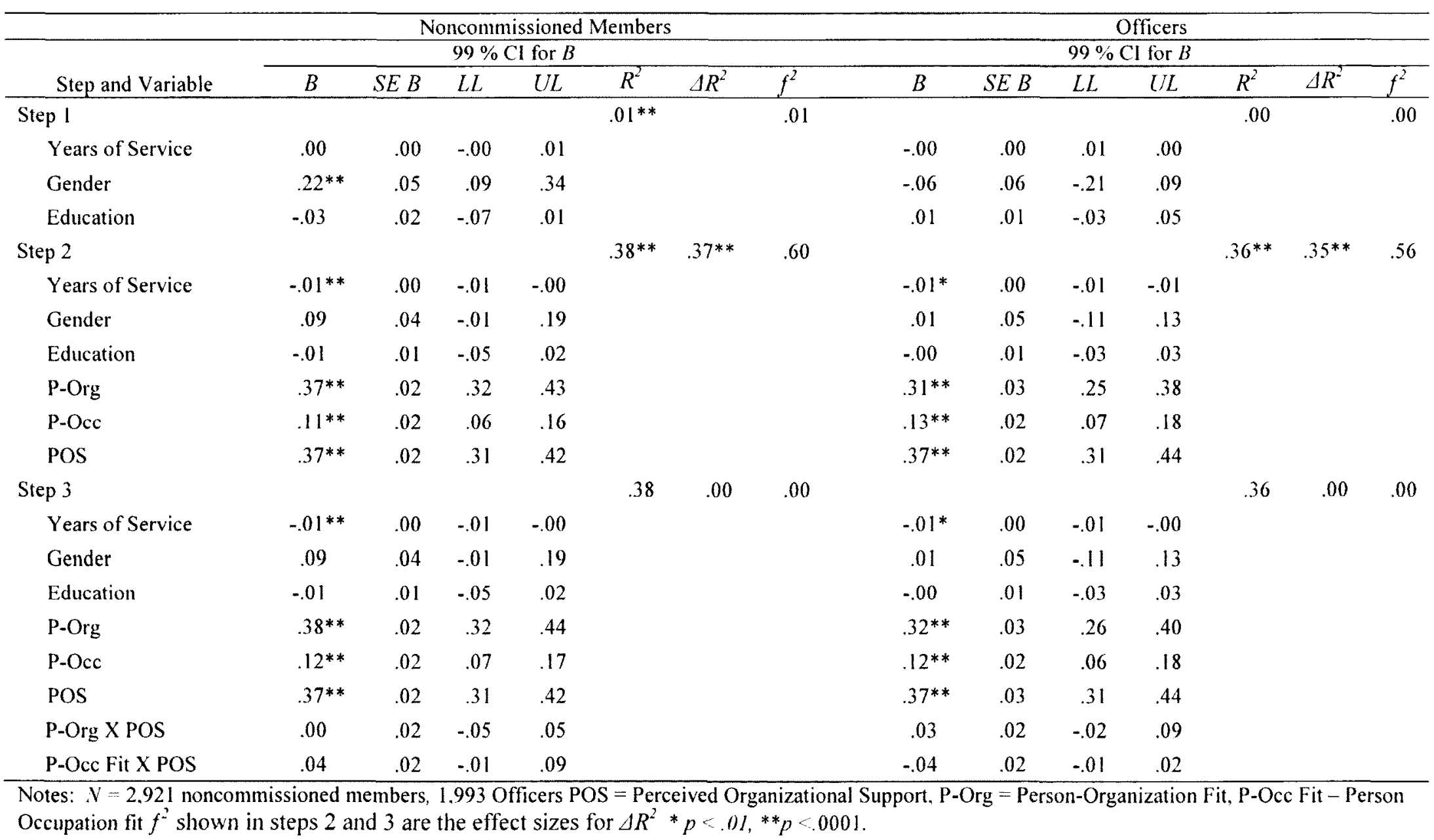




\section{Moderator Tests for Organizational Withdrawal}

The next series of hierarchical multiple regressions tested the remaining hypotheses $\mathrm{H} 5 \mathrm{~b}, \mathrm{H} 6, \mathrm{H} 7$, and $\mathrm{H} 8$; the moderator effects of perceived organizational support, continuance commitment, civilian equivalence, and perceived job alternatives on turnover intention and psychological withdrawal for each group. Following the recommendations of Frazier et al., (2004) all of the moderators were tested in the same regression for each outcome to avoid Type 1 errors that could result from analyzing each moderator separately.

Moderator Effects of Perceived Organizational Support. As evidenced in Tables 10 and 11 , similar to the results for affective and normative commitment, perceived organizational support did not moderate the association of person-occupation or person organization fit with organizational withdrawal. Therefore, hypothesis $\mathrm{H} 5 \mathrm{~b}$ was not supported for either noncommissioned members or officers. However, just as was seen for the commitment outcomes, there were significant conditional effects of perceived organizational support for both noncommissioned members, $B=-.16, \mathrm{SE}=.03$, $\mathrm{p}<.0001$ and for officers, $B=-.14, \mathrm{SE}=.03, \mathrm{p}<.0001$ on turnover intention. The conditional effects were even stronger for psychological withdrawal for noncommissioned members $B=-.44, S E=.03, p<.0001$, and $B=-.42, S E=.03, p<$ .0001 for officers.

Moderator Effects of Continuance Commitment. The results of the hierarchical multiple regression analyses testing the moderator effects of continuance commitment on organizational withdrawal (H6) are summarized in Tables 10 to 12. Hypothesis H6, which predicted that continuance commitment would mitigate the effect of poor fit on 
organizational withdrawal, was only partially supported for both noncommissioned members and officers, in that moderator effects of continuance commitment were only evident for turnover intention. However the combined conditional effects of personorganization fit, person-occupation fit, perceived organization support, and continuance commitment were quite substantial explaining $52 \%$ of the variance in psychological withdrawal for officers and $51 \%$ of the variance in psychological withdrawal for noncommissioned members.

Moderator effects of continuance commitment were detected for the effect of person-organization fit on turnover intention for noncommissioned members, $B=-06$, $S E=.02, p=.003$, however the effect was very small $s r^{2}=.002$. In fact, years of service made a greater unique contribution to the variance in turnover intention, $s r^{2}=.05$. The results indicated that continuance commitment buffers the effects of low perceptions of organizational fit for noncommissioned members on turnover intention. Individuals who reported low person-organization fit also reported higher continuance commitment and lower turnover intention. The interaction effects are presented graphically in Figure 2. 
Table 10

Analysis of Moderators on Turnover Intentions for Noncommissioned Members

\begin{tabular}{|c|c|c|c|c|c|c|c|}
\hline \multirow[b]{2}{*}{ Step and Variable } & \multicolumn{6}{|c|}{$99 \%$ CI for $B$} & \multirow[b]{2}{*}{$f^{2}$} \\
\hline & $B$ & $S E B$ & $L L$ & $U L$ & $R^{2}$ & $\Delta R^{2}$ & \\
\hline Step I & & & & & $.05 * *$ & & .05 \\
\hline Years of Service & $.03 * *$ & .00 & .02 & .03 & & & \\
\hline Gender & -.04 & .05 & -.17 & .09 & & & \\
\hline Education & -.03 & .02 & -.07 & .02 & & & \\
\hline Step 2 & & & & & $.23 * *$ & .18 & .23 \\
\hline Years of Service & $.03 * *$ & .00 & .03 & .04 & & & \\
\hline Gender & .10 & .05 & -.02 & .22 & & & \\
\hline Education & -.04 & .02 & -.08 & -.00 & & & \\
\hline POrg & $-.21 * *$ & .03 & -.28 & -.15 & & & \\
\hline POcc & $-.18 * *$ & .02 & -.24 & -.12 & & & \\
\hline POS & $-.16 * *$ & .03 & -.23 & -.10 & & & \\
\hline PAlt & -.02 & .02 & -.07 & .03 & & & \\
\hline $\mathrm{CC}$ & $-.26 * *$ & .02 & -.31 & -.22 & & & \\
\hline Civ Equiv & -.05 & .06 & -.20 & .09 & & & \\
\hline Step 3 & & & & & $.24 * *$ & .00 & .01 \\
\hline Years of Service & $.03^{* *}$ & .00 & .03 & .04 & & & \\
\hline Gender & .10 & .05 & -.02 & .22 & & & \\
\hline Education & $-.04 *$ & .02 & -.08 & -.00 & & & \\
\hline POrg & $-.20^{* *}$ & .03 & -.28 & -.13 & & & \\
\hline POcc & $-.18 * *$ & .03 & -.24 & -.12 & & & \\
\hline POS & $-.16 * *$ & .03 & -.23 & -.10 & & & \\
\hline PAlt & -.02 & .02 & -.07 & .03 & & & \\
\hline $\mathrm{CC}$ & $-.26 * *$ & .02 & -.30 & -.21 & & & \\
\hline Civ Equiv & -.06 & .06 & -.21 & .09 & & & \\
\hline POrg X POS & .00 & .02 & -.05 & .06 & & & \\
\hline POrg X PAlt & -.02 & .02 & -.08 & .04 & & & \\
\hline POrg X CC & $.06^{*}$ & .02 & .01 & .11 & & & \\
\hline POrg X Civ Equiv & -.02 & .07 & -.19 & .16 & & & \\
\hline POcc X POS & .00 & .02 & -.05 & .06 & & & \\
\hline POcc Fit X PAlt & .02 & .02 & -.04 & .07 & & & \\
\hline POcc Fit X CC & .02 & .02 & -.03 & .07 & & & \\
\hline POcc Fit X Civ Equiv & -.03 & .05 & -.15 & .10 & & & \\
\hline
\end{tabular}

Notes: $N=2914$ POS = Perceived Organizational Support, POrg = Person-organization fit, $\mathrm{POcc}=$ PersonOccupation Fit, $\mathrm{PAlt}=$ Perceived Job Alternatives, $\mathrm{CC}=$ Continuance Commitment, Civ Equiv $=$ Civilian Equivalence $f^{2}$ shown in steps 2 and 3 are the effect sizes for $\Delta R^{2}$.

${ }^{*} p=.003,{ }^{* *} p<.0001$. 
Table 11

\section{Analysis of Moderators on Psychological Withdrawal for Noncommissioned Members}

\begin{tabular}{|c|c|c|c|c|c|c|c|}
\hline \multirow[b]{2}{*}{ Step and Variable } & \multicolumn{6}{|c|}{$99 \%$ CI for $B$} & \multirow[b]{2}{*}{$f^{2}$} \\
\hline & $B$ & $S E B$ & $L L$ & $U L$ & $R^{2}$ & $\Delta R^{2}$ & \\
\hline Step 1 & & & & & $.02^{* *}$ & & .02 \\
\hline Years of Service & $-.02 * *$ & .00 & -.03 & -.01 & & & \\
\hline Gender & $-.20^{*}$ & .06 & -.33 & -.03 & & & \\
\hline Education & -.01 & .02 & -.06 & .04 & & & \\
\hline Step 2 & & & & & $.51^{* *}$ & .50 & 1.02 \\
\hline Years of Service & .00 & .00 & -.00 & .01 & & & \\
\hline Gender & -.01 & .00 & -.11 & .10 & & & \\
\hline Education & -.03 & .01 & -.07 & .00 & & & \\
\hline P-Org & $-.40 * *$ & .02 & -.46 & -.35 & & & \\
\hline $\mathrm{P}-\mathrm{Occ}$ & $-.37^{* *}$ & .02 & -.42 & -.32 & & & \\
\hline POS & $-.44 * *$ & .02 & -.50 & -.38 & & & \\
\hline PAlt & -.03 & .02 & -.08 & .01 & & & \\
\hline $\mathrm{CC}$ & $.10^{* *}$ & .02 & .06 & .14 & & & \\
\hline Civ Equiv & -.10 & .05 & -.22 & .04 & & & \\
\hline Step 3 & & & & & $.52^{* *}$ & .00 & .00 \\
\hline Years of Service & .00 & .00 & -.00 & .00 & & & \\
\hline Gender & -.01 & .04 & -.12 & .10 & & & \\
\hline Education & -.03 & .01 & -.06 & .00 & & & \\
\hline P-Org & $-.41 * *$ & .03 & -.48 & -.35 & & & \\
\hline P-Occ & $-.36^{* *}$ & .02 & -.41 & -.30 & & & \\
\hline POS & $-.44^{* *}$ & .02 & -.49 & -.38 & & & \\
\hline PAlt & -.03 & .02 & -.07 & .01 & & & \\
\hline $\mathrm{CC}$ & $.10^{* *}$ & .02 & .06 & .15 & & & \\
\hline Civ Equiv & -.11 & .05 & -.24 & .02 & & & \\
\hline P-Org Fit X POS & .02 & .02 & -.04 & .06 & & & \\
\hline P-Org Fit X PAlt & .01 & .02 & -.04 & .06 & & & \\
\hline P-Org Fit X CC & .02 & .02 & -.03 & .06 & & & \\
\hline P-Org Fit X Civ Equiv & .15 & .06 & -.01 & .30 & & & \\
\hline P-Occ X POS & .01 & .02 & -.04 & .06 & & & \\
\hline P-Occ Fit X PAlt & -.00 & .02 & -.05 & .05 & & & \\
\hline P-Occ Fit X CC & -.01 & .02 & -.05 & .04 & & & \\
\hline P-Occ Fit X Civ EQuiv & -.11 & .04 & -.22 & .00 & & & \\
\hline
\end{tabular}

Notes: $N=2,914$ POS = Perceived Organizational Support, P-Org = Person-organization fit, $\mathrm{P}-\mathrm{Occ}=$ Person-Occupation Fit, PAlt $=$ Perceived Job Alternatives, $\mathrm{CC}=$ Continuance Commitment, Civ Equiv = Civilian Equivalence $f^{2}$ shown in steps 2 and 3 are the effect sizes for $\Delta R^{2}{ }^{*} p<.01,{ }^{* *} p<.0001$ 


\section{Figure 2}

\section{Moderator Effects of Continuance Commitment for Noncommissioned Members}

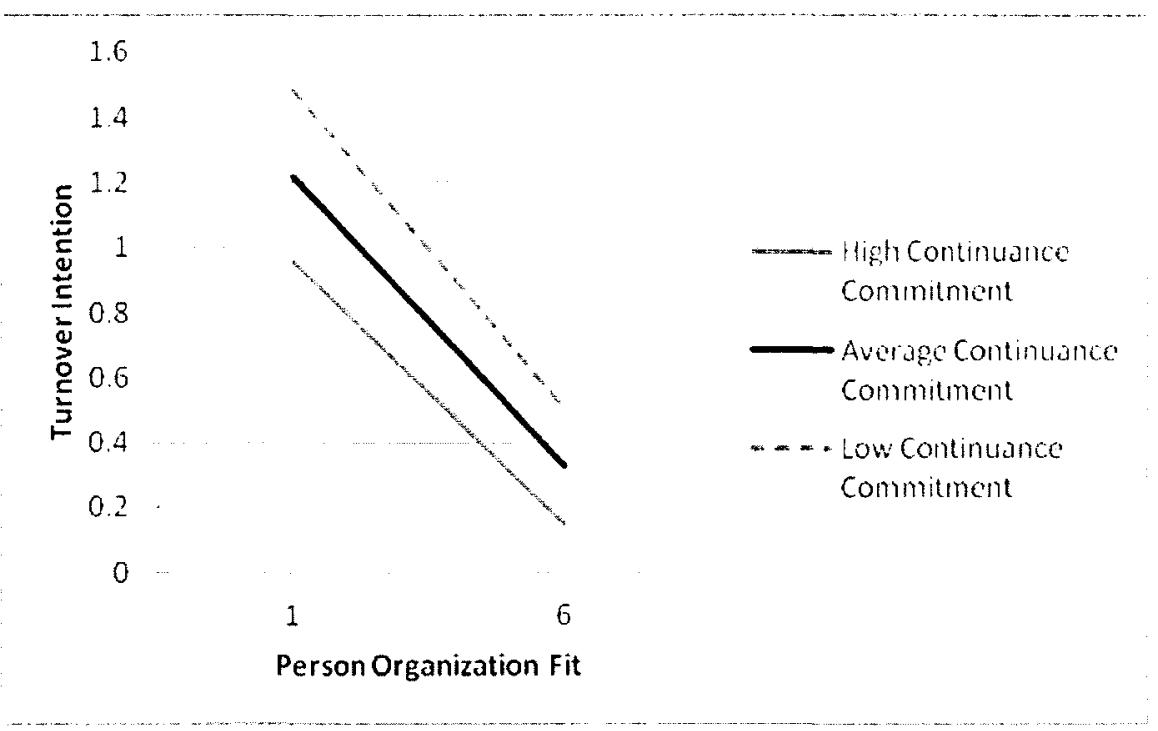

Figure 2. Interaction graph depicting the moderating effect of continuance commitment on the association between person-organization fit and turnover intention for noncommissioned members

The moderator effects of continuance commitment for organizational withdrawal for the officer group are summarized in Tables 12 and 13. Similar to the results for noncommissioned members, H6 was only partially supported in that moderator effects were only evident for turnover intention. Interestingly, in contrast to the results for noncommissioned members, continuance commitment moderated the effect of personoccupation fit on turnover intention, $B=.07, S E=.02, p=.005$. Officers who reported the lowest levels of person-occupation fit also reported the highest levels of continuance commitment, and the lowest levels of turnover intention. However, once again the effect was quite small $s r^{2}=.003$, contributing just over $.3 \%$ to the variance in turnover intention. Years of service once again was a stronger predictor, $s r^{2}=.05$, contributing $5 \%$ to the overall variance in turnover intention. 
Table 12

Analysis of Moderators on Turnover Intention for Officers

\begin{tabular}{|c|c|c|c|c|c|c|c|}
\hline \multirow[b]{2}{*}{ Step and Variable } & \multicolumn{6}{|c|}{$99 \% \mathrm{CI}$ for $B$} & \multirow[b]{2}{*}{$f^{2}$} \\
\hline & $B$ & $S E B$ & $L L$ & $U L$ & $R^{2}$ & $\Delta R^{2}$ & \\
\hline Step 1 & & & & & $.06 * *$ & & .06 \\
\hline Years of Service & $.03^{* *}$ & .00 & .02 & .04 & & & \\
\hline Gender & .07 & .06 & -.10 & .22 & & & \\
\hline Education & -.01 & .02 & -.05 & .03 & & & \\
\hline Step 2 & & & & & $.22 * *$ & .16 & .21 \\
\hline Years of Service & $.03^{* *}$ & .00 & .02 & .04 & & & \\
\hline Gender & .05 & .06 & -.09 & .19 & & & \\
\hline Education & -.02 & .01 & -.05 & .02 & & & \\
\hline P-Org & $-.16^{*}$ & .03 & -.24 & -.08 & & & \\
\hline P-Occ & $-.16^{*}$ & .03 & -.24 & -.10 & & & \\
\hline POS & $-.14 *$ & .03 & -.22 & -.06 & & & \\
\hline PAlt & -.06 & .02 & -.12 & .00 & & & \\
\hline $\mathrm{CC}$ & $-.29 * *$ & .02 & -.34 & -.23 & & & \\
\hline Civ Equiv & -.01 & .05 & -.13 & .11 & & & \\
\hline Step 3 & & & & & $.23^{*}$ & .01 & .01 \\
\hline Years of Service & $.03 * *$ & .00 & .02 & .03 & & & \\
\hline Gender & .05 & .05 & -.09 & .19 & & & \\
\hline Education & -.02 & .01 & -.06 & .02 & & & \\
\hline P-Org & $-.15^{*}$ & .05 & -.28 & -.02 & & & \\
\hline P-Occ & -.12 & .05 & -.24 & .00 & & & \\
\hline POS & $-.14 * *$ & .03 & -.22 & -.06 & & & \\
\hline PAlt & $-.07 *$ & .02 & -.13 & -.01 & & & \\
\hline $\mathrm{CC}$ & $-.28 * *$ & .02 & -.33 & -.26 & & & \\
\hline Civilian Equivalence & -.01 & .05 & -.13 & .11 & & & \\
\hline P-Org X POS & .04 & .03 & -.03 & .10 & & & \\
\hline P-Org X PAlt & -.03 & .03 & -.11 & .06 & & & \\
\hline P-Org X CC & .04 & .02 & -.03 & .17 & & & \\
\hline P-Org X Civ Equiv & .02 & .06 & -.13 & .17 & & & \\
\hline P-Occ X POS & .02 & .03 & -.05 & .09 & & & \\
\hline P-Occ Fit X PAlt & -.00 & .02 & -.07 & .07 & & & \\
\hline P-Occ Fit X CC & $.07 *$ & .02 & .01 & .12 & & & \\
\hline P-Occ Fit X Civ EQuiv & -.06 & .05 & -.20 & .08 & & & \\
\hline
\end{tabular}

Notes: $N=1,192$ POS = Perceived Organizational Support, P-Org = Person-organization fit, P-Occ = Person-Occupation Fit, PAlt $=$ Perceived Job Alternatives, $\mathrm{CC}=$ Continuance Commitment, Civ Equiv $=$ Civilian Equivalence $f^{2}$ shown in steps 2 and 3 are the effect sizes for $\Delta R^{2}$

${ }^{*} p<.01,{ }^{* *} p<.0001$. 
Table 13

\section{Analysis of Moderators on Psychological Withdrawal for Officers}

\begin{tabular}{|c|c|c|c|c|c|c|c|}
\hline \multirow[b]{2}{*}{ Step and Variable } & \multicolumn{6}{|c|}{$99 \%$ CI for $B$} & \multirow[b]{2}{*}{$f^{2}$} \\
\hline & $B$ & $S E B$ & $L L$ & $U L$ & $R^{2}$ & $\Delta R^{\prime}$ & \\
\hline \multicolumn{8}{|l|}{ Step 1} \\
\hline Years of Service & .00 & .00 & -.01 & .01 & $.01^{* *}$ & & .01 \\
\hline Gender & .16 & .07 & -.02 & .34 & & & \\
\hline Education & $-.07^{* *}$ & .02 & -.11 & -.02 & & & \\
\hline Step 2 & & & & & $.51^{* *}$ & .50 & 1.01 \\
\hline Years of Service & .01 & .00 & .00 & .01 & & & \\
\hline Gender & .06 & .05 & -.07 & .18 & & & \\
\hline Education & -.03 & .01 & -.06 & .00 & & & \\
\hline P-Org & $-.35 * *$ & .03 & -.42 & -.28 & & & \\
\hline P-Occ & $-.38^{* *}$ & .02 & -.44 & -.32 & & & \\
\hline POS & $-.42 * *$ & .03 & -.49 & -.35 & & & \\
\hline PAlt & -.01 & .02 & -.06 & .05 & & & \\
\hline $\mathrm{CC}$ & $.11^{* *}$ & .02 & .06 & .16 & & & \\
\hline Civ Equiv & .01 & .04 & -.10 & .12 & & & \\
\hline Step 3 & & & & & $.51^{* *}$ & .00 & .00 \\
\hline Years of Service & .01 & .00 & .00 & .01 & & & \\
\hline Gender & .06 & .05 & -.07 & .19 & & & \\
\hline Education & -.03 & .01 & -.06 & .00 & & & \\
\hline P-Org & $-.33^{* *}$ & .04 & -.45 & -.22 & & & \\
\hline P-Occ & $-.37^{* *}$ & .04 & -.47 & -.26 & & & \\
\hline POS & $-.41 * *$ & .03 & -.48 & -.34 & & & \\
\hline PAlt & .00 & .02 & -.06 & -.06 & & & \\
\hline $\mathrm{CC}$ & $.11^{* *}$ & .02 & .07 & .16 & & & \\
\hline Civ Equiv & .01 & .04 & -.10 & .12 & & & \\
\hline P-Org Fit X POS & .01 & .02 & -.05 & .07 & & & \\
\hline P-Org Fit X PAlt & $-.08 *$ & .03 & -.15 & -.01 & & & \\
\hline P-Org Fit X CC & -.01 & .02 & -.07 & .04 & & & \\
\hline P-Org Fit X Civ Equiv & -.04 & .05 & -.17 & .09 & & & \\
\hline P-Occ X POS & .02 & .02 & -.05 & .08 & & & \\
\hline P-Occ Fit X PAlt & $.09^{* *}$ & .02 & .03 & .15 & & & \\
\hline P-Occ Fit X CC & .03 & .02 & -.02 & .09 & & & \\
\hline P-Occ Fit X Civ EQuiv & -.00 & .05 & -.12 & .12 & & & \\
\hline
\end{tabular}

Notes: $N=1,192$ POS = Perceived Organizational Support, P-Org = Person-organization fit, $\mathrm{P}-\mathrm{Occ}=$ Person-Occupation Fit, PAlt $=$ Perceived Job Alternatives, $\mathrm{CC}=$ Continuance Commitment, Civ Equiv = Civilian Equivalence $f^{2}$ shown in steps 2 and 3 are the effect sizes for $\Delta R^{2}{ }^{*} p<.01,{ }^{* *} p<.0001$ 


\section{Figure 3}

\section{Moderator Effects of Continuance Commitment for Officers}

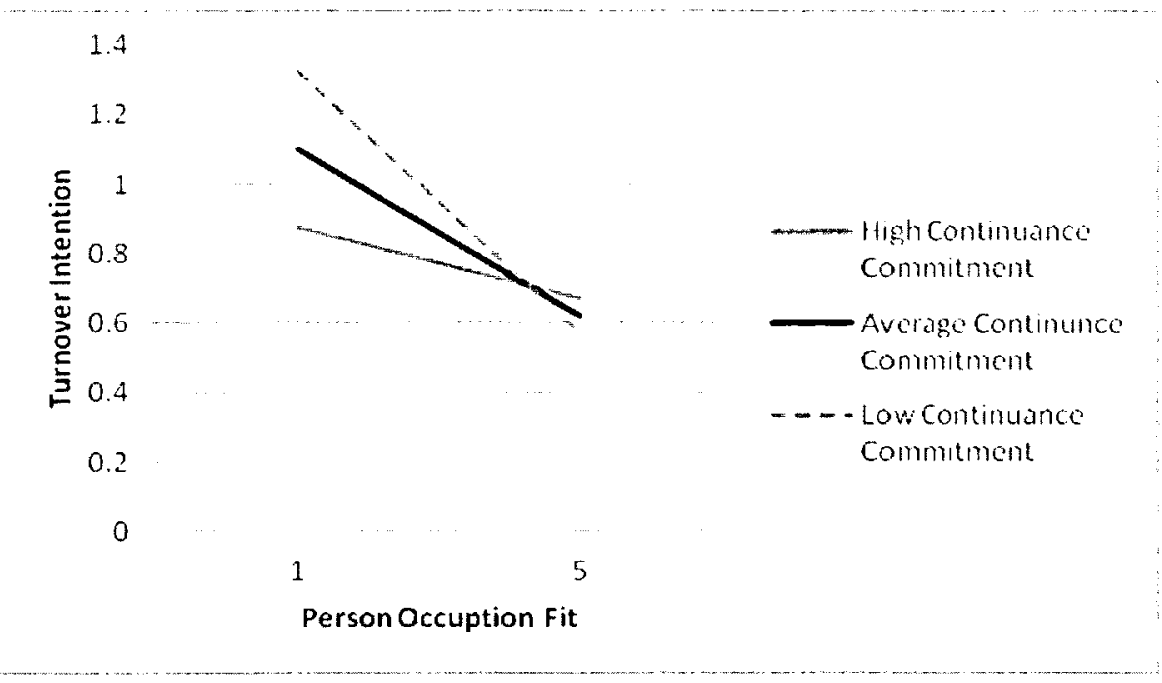

Figure 3. Interaction graph depicting the moderating effect of continuance commitment on the association between person-occupation fit and turnover intention for officers

Moderator Effects of Civilian Equivalence. Hypothesis $\mathrm{H} 7$ predicted that civilian equivalence would mitigate the effect of poor person-environment fit on organizational withdrawal. In other words, it was expected that being in an occupation that had a direct civilian equivalent would be associated with a decrease in the likelihood of an individual experiencing psychological withdrawal and potentially increase turnover intention for those individuals who experience poor fit. Contrary to predictions in hypothesis $\mathrm{H} 7$, civilian equivalence did not moderate the effects of fit for either group, indeed it did not contribute significantly to the variance for either of the outcomes. This is not entirely surprising given that there were only two significant correlations for civilian equivalence in relation to the outcomes and predictors. The first significant correlation between civilian equivalence and person-occupation fit (Table 6), for noncommissioned members suggested that fit to their occupation was partially influenced by how related it 
was to a civilian occupation such that for members in an occupation with no direct equivalence, perceptions of person-occupation fit were lower. The second significant association was a positive correlation with continuance commitment (Table 6) indicating that officers in an occupation with a civilian equivalence were more likely to have higher continuance commitment. However, the direct equivalence of a member's occupation to the civilian workplace was not associated with any of the other workplace attitudes in the current study.

Moderator Effects of Perceived Alternatives. Hypotheses H8, which predicted that perceived alternatives would moderate the influence of person-environment fit on organizational withdrawal, was not supported for noncommissioned members; perceived job alternatives was not a significant predictor nor a significant moderator of the association of person-environment fit with organizational withdrawal (Tables 10 and 12).

However, in the case of the officer group there were two significant interactions supporting hypothesis H8. Perceived job alternatives significantly moderated the effect of person-organization, $B=-.08, S E=.03, p=.004, s r^{2}=.002$ and person-occupation fit, $B$ $=.09, \mathrm{SE}, 024 p<.0001, s r^{2}=.003$. Intriguingly, the effects are in opposite directions, indicating that for person-organization fit, if the officers believed that they had more job alternatives it had a synergistic effect and the negative association between personorganization fit and psychological withdrawal was lower, resulting in less psychological withdrawal. On the other hand, for person-occupation fit, perceived job alternatives had an antagonistic effect and increased the negative association of person-occupation fit with withdrawal, such that individuals who perceived low person-occupation fit, but believed 
they had an increased number of job alternatives, experienced more psychological withdrawal. The interaction effects are graphed in Figures 4 and 5.

\section{Figure 4}

\section{Moderator Effects of Perceived Job Alternatives for Officers}

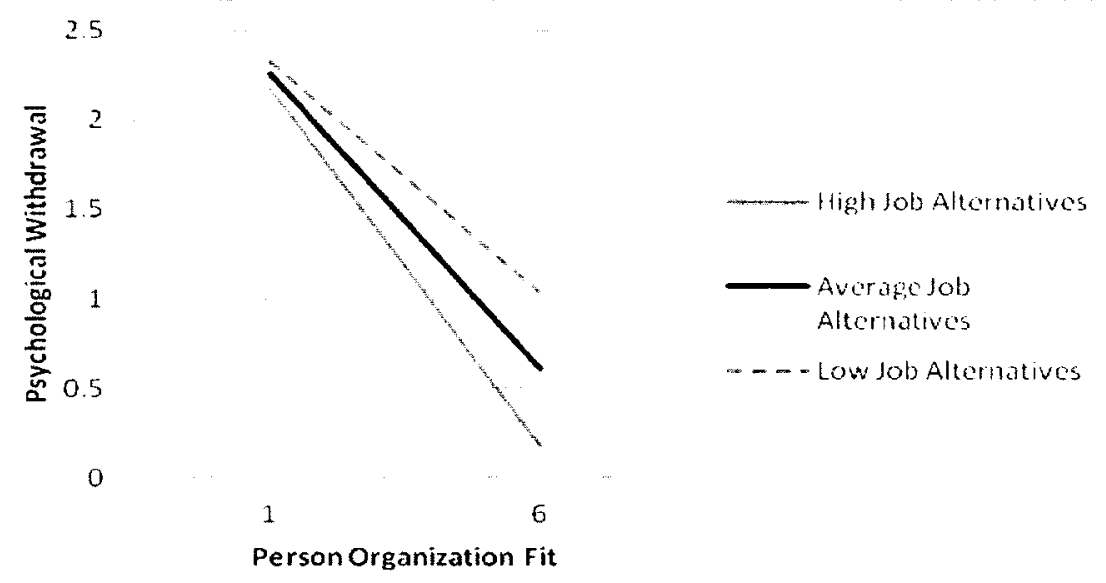

Figure 4. Interaction graph depicting the moderating effect of perceived job alternatives on the association between person-organization fit and psychological withdrawal for officers

Figure 5

Moderator Effects of Perceived Job Alternatives for Officers

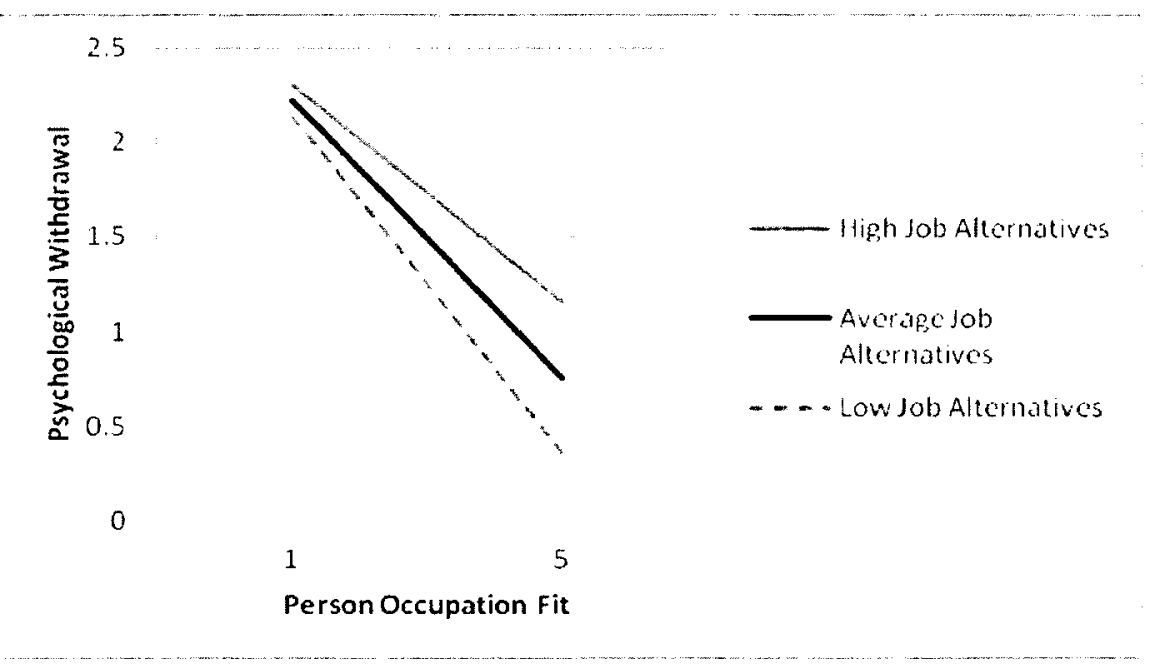

Figure 5. Interaction graph depicting the moderating effect of perceived job alternatives on the association between person-occupation fit and psychological withdrawal for officers 


\section{Cross Validation Results}

To cross validate the findings from the current research, the conceptual framework depicted in Figure 1 was retested using a sample of $20 \%$ of the participants for both groups. Summary tables and figures related to these analyses are contained in Appendices $\mathrm{H}$ to J. Comparison of both sets of results provided good evidence of the robustness of the original results and the generalizability of the current set of results to a similar CF population. The confidence intervals of the $80 \%$ data set were used as the benchmark to determine whether the findings were replicated. Correlations, means, and standard deviations (Table14, Appendix $\mathrm{H}$ ) were very similar in terms of magnitude, direction, and significance levels, with only minor deviations occurring for the smaller $r(s)$. Comparison of multiple regression analyses (Tables 15 to 22, Appendix I) showed the same patterns. However, as can be expected with smaller sample sizes $R^{2} s$ and $B(\mathrm{~s})$ values became less robust and were often larger than in $80 \%$ set (i.e. overestimated Tabachnick and Fidell, 2007). This was evidenced by the fact that as the effect sizes decreased, standard errors increased. Nonetheless, for the most part the $B s$ for the smaller sample were within the confidence interval of the larger data set.

Interactions from the moderator analyses were replicated in two out of the four cases. Despite the smaller sample size, for noncommissioned members, continuance commitment remained a significant moderator of the effect of low person-organization fit on turnover intentions (Figure 6, Appendix J), $B=.12, S E .=.04, p=.001$. Similarly, for the officer group the moderator effects for perceived job alternatives on the effects of person-occupation fit on psychological withdrawal were also replicated (Figure 7, Appendix J), $B=.17, S E=.05, p=.002$. 
The $20 \%$ data sets were limited by the fact that these groups did not have sufficient power to detect some of the smaller effects. The smaller officer group had 477 cases and a post hoc analysis using an online calculator, found at http:/www.danielsoper.com/statcalc3 (Cohen et al., 2003; Soper, 2012), observed power was calculated to be .06 , considering that the observed effects sizes for the moderators were .01 or less. Power analysis for the noncommissioned member group resulted in an observed power of .13, well below the recommended $80 \%$ (Cohen, 1991). However observed power for the smallest of the conditional and direct effects were well over .90 . In summary, the cross validation analyses, despite the power limitations, provided good evidence of the robustness of the current research.

\section{Discussion}

The overall purpose of the present research was to explore the associations between person-environment fit perceptions and organizational commitment and organization withdrawal attitudes in a sample of Canadian Forces Members. In addition, the study explored whether the effects of person-organization and person-occupation fit were increased by combining these domains or whether the effects of the two domains of fit were convergent. Finally, the current study evaluated the influence of four moderators of fit on the outcomes, namely perceived organizational support, continuance commitment, civilian equivalence, and perceived job alternatives.

Practitioners and researchers are converging on the conclusion that drawing clearer links between recruiting, selection, and attrition through the framework of personenvironment fit is critical to the development of more effective and efficient recruiting and selection processes because recruiting, selection, and retention policies that consider 
the influence of person-environment fit are likely to be more successful at attracting and selecting individuals into organizations who will not only stay but contribute effectively to organizational success (Barrick \& Zimmerman, 2009; Karren \& Graves, 1994;

Sekiguchi, 2007; Werbel, 2001). Hence, the driving force behind the present research was to gather empirical evidence to support incorporating improved measures of personenvironment fit into the Canadian Forces recruiting and selection processes.

Overall person-environment fit, consisting of person-organization and personoccupation fit, was positively associated with organizational commitment and negatively associated with organizational withdrawal, providing support for Schneider's attractionselection-attrition model (Schneider, 1987a; 1987b) which purports that better personenvironment fit leads to stronger organizational commitment and a lower likelihood that individuals would choose to withdraw. The results also indicated that the effects of the fit domains was additive, suggesting that both domains are important predictors of organizational commitment and organizational withdrawal, building on each other to influence the outcomes. Consistent with previous research, person-organization fit is most strongly associated with organizational commitment (Kristof-Brown \& Guay 2011), and somewhat contrary to previous research, person-organization fit was also a slightly stronger predictor of organizational withdrawal relative to person-occupation fit (KristofBrown \& Guay, 2011; Kristof-Brown et al., 2005; Scroggins, 2007; Wheeler et al., 2005; Verquer et al., 2003; Tak, 2011). The results varied however, depending on whether the participants were officers or noncommissioned members. 


\section{Domains of Fit}

One of the major criticisms of person-environment fit research is that, to date, most research has only focused on evaluating one domain at a time and on one outcome at a time (Edwards \& Billsberry, 2010; Kristof-Brown \& Guay, 2011; Scroggins, 2007, Wheeler et al., 2005). The current research evaluated person-organization and personoccupation fit. Person-occupation fit was an amalgam of person-job and person-vocation fit, but considering that the association of person-occupation fit with other study variables was very similar to results for person-job fit reported in previous research (Kristof-\& Guay, 2011; Lauver \& Kristof, 2001; Cable \& DeRue, 2002; Scroggins, 2007), it appears that the person-occupation fit variable in this study was a close approximation of personjob fit. On the other hand, the results for person-occupation fit were somewhat stronger than what previous research has found (Cable \& DeRue, 2002; Kristof-Brown \& Guay, 2011), suggesting that the person-occupation fit variable used in this research may be broader than traditional job fit measures. In the context of Canadian Forces members, it may be that fit to the occupation encompasses some aspects of person-organization fit given that approximately $64 \%$ of the occupations surveyed for this study are occupations specific to a military environment. Despite this possibility, the moderate correlation found between the two domains of fit and the pattern of results for the influence of the domains of fit on the outcomes provide good evidence that study participants distinguished between the two domains of fit.

Previous research (Cable \& DeRue, 2002; Cable \& Judge, 1996; Edwards, 2008; Kristof-Brown \& Guay, 2011; Kristof-Brown \& Jansen, 2007) has found that personorganization fit is most strongly associated with organization level outcomes such as 
organizational commitment, perceived organizational support, citizenship behaviours, and turnover. Person-job fit has generally been most strongly associated with job level outcomes such as job satisfaction, career success, job performance, and turnover intentions. Results of the current research support person-organization fit as a strong predictor of organizational commitment, perceived organizational support, and organizational withdrawal behaviours. However, results also found that personoccupation fit was strongly associated with these same workplace attitudes. Equally important, the study results indicated that the effects of fit were cumulative and therefore it was the combination of person-occupation and person-organization fit that resulted in the best outcomes and provide the most predictive power for organizational commitment and organizational withdrawal.

In that light, future research should be expanded to incorporate the four main domains of fit - person-organization, person-job, person-vocation, and person-group fit. Vogel and Feldman (2009) propose that person-vocation fit may be an important antecedent to person-organization and person-job fit, and that individuals may not be able to achieve person-job or person-organization fit until a certain threshold of personvocation fit is achieved. They suggest that if a person is struggling to learn or fit into their chosen occupation, it will be difficult to achieve or feel competent or comfortable in their assigned job (Vogel \& Feldman, 2009). Another avenue for further investigation of fit domains is person-group fit, which really refers to interpersonal fit. This domain of fit may not be as important for recruiting or selection however, it may have important implications for teamwork, leadership roles, increasing cooperation between work groups, satisfaction with supervisors, career success, and thereby may increase 
organizational effectiveness and employee retention (Jansen and Kristof-Brown, 2006;

Kristof-Brown et al., 2005; Werbel \& Johnston, 2001). In summary, understanding the full gamut of fit domains and how they interact will add to a better understanding of the workplace.

\section{Turnover Intention}

An interesting result found in the current research was that person-organization fit, rather than person-occupation (job) fit, was the stronger predictor of turnover intention. These result were somewhat inconsistent with previous findings (Kristof $\&$ Guay, 2011; Kristof-Brown et al., 2005; Scroggins, 2007; Wheeler, et al, 2005), but similar to results found by Lauver and Kristof-Brown (2001). Another interesting difference was that, contrary to Scroggins (2007) who found that the influence of personorganization fit did not explain additional variance in turnover intention over and above what was explained by person-job fit, the present results indicated that the effect of both domains was additive and it was the combined effects of each domain that explained the greatest amount of variance in turnover intention. Another important finding in this study was that although person-environment fit was a significant predictor of turnover intention, a closer examination of the unique contributions of each variable indicated that years of service contributed more unique variance to turnover intention than did either person-organization or person-occupation fit.

These findings, although consistent with turnover research (Griffeth et al., 2000;

Otis and Straver, 2008), also highlight one of the major limitations with this study, in that, on average participants had 18 years of service and therefore were close to a retirement gateway (20 years of service) that comes with an unreduced pension. The 
younger demographic of employees with fewer years of service were not well represented (Goldenberg, 2011). Future research needs to ensure better representation of the younger demographic, perhaps with the use of stratified sampling or a longitudinal design, which would allow researchers to examine fit at different career stages and perhaps incorporate candidates before they are enrolled. Nonetheless, the findings of this study suggest that for this sample of Canadian Forces members, person-organization and person-occupation fit were both important attitudes to consider for increasing retention.

Turnover intention and perceived job alternatives were not correlated for either officers or noncommissioned members, which was a surprising result given that the perception of alternatives is considered a weak but key link in the turnover process. Previous research indicates that the majority of voluntary turnover is preceded by the search for alternative employment (Griffeth et al., 2000; Lee et al., 1996). However, the present study's finding may be inconsistent because less than $10 \%$ of the sample indicated they were considering leaving the Canadian Forces within the next year. Hence, the results may be a function of range restriction rather than any indication that perceived alternatives is not an important link in the turnover process for military members.

\section{Psychological Withdrawal}

The present study was the first time psychological withdrawal was explored as an outcome of person-environment fit. The results indicated that person-environment fit was a significant predictor of psychological withdrawal, but interestingly there were differences between noncommissioned members and officers in the experience of psychological withdrawal. One difference was that more years of service was associated 
with increased psychological withdrawal, for noncommissioned members, however the effect was very small. Both domains of fit contributed relatively equally to the creation of psychological withdrawal in both groups, however a closer examination of the unique contributions of each domain indicated that person-organization fit was slightly more influential, particularly for noncommissioned members.

It was not possible in the current research to determine whether psychological withdrawal is an alternative or a precursor to actual turnover, but its higher associations with person-organization fit, commitment, and perceived organizational support suggest it may be more influenced by organizational factors than by job level factors. The current findings also support predictions that one of the effects of poor person-environment fit is that workers may adjust by creating a psychological distance from the workplace; potentially being less engaged and theoretically less productive (Hanisch \& Hulin, 1991; Steel \& Lounsbury, 2009). These outcomes are not positive for organizations, and these findings support the need to conduct recruiting and selection activities with an increased focus on improving person-environment fit, and perhaps more specifically personorganization fit.

\section{Organizational Commitment}

Person-organization fit is believed to be one of strongest antecedents of affective organizational commitment (Chatman, 1991; Kristof-Brown \& Guay, 2011; Wheeler et al., 2005), and the results of the current research provide support for this hypothesis. Moreover, the current research adds to the literature by building on Scroggins' (2007) results and providing additional evidence that person-organization fit and personoccupation fit have an additive effect on affective commitment, so that each domain may 
be important to the creation of commitment. Affective commitment is also normally very strongly associated with years of service, which was also the case in this research; however, once person-environment was considered the effects of years of service were no longer in evidence. The one concern from the present study is that the correlation was so high, .70 , that future research should explore the convergent and divergent validity of person-organization fit and assess its uniqueness as a construct separate from affective organizational commitment.

The current study also assessed normative commitment as an outcome. Normative commitment was of particular interest to this study as it is hypothesized to be particularly important to military samples (Griffeth et al., 2000; Popper \& Lipshitz, 1992). Both domains of person-environment fit were moderate predictors of normative commitment, whereas years of service was not. Moreover, the mean level of normative commitment was almost identical for both officers and noncommissioned members. The basis of normative commitment as proposed by Allen and Meyer (1990) is pre-entry socialization provided by family and culture and post-entry socialization provided by organizations; however, if post-entry socialization is a factor, it would seem that normative commitment would increase with more tenure. The results from the present study appear to indicate that pre-entry socialization may be more influential and that individuals may choose the Canadian Forces because, as Griffeth and colleagues (2000) suggest, they feel a sense of obligation to serve their country; this could be an intriguing avenue for future research. Popper and Lipshitz (1992) suggested that in addition to organizational characteristics and work experience, personal values are important to normative commitment and individuals who hold strong normative values may be attracted to organizations that have 
high value contents, such as police or other para-military organizations. What these results do support more clearly, however, is normative commitment and affective commitment as two separate components of commitment.

The current research added to the literature by evaluating two forms of fit on multiple outcomes in the same study and the results add to growing empirical support that concludes that fit is important to organizations for increasing commitment and reducing attrition, however one crucial outcome not investigated was worker performance. There is substantial research that indicates highly committed employees will be stronger performers, be more motivated to accomplish organizational goals, and be more likely to carry out extra role activities, exhibit higher contextual performance, and enjoy increased career success (Bretz \& Judge, 1994, Gellatly et al., 2006; Kristof-Brown et al., 2002; Lauver \& Kristof-Brown, 2001; Meyer \& Luchak, 2006; Meyer \& Maltin, 2010). Further, there is growing evidence that person-job fit is a good predictor of performance (Cable \& DeRue, 2002; Lauver \& Kristof-Brown, 2001). The link between personorganization fit and performance appears to be primarily through organizational commitment, however very few studies have evaluated job performance as an outcome of person-organization fit (Werbel \& Gilliand, 1999). This is a crucial avenue for future researchers to pursue, if multiple forms of person-environment fit, including personorganization fit are to be included in legally defensible and fair selection protocols (Barrick, Mount, \& Judge, 2001; Karren \& Graves, 1994; Sekiguchi, 2007; Werbel \& Gilliand, 1999). 


\section{Noncommissioned Members and Officers}

The Canadians military is essentially made up of two cadres of personnel -officers and noncommissioned members. Officers can be equated to the middle and senior management of an organization and/or the professional workforce (doctors, nurses etc.). Noncommissioned members by contrast are the skilled frontline workforce and are generally employed in occupations such as clerks, drivers, dental technicians, electricians, plumbers, and so forth. After several years of experience in their occupation, they may also become first line managers. These two roles require very different skill sets, and educational backgrounds and thus, it was expected that person-environment fit influences might be different for these two groups. Indeed preliminary analyses indicated that this was the case.

Officers were more highly educated, were more likely to be employed in occupations with civilian equivalence, and tended to have more years of service. Further they reported higher affective commitment, less continuance commitment, stronger person-organization and person-occupation fit, fewer turnover intentions, and less psychological withdrawal in comparison to noncommissioned members. The lower reported continuance commitment and psychological withdrawal would suggest that officers may feel less constrained to stay in the military than do noncommissioned members. This is likely related to the fact that on average officers earn more than noncommissioned members averaging $\$ 73,000(2002 \$)$ versus $\$ 48,000(2002 \$)$, respectively (Park, 2008), are more highly educated, and are more likely to possess more transferable skills. However, the higher level of affective commitment and lower turnover intentions may also indicate that on average officers are more likely to stay in the military 
out of desire rather than because they have a fear of loss, relative to noncommissioned members.

The differences seen between noncommissioned members and officers would suggest that there are differences that could impact how workers are recruited and selected and the retention strategies that are employed. For example, Sekiguchi (2007) proposed that when hiring employees who will gain most of their job knowledge and skills once they are hired (like noncommissioned members) selecting for person-job fit may be less important than selecting for person-organization fit. On the other hand if you are hiring professionals (most like officers), who will bring education, knowledge, and skill into the organization it may be more important to select individuals based on personjob and/or person-vocation fit.

The fact that person-environment fit was stronger for officers could be related to having more realistic expectations, given that officers tended to be employed in occupations with more civilian equivalence, which may be associated with a better understanding of the job requirements and therefore a more informed job choice. It is likely that the higher perceptions of fit explain the higher levels of affective commitment, and support hypotheses that fit is an antecedent to organizational commitment (Griffeth \& Hom, 2001; Hom et al., 2008; Steel \& Lounsbury, 2009). However, what these finding also indicate, as noted by previous fit researchers (Edwards, 1991; Kristof-Brown et al., 2005 ), is that more research is required to better understand the antecedents of personenvironment fit. 


\section{Moderators of Person-Environment Fit}

In addition to exploring the direct associations between person-organization and person-occupation fit and organizational commitment and organizational withdrawal, the current study evaluated four variables, including perceived organizational support, continuance commitment, civilian equivalence and perceived job alternatives, which were hypothesized to moderate the effects of fit on the outcomes.

These four proposed moderators did not substantially mitigate or buffer the influences of person-environment fit on the outcomes. Only perceived job alternatives and continuance commitment had any significant effects, but the small effect sizes indicate that the results might not be meaningful. It was somewhat surprising that perceived organizational support did not moderate the influence of poor fit on any of the outcomes, even though it was associated with both fit domains; however, the strong direct associations suggest that it may play a role in the creation of organizational commitment and in decreasing withdrawal cognitions.

The civilian equivalence of a member's occupation did not appear to be a factor in predicting organizational commitment or organization withdrawal for noncommissioned members or officers. Civilian equivalence had a small positive correlation with affective commitment and education; it was also weakly associated with lower continuance commitment and lower psychological withdrawal, but had no association with turnover intentions. Working in an occupation that can be more easily translated into a civilian job appears to lessen members' feelings of being constrained to stay with the organization, but does not necessarily increase their propensity to leave and in fact may actually increase affective commitment. These results may be related to the idea that individuals 
who choose the Canadian Forces as a career may choose their occupation based on the fact that they can carry out their functions as a member of the military, fulfilling a need to work in an organization that matches their values, and therefore civilian equivalence is likely not an factor in withdrawal cognitions.

When we evaluate the associations by group, it is interesting to note that for noncommissioned members, civilian equivalence is associated with lower personoccupation fit. These results are very intriguing and support Sekiguchis', (2007) proposition that for workers who gain most of their job knowledge and experience through the organization, person-organization fit is more important than person-job (occupation) fit. For officers civilian equivalence was not associated with either domain of fit. However, correlations for officers appear to indicate that working in an occupation with a civilian equivalent increases continuance commitment. It might be that for officers, even though they are working in an occupation with a civilian equivalent, it may not be as easy to transfer to a civilian occupation and still earn the same salary and benefits, so they may be staying out of a fear of loss, perhaps, not only financially but because it may take years in a civilian environment to regain the same level of career progression and workplace status.

Continuance Commitment. Although it was expected that continuance commitment would be a moderator of person-environment fit it was negatively associated with person-occupation fit for both noncommissioned members and officers and not associated with person-organization fit at all. This lack of association may be an indication that continuance commitment is influenced more by job-level factors than by organizational-level factors. Interestingly, the more years of service individuals had the 
lower their continuance commitment, providing potential substantiation that continuance commitment is associated with compensatory factors. The more years of service a Canadian Forces member has, the closer they are to retirement with a pension, and further, after 30 years of service, pension benefits no longer accrue, so there is no financial benefit to staying beyond this period, in terms of retirement benefits.

Results were weak with regard to continuance commitment as a moderator and were only in evidence for turnover intention. The more interesting finding was that it influenced noncommissioned members and officers differently. For noncommissioned members, continuance commitment mitigated the effects of poor person-organization fit; with the results indicating that individuals with the highest level of continuance commitment also reported the lowest turnover intentions; however, it did not mitigate the effects of poor person-occupation fit. Most noncommissioned members are enrolled in the Canadian Forces with very little training or experience in their occupation; gaining the skills and knowledge required through the Canadian Forces training system, therefore it may be that as suggested by Sekiguchi (2007), for these types of workers, personorganization fit plays a greater role in the formation of their workplace attitudes and behaviours. The finding for officers also provides support for Sekiguchis' (2007), propositions, given that for this group, continuance commitment acted as a buffer between poor person-occupation fit and turnover intention. Officers may feel a stronger bond to their occupation, given that it takes years of training both within and/or outside the Canadian Forces where they are focused on attaining the skills and knowledge to carry out these roles. 
Perceived Job Alternatives. The final moderator assessed was in some ways the most intriguing. Perceived alternatives was not associated with turnover, however it was a weak moderator of both person-organization and person-occupation fit's influence on psychological withdrawal for the officer group. The effects were very small, which may limit their meaning; however the fact that the direction of the effects was opposite for each domain was very interesting. Officers who reported poor person-organization fit, but believed they had more job alternatives, also reported less psychological withdrawal. These results are logical. The belief that more job options are available should reduce feeling of being constrained to stay and result in retention due to desire versus obligation or a fear of loss.

The intriguing result was for moderating effects of perceived alternatives on person-occupation fit's influence on psychological withdrawal. The findings of this study indicated that a belief that there were viable job options actually increased psychological withdrawal for those individuals with poorer perceptions of occupation fit. Lack of fit to their occupation appears to have created psychological tension which may not be resolved by leaving the organization, in this sense, perhaps in this case psychological withdrawal is being used as an alternative to turnover.

\section{Limitations}

Although the cross validation results indicate that the findings in this study are quite robust, at least in terms of the direct effects, the study also has several limitations, perhaps the most important of which was the measurement of fit perceptions. One of the most common critiques of the person-environment fit literature is a lack of standardized validated measures, which is largely due to the wide variety of conceptualizations and 
operationalizations of person-environment fit, leading to disagreement as to how to measure it (Cable \& DeRue, 2002; Edwards \& Billsberry, 2010; Kristof-Brown \& Guay, 2011; Piasentin \& Chapman, 2006). This variability in measures makes comparisons across studies very difficult and can result in inconsistent findings. The fit measures used in the present research were created for this study and although the reliability of the measures was acceptable for preliminary research (Nunnally, 1978), the reliability of the measures were below the .80 . Considering the low reliability of the fit measures, the strength of the findings for the direct effects provides strong support that personenvironment fit may be an important variable for understanding work-related attitudes. On the other hand the low reliability and coarseness of the measures, coupled with the restricted range of responses for turnover intention likely contributed to the small effect sizes found in the moderator analyses. The reliability of fit measures used in this study could be improved by adding additional items to each of the measures (Nunnally, 1978). However, future research may also be improved by using measures already available in the literature (Cable \& DeRue, 2002; Uysal-Irak, 2010). This would result in less inconsistent results and make it easier to build a body of research that could have more practical applications.

A second limitation was the sample used to conduct this research. The retention survey is administered to Canadian Forces members who are in occupations that are at risk with regard to effective staffing levels, therefore the individuals in this study worked in occupations that were facing high attrition or were having difficulty recruiting sufficient personnel to offset the number of members who were leaving the occupation. This may have resulted in the fact that the sample for this study was not representative of 
all age and rank groups within the Canadian Forces. The younger demographic that is at the highest risk for attrition was not well represented. One of the potential reasons for the poorer representation of the less experienced group was that the survey was web-based and was only distributed to individuals who had ready access to the Canadian Forces" email system. Theoretically everyone has access to an email account and the internal intranet, however individuals in the younger demographic may have had limited access to computers and there is a strong probability that they wouldn't use their computer time to complete a survey. The other potential reason for lack of representation of younger age and rank groups could have been that insufficient personnel had been recruited for that occupation or that there were a high proportion of training failures. Future research should consider these factors and perhaps incorporate the administration of paper surveys or explore other ways to reach this group. Longitudinal research perhaps starting before enrolment (pre-hire, Arthur et al., 2006) and following through to the first turnover gateway would be most beneficial in determining how perceptions are created and maintained, and if they are a result of socialization or other factors.

\section{Summary and Conclusions}

The overall aim of the research was to evaluate perceptions of personenvironment fit for potential use in recruiting and selection of Canadian Forces members, especially in light of the fact that not unlike many other organizations, first year attrition is high often exceeding $20 \%$. This research, combined with previous findings is providing growing evidence that fit is important to individuals and organizations and furthermore that it is important at all stages of organizational life (Judge \& Cable 1996). Personenvironment fit is believed to be an important component of what attracts individuals to 
organizations (Judge \& Cable, 1996) and the jobs and careers they choose (Cable \& Turban, 2001; Cable \& Yu, 2007), it is also believed to be an important, component of selection (Schneider, 1987a;1987b;2001). It has been strongly implicated as an important factor in the creation of job attitudes, in the promotion of employee wellbeing, and in influencing workplace attitudes and behaviour such as organizational commitment and withdrawal behaviour (Edwards \& Billsberry, 2010; Kristof-Brown \& Guay, 2011 ).

One of the major strengths of the current research was that it answered the call for more field research (Rynes \& Cable, 2003) that evaluates multiple domains of fit on multiple outcomes in the same study (Kristof, 1996; Kristof-Brown \& Guay, 2011; Kristof-Brown et al., 2005; Tak, 2011). Moreover, the study involved participants at several levels of the organization with a wide range of experience and lengths of service in the organization. The survey covered 47 different occupations and resulted in a large sample of data with sufficient power to test the proposed multivariate - multidimensional framework. The large data set also allowed for testing of subgroup differences (noncommissioned members and officers) and cross validation of the framework proposed for the study, thus improving the robustness of the results and providing insight into the differences between the two main corps (officers and noncommissioned members) of the Canadian Forces. Given the differences seen for the fit perceptions and other attitudes by the two different types of workers identified in this study, future research should not only examine different domains of fit but whether fit is experienced differently for workers at different levels of the organization such as management versus front line staff. 
In the selection literature, cognitive ability and personality have been established as effective criteria for selecting employees; however the results of the present research suggest that considering person-environment fit in selection may also add to the incremental validity of selection protocols. Currently, selection protocols in the Canadian Forces assesses potential person-job fit through the use of a structured interview and bio data screening to ensure that recruits meet the minimum educational and experiential requirements established for their occupation choices. However, there is a growing body of research supported by the current research that suggests that assessment of other forms of fit such as person-organization, person-group, and person-vocation fit may also be important to ensuring that the right people are recruited for the jobs available (Arthur et al., 2006; Karren \& Graves, 1994; Sekiguchi, 2007; Werbel \& Gilliland, 1999). The results of the current research suggested that for Canadian Forces members both personorganization and person-occupation fit may be important to fostering organizational commitment and reducing attrition.

Although many researchers and practitioners are advocating incorporating multiple measures of fit into selection process, researchers have also cautioned that selecting workers based on perceived match on value and culture could lead to adverse impact on minority groups and is less legally defensible (Arthur et al., 2006; Karren \& Graves; Hoffman \& Woher, 2006; Sekiguchi, 2007; Werbel \& Gilliland, 1999). Further, the Canadian Human Rights Act (2012) and the standards and practices for selection (Principles, 2003), which the Canadian Forces adhere to in the development of selection instruments, specifies that it is illegal to discriminate against workers, in employment settings unless it is for a bona fide job requirement, and is related to job performance. 
Therefore, great care must be taken to show that criteria used are defensible, fair, and based on job requirements. Hence, future research needs to evaluate person-environment fit, particularly person-organization fit in relation to job and work performance. Nonetheless despite these cautions, evidence from this study and previous research is demonstrating that multiple aspects of fit are strongly associated with creating positive workplace outcomes; work should now turn to a better understanding of how good fit perceptions are created and how they are related to job performance and career success. 


\section{References}

Allen, N. J., \& Meyer, J. P. (1990). The measurement and antecedents of affective, continuance and normative commitment to the organization. Journal of Occupational Psychology, 63(1), 1-1-18.

Allen, N. J., \& Meyer, J. P. (1996). Affective, continuance, and normative commitment to the organization: An examination of construct validity. Journal of Vocational Behavior, 49(3), 252-276. doi:10.1006/jvbe.1996.0043

Arthur, W., Bell, S. T., Villado, A. J., \& Doverspike, D. (2006). The use of personorganization fit in employment decision making: An assessment of its criterionrelated validity. Journal of Applied Psychology, 91(4), 786-801. doi: $10.1037 / 0021-9010.91 .4 .786$

Ajzen, I., \& Fishbein, M. (1980). Understanding attitudes and predicting social behavior. Englewood Cliffs, NJ: Prentice-Hall.

Ajzen, I. (2000). In Kazdin A. E. (Ed.), Theory of reasoned action. United States: doi: $10.1037 / 10523-026$

Barrick, M. R., Mount, M. K., \& Judge, T. A. (2001). Personality and performance at the beginning of the new millennium: What do we know and where do we go next? International Journal of Selection and Assessment, 9(1-2), 9-30. doi: http://dx.doi.org.proxy.library.carleton.ca/10.1111/1468-2389.00160

Barrick, M.R., \& Zimmerman, R.D. (2009). Hiring for retention and performance, Human Resource Management, March-April, Vol. 48, No. 2, 183-206. doi: $10.1002 / \mathrm{hrm} .20275$ 
Billsberry, J. (2007). Attracting for values: An empirical study of ASA's attraction proposition. Journal of Managerial Psychologv, 22(2), 132-132-149. doi: $10.1108 / 02683940710726401$

Blau, P. M. (1964). Exchange and power in social life. New York: Wiley.

Brown, S.P. (1996). A meta-analysis and review of organizational research on job involvement. Psychological Bulletin, 120, 235-255.

Cable, D. M., \& DeRue, D. S. (2002). The convergent and discriminant validity of subjective fit perceptions. Journal of Applied Psychology, 87(5), 875-884. doi: $10.1037 / 0021-9010.87 .5 .875$

Cable, D.M, \& Edwards, J.R. (2004). Complementary and supplementary fit: A theoretical and empirical integration. Journal of Applied Psychology 2004, Vol. 89, No. 5, 822-834: doi: 10.1037/0021-9010.89.5.822

Cable, D. M., \& Judge, T. A. (1996). Person-Organization fit, job choice decisions, and organizational entry. Organizational Behavior and Human Decision Processes, 67(3), 294-311. doi:10.1006/obhd.1996.0081

Cable, D. M., \& Turban, D. B. (2001). Establishing the dimensions, sources and value of job seekers' employer knowledge during recruitment. In G. R. Ferris (Ed.), Research in Personnel and Human Resources Management Vol 20. (pp. 115-163). US: Elsevier Science/JAI Press. doi:10.1016/S0742-7301(01)20002-4

Cable, D. M., \& Yu, K. Y. T. (2007). How selection and recruitment practices develop the beliefs used to assess fit. In C. Ostroff \& T. A. Judge (Eds.), Perspectives on organizational fit (pp. 185-181). Mahwah, NJ, US: Lawrence Erlbaum Associates Publishers. 
Canada Year Book (2011). Labour, Chapter 21. Statistics Canada-Catalogue no. 11.402-X Retrieved from http://www.statcan.gc.ca/pub/11-402-x/2011000/chap/labtra/lab-tra-eng.htm

Canadian Human Right Act, R.S.C., 1985, c. H-6, (2012), Part I, Section 7, 1976-77, c. 33, s. $7 ; 1980-81-82-83$, c. 143 , s. 3(F). Published by the Minister of Justice at the following address: http://laws-lois.justice.gc.ca.

Carless, S. A. (2005). Person-job fit versus person-organization fit as predictors of organizational attraction and job acceptance intentions: A longitudinal study. Journal of Occupational and Organizational Psychology, 78(3), 411-411-429. doi:10.1348/096317905X25995

Carrick, D. (2003). Early Career Stay/Leave Patterns of Canadian Forces NonCommissioned Members: A longitudinal analysis of three entry cohorts through the first basic engagement. DMEP-A/RT Report 2003-002.

Catano, V. M., Wiesner, W.H., Hackett, R.D. Methot, L.L, \& Belcourt, M (2005). Recruitment and selection in Canada ( $3^{\text {rd }}$ ed.). Scarborough, Ont: Nelson Thomson Learning.

Chatman, J. A. (1991). Matching people and organizations: Selection and socialization in public accounting firms. Administrative Science Quarterly, 36(3), 459-484.

Country Commerce (2008), Country Forecast Canada (September 2008). The Economist Intelligence Unit Limited 2008@, www.eiu.com

Department of National Defence (2009). Annual Report on Regular Force Attrition 2007/2008 (2009). Attrition and Retention Team Director General Military Personnel Research and Analysis Department of National Defence. 
Department of National Defence (2011). Recruiting and Retention in the Canadian Forces, Backgrounder $B G 11.007,27$ May 2011. Accessed from http:/www.forces.gc.ca/site/news-nouvelles/news-nouvelles-eng.

Department of National Defence (2011). Report On Plans And Priorities 2011-12, Part II Estimates, retrieved from http://www.tbs-sct.gc.ca/rpp/2011-2012/inst/dnd/dnd03eng.asp

Edwards, J. R. (1991). Person-job fit: A conceptual integration, literature review, and methodological critique. Oxford, England: John Wiley \& Sons.

Edwards, J. R. (1996). An examination of competing versions of the person-environment fit approach to stress. Academy of Management Journal, 39(2), 292-292-339. doi: $10.2307 / 256782$

Edwards, J.R. (2008) Person-environment fit in organizations: An assessment of theoretical progress, The Academy of Management Annals, 2:1, 167-230. doi: $10.1080 / 19416520802211503$

Edwards, J. R., \& Billsberry, J. (2010). Testing a multidimensional theory of personenvironment fit. Journal of Managerial Issues, 22(4), 476-476-493.

Edwards, J.R, \& Shipp, A.J, (2007). The relationship between person-environment fit and outcomes: An integrative theoretical framework. In C. Ostroff \& T. A. Judge (Eds.), Perspectives on organizational fit (pp. 209-258). San Francisco: JosseyBass, 2007.

Edwards, J. R., \& Harrison, R. (1993). Job demands and worker health: Threedimensional reexamination of the relationship between person-environment fit 
and strain. Journal of Applied Psychologv, 78(4), 628-628-648.

doi: $10.1037 / 0021-9010.78 .4 .628$

Ehrhart, K. H., \& Makransky, G. (2007). Testing vocational interests and personality as predictors of person-vocation and person-job fit. Journal of Career Assessment, 15(2), 206-206-226. doi:10.1177/1069072706298105

Eisenberger, R., Huntington, R., Hutchison, S., \& Sowa, D. (1986). Perceived organizational support. Joumal of Applied Psychology, 71(3), 500-500-507. doi: $10.1037 / 0021-9010.71 .3 .500$

Eisenberger, R., Stinglhamber, F., Vandenberghe, C., Sucharski, I. L., \& Rhoades, L. (2002). Perceived supervisor support. Journal of Applied Psychology, 87(3), 565573. doi: $10.1037 / 0021-9010.87 .3 .565$

Field, A. (2005). Discovering statistics using SPSS (2nd ed.). Thousand Oaks, CA, US: Sage Publications, Inc.

Fisk, G., \& Skattebo, A. (2010). In Glenda Fisk and Amie Skattebo. (Ed.), Recruiting the best and brightest for employment in Canada's public sector Kingston, Ont: Queen's University, Centre for the Study of Democracy, 2010.

Frazier, P.A., Tix, A.P., \& Barron, K.E. (2004). Testing moderator and mediator effects in counseling psychology. Journal of Counseling Psychology, 51, 115-134.

Fugate, M. (2004). Employability: A psycho-social construct, its dimensions, and applications. Journal of vocational behavior, 65(1), 14-38.

Fuller, J.B., Hester, K., Dickson, P., Allison, B.J. \& Birdseye, M. (1996). A closer look at select cognitive precursors to organizational turnover: What has been missed and Why. Psychological Reports, 78, 1331-1352. 
Greguras, G. J., \& Diefendorff, J. M. (2009). Different fits satisfy different needs: Linking person-environment fit to employee commitment and performance using self-determination theory. Journal of Applied Psychology, 94(2), 465-465-477. doi: $10.1037 / \mathrm{a} 0014068$

Gellatly, I. R., Meyer, J. P., \& Luchak, A. A. (2006). Combined effects of the three commitment components on focal and discretionary behaviors: A test of Meyer and Herscovitch's propositions. Journal of Vocational Behavior, 69(2), 331-345. doi:10.1016/j.jvb.2005.12.005

Goldenberg (2011). Canadian Forces Retention Survey: Perceptions of Organizational Fairness, Work and Organizational Cynicism, and Organizational Commitment. Attrition and Attention Personnel Generation Research. DGMPRA TM 2011-026 November 2011. Defence R\&D Canada. Director General Military Personnel Research \& Analysis, Chief Military Personnel.

Griffeth, R.W., \& Hom, P.W. (2001). Retaining Valued Employees. Thousand Oaks, CA: Sage Publications.

Griffeth, R. W., Hom, P. W., \& Gaertner, S. (2000). A meta-analysis of antecedents and correlates of employee turnover: Update, moderator tests, and research implications for the next millennium. Journal of Management, 26(3), 463-488. doi:10.1177/014920630002600305

Griffeth, R. W., Steel, R. P., Allen, D. G., \& Bryan, N. (2005). The development of a multidimensional measure of job market cognitions: The Employment Opportunity Index (EOI). Journal of Applied Psychology, 90(2), 335-349. doi: $10.1037 / 0021-9010.90 .2 .335$ 
Halbesleben, J. R. B., \& Wheeler, A. R. (2008). The relative roles of engagement and embeddedness in predicting job performance and intention to leave. Work \& Stress, 22(3), 242-256. doi:10.1080/02678370802383962

Hanisch, K. A., \& Hulin, C. L. (1990). Job attitudes and organizational withdrawal: An examination of retirement and other voluntary withdrawal behaviors. Joumal of Vocational Behavior, 37(1), 60-78. doi:10.1016/0001-8791(90)90007-O

Hanisch, K. A., \& Hulin, C. L. (1991). General attitudes and organizational withdrawal: An evaluation of a causal model. Journal of Vocational Behavior, 39(1), 110-128. doi: 10.1016/0001-8791(91)90006-8

Harman, W. S., Lee, T. W., Mitchell, T. R., Felps, W., \& Owens, B. P. (2007). The psychology of voluntary employee turnover. Current Directions in Psychological Science, 16(1), 51-54. doi:10.1111/j.1467-8721.2007.00474.x

Harrison, D.A. (2007). Pitching fits in Applied Psychological Research: Making fit methods fit theory. In In C. Ostroff \& T. A. Judge (Eds.), Perspectives on organizational fit (pp. 389-416). Mahwah, NJ, US: Lawrence Erlbaum Associates Publishers, Mahwah, NJ.

Hoffman, B. J., \& Woehr, D. J. (2006). A quantitative review of the relationship between person-organization fit and behavioral outcomes. Journal of Vocational Behavior, 68(3), 389-399. doi:10.1016/j.jvb.2005.08.003

Holland J.L, (1959). A theory of vocational choice. Journal of Counseling Psychology Vol. 6, No. 1, 35-45. 
Holt, D. T., Rehg, M. T., Lin, J. H. S., \& Miller, J. (2007). An application of the unfolding model to explain turnover in a sample of military officers. Human Resource Management, 46(1), 35-49. doi:10.1002/hrm.20144

Hom, P.W., Caranikas-Walker, F., Prussia, G.E., \& Griffeth, R.W. (1992). A metaanalytic structural equations analysis of a model of employee turnover. Joumal of Applied Psychology, 77, 890-909

Hom, P. W., \& Kinicki, A. J. (2001). Toward a greater understanding of how dissatisfaction drives employee turnover. Academy of Management Journal, 44(5), 975-987. doi: $10.2307 / 3069441$

Hom, P. W., Roberson, L., \& Ellis, A. D. (2008). Challenging conventional wisdom about who quits: Revelations from corporate America. Journal of Applied Psychology, 93(1), 1-1-34. doi:10.1037/0021-9010.93.1.1

Hom, P. W., Tsui, A. S., Wu, J. B., Lee, T. W., Zhang, A. Y., Fu, P. P., \& Li, L. (2009). Explaining employment relationships with social exchange and job embeddedness. Journal of Applied Psychology, 94(2), 277-277-297. doi: $10.1037 / \mathrm{a} 0013453$

Iplik, F. N., Kilic, K. C., \& Yalcin, A. (2011). The simultaneous effects of personorganization and person-job fit on Turkish hotel managers. International Journal of Contemporary Hospitality Management, 23(5), 644-661. doi: $10.1108 / 09596111111143386$

Ito, J. K., \& Brotheridge, C. M. (2005). Does Supporting Employees' Career Adaptability Lead to Commitment, Turnover, or Both? Human resource management, 44(1), 5-19. doi:10.1002/hrm.20037 
Jansen, K. J., \& Kristof-Brown, A. (2006). Toward a multidimensional theory of personenvironment fit. Journal of Managerial Issues, 18, 193-212.

Jaros, S.J. (1997). An assessment of Meyer and Allen`s (1991) three-component model of organizational commitment and turnover intentions. Journal of Vocational Behavior, 51, 319-337

Judge, T. A. (2007). The future of person-organization fit research: Comments, observations, and a few suggestions. In Ostroff C., Judge T. A. (Eds.), Perspectives on Organizational fit (pp. 419-441): Mahwah, NJ, US: Lawrence Erlbaum Associates Publishers, Mahwah, NJ.

Judge, A. \& Bretz, R.D. (1992). Effects of work values on job choice decisions. Journal of Applied Psychology, 77(3), 261-271. doi: 10.1037/0021-9010.77.3.261

Judge, T. A., \& Cable, D. M. (1997). Applicant personality, organizational culture, and organization attraction. Personnel Psychology, 50(2), 359-359-394. doi: 10.1111/j.1744-6570.1997.tb00912.x

Kammeyer-Mueller, J. D., Wanberg, C. R., Glomb, T. M., \& Ahlburg, D. (2005). The role of temporal shifts in turnover processes: It's about time. Journal of Applied Psychology, 90(4), 644-658. doi:10.1037/0021-9010.90.4.644

Karren, R. J., \& Graves, L. M. (1994). Assessing person-organization fit in personnel selection: Guidelines for future research. International Journal of Selection and Assessment, 2(3), 146-146-156. doi:10.1111/j.1468-2389.1994.tb00135.x

Kim, S., Price, J.L., Mueller, C.W. \& Watson, T.W. (1996). The determinants of career intent among physicians at a U.S. air force hospital. Human Relations, 49, 947976. 
Koslowsky, M. (2009). A multi-level model of withdrawal: Integrating and synthesizing theory and findings. Human Resource Management Review; 19(4), 283-303. doi: 10.1016/j.hrmr.2008.12.001

Koslowsky, M., Sagie, A., Krausz, M., \& Singer, A. D. (1997). Correlates of employee lateness: Some theoretical considerations. Journal of Applied Psychology, 82(1), 79-88. doi: $10.1037 / 0021-9010.82 .1 .79$

Koundakjian K., \& Michaud, 2011, K., (2011) Retention in the Canadian Force Descriptive Results of the 2008 Retention Survey. DGMPRA TM 2011-004 Director General Military Personnel Research \& Analysis, National Defence Headquarters, Ottawa, Ontario, Canada.

Kristof, A. L. (1996). Person-organization fit: An integrative review of its conceptualizations, measurement, and implications. Personnel Psychology, 49(1), $1-49$.

Kristof-Brown, A. L., Jansen, K. J., \& Colbert, A. E. (2002). A policy-capturing study of the simultaneous effects of fit with jobs, groups, and organizations. Journal of Applied Psychology, 87(5), 985-993. doi:10.1037/0021-9010.87.5.985

Kristof-Brown, A. L. (2000). Perceived applicant fit: Distinguishing between recruiters' perceptions of person-job and person-organization fit. Personnel Psychology, 53(3), 643-671. doi:10.1111/j.1744-6570.2000.tb00217.x

Kristof-Brown, A.L., \& Guay, R. P. (2011). Person-environment fit. In S. Zedeck (Ed.), APA handbook of industrial and organizational psychology, Vol 3: Maintaining, expanding, and contracting the organization. (pp. 3-50). Washington, DC, US: American Psychological Association. doi:10.1037/12171-001 
Kristof-Brown, A. L., \& Jansen, K. J. (2007). Issues of person-organization fit. In C.

Ostroff, \& T. A. Judge (Eds.), Perspectives on organizational fit. (pp. 123-153).

Mahwah, NJ, US: Lawrence Erlbaum Associates Publishers.

Kristof-Brown, A. L., Zimmerman, R. D., \& Johnson, E. C. (2005). Consequences of individual's fit at work: A meta-analysis of person-job, person-organization, person-group, and person-supervisor fit. Personnel Psychology, 58(2), 281-342. doi:10.1111/j.1744-6570.2005.00672.x

Latham, G. P., \& Sue-Chan, C. (1998). Selecting employees in the 21 st century: Predicting the contribution of I-O psychology to Canada. Canadian Psychology/Psychologie Canadienne, 39(1-2), 14-22. doi:10.1037/h0086791

Lauver, K. J., \& Kristof-Brown, A. (2001). Distinguishing between employees' perceptions of person--job and person--organization fit. Journal of Vocational Behavior, 59(3), 454-454-470. doi:10.1006/jvbe.2001.1807

Lee, T. W., Mitchell, T. R., Wise, L., \& Fireman, S. (1996). An unfolding model of voluntary employee turnover. Academy of Management Journal, 39(1), 5-36. doi: $10.2307 / 256629$

Lynch, P.D., Eisenberger R., \& Armeli, S. (1999). Perceived organizational support: inferior versus superior performance by wary employees. Journal of Applied Psychology, 84, 467-483.

Mantler, J. (2006). The psychological withdrawal scale. Unpublished manuscript.

Martel, L., Malenfant, E.C., Morency, J., Lebel, A., Belanger, A., \& Bastien, N., (2011). Projected trends to 2031 for the Canadian labour force. Canadian Economic Observer, Vol 24 no 8, Section 3. Statistics Canada catalogue number 11-010-X 
accessed from http:/www.statcan.gc.ca/pub/11-010-x/2011008/part-partie3eng.htm. Monthly

Maurer, T. J., \& Lippstreu, M. (2008). Who will be committed to an organization that provides support for employee development? Journal of Management Development, 27(3), 328-347. doi:10.1108/02621710810858632

McQuaid, Ronald W and Lindsay, C. (2005). The concept of employability. Urban Studies, 42(2), 197-219.

Meyer, J. P. (2009). Commitment in a changing world of work. New York, NY, US: Routledge/Taylor \& Francis Group.

Meyer, J. P., Allen, N. J., \& Smith, C. A. (1993). Commitment to organizations and occupations: Extension and test of a three-component conceptualization. Journal of Applied Psychology, 78(4), 538-538-551. doi:10.1037/0021-9010.78.4.538

Meyer, J.P, Becker, T.E., Vandenberghe, C. (2004). Employee Commitment and Motivation: A Conceptual Analysis and Integrative Model. Journal of Applied Psychology, Vol. 89, No. 6, 991-1007 doi: 10.1037/0021-9010.89.6.991

Meyer, J. P., \& Maltin, E. R. (2010). Employee commitment and well-being: A critical review, theoretical framework and research agenda. Journal of Vocational Behavior, 77(2), 323-323-337. doi:10.1016/j.jvb.2010.04.007

Meyer, J. P., \& Parfyonova, N. M. (2010). Normative commitment in the workplace: A theoretical analysis and re-conceptualization. Human Resource Management Review, 20(4), 283-283-294. doi:10.1016/j.hrmr.2009.09.001

Meyer, J.P., Stanley, D.J., Herscovitch, L., Toplnystsk, L. (2002). Affective, continuance, and normative commitment to the organization: A meta-analysis of 
antecedents, correlates, and consequences. Joumal of Vocational Bchavior, 61 , $20-52$.

Michaud, K. (2010). Influence of Disconfirmed expectations on CF departing members. DGMPRA TM 2010-031. Director General Military Personnel Research and Analysis, National Defence Headquarters, Ottawa, Ontario, Canada

Muchinsky, P. M., \& Monahan, C. J. (1987). What is person-environment congruence? supplementary versus complementary models of fit. Journal of Vocational Behavior, 31(3), 268-277. doi:10.1016/0001-8791(87)90043-1

Murray, H. A. (1938). Explorations in personality. Oxford, England: Oxford Univ. Press, Oxford.

Nauta, A., Vianen, A., Heijden, B., Dam, K., \& Willemsen, M. (2009). Understanding the factors that promote employability orientation: The impact of employability culture, career satisfaction, and role breadth self-efficacy. Journal of Occupational and Organizational Psychology, 82(2), 233-251.

doi: $10.1348 / 096317908 \times 320147$

Nunnally, J. C. (1978). Psychometric theory (2nd ed.). New York: McGraw-Hill.

Ostroff, C.L, \& Shulte, M. (2007). Multiple perspectives of fit in organizations across levels of analysis. In C. Ostroff \& T. A. Judge (Eds.), Perspectives on organizational fit (pp. 3-69). Mahwah, NJ, US: Lawrence Erlbaum Associates Publishers.

Otis, N \& Straver, M (2008). Review of Attrition and Retention Research for the Canadian Forces. DRDC CORA TM 2008-030, Defence R\&D Canada Centre for 
Operational Research and Analysis Director General Military Personnel Research \& Analysis Chief Military Personnel, National Defence Headquarters.

Park, J (2008). A profile of the Canadian Forces. Perspectives, Statistics CanadaCatalogue no. 75-001-X, July 2008, p 17-30. Retrieved from http://www.statcan.gc.ca/pub/75-001-x/2008107/pdf/10657-eng.pdf.

Piasentin, K. A., \& Chapman, D. S. (2006). Subjective person-organization fit: Bridging the gap between conceptualization and measurement. Journal of Vocational Behavior, 69(2), 202-221. doi:10.1016/j.jvb.2006.05.001

Popper, M., \& Lipshitz, R. (1992). "Ask not what your country can do for you": The normative basis of organizational commitment. Journal of Vocational Behavior, 4l(1), 1-1-12. doi:10.1016/0001-8791(92)90035-X

Preacher, K. J., Curran, P. J., \& Bauer, D. J. (2006). Computational tools for probing interaction effects in multiple linear regression, multilevel modeling, and latent curve analysis. Journal of Educational and Behavioral Statistics, 31, 437-448.

Randall. D.M., O’Driscoll, M.P. (1997). Affective versus calculative commitment: Human Resource Implications. Journal of Social Psychology, 137, 606-617.

Resick, C. J., Baltes, B. B., \& Shantz, C. W. (2007). Person-organization fit and workrelated attitudes and decisions: Examining interactive effects with job fit and conscientiousness. Journal of Applied Psychology, 92(5), 1446-1446-1455. doi:10.1037/0021-9010.92.5.1446

Rosse, J. G., \& Hulin, C. L. (1985). Adaptation to work: An analysis of employee health, withdrawal, and change. Organizational Behavior and Human Decision Processes, 36(3), 324-347. doi:10.1016/0749-5978(85)90003-2 
Rynes, S. L., \& Cable, D. M. (2003). Recruitment research in the twenty-first century. Hoboken, NJ, US: John Wiley \& Sons Inc.

Sagie, A., Birati, A., \& Tziner, A. (2002). Assessing the costs of behavioral and psychological withdrawal: A new model and an empirical illustration. Applied Psychology: An International Review: Special Issue: Challenges of Applied Psychology for the Third Millennium, 51(1), 67-89. doi:10.1111/1464-0597.00079

Saks, A. M., \& Ashforth, B. E. (1997). A longitudinal investigation of the relationships between job information sources, applicant perceptions of fit, and work outcomes. Personnel Psychology, 50(2), 395-395-426. doi:10.1111/j.17446570.1997.tb00913.x

Sankey (2012). Issues for employers; recruitment and retention solutions. Post Media News, The Province. January 22 2010, www.theprovince.com

Schneider, B. (1987a). The people make the place. Personnel Psychology, 40(3), 437 453.

Schneider, B. (1987b). $E=f(P, B)$ : The Road to a Radical Approach to PersonEnvironment Fit. Journal of Vocational Behavior 31, 353-361

Schneider, B. (2001). Fits About Fit. Applied Psychology, 50(1), 141-152. doi: $10.1111 / 1464-0597.00051$

Schneider, B., Smith, D. B., \& Paul, M. C. (2001). P-E fit and the attraction-selectionattrition model of organizational functioning: Introduction and overview. In $\mathrm{M}$. Erez, U. Kleinbeck \& H. Thierry (Eds.), Work motivation in the context of a globalizing economy. (pp. 231-246). Mahwah, NJ, US: Lawrence Erlbaum Associates Publishers. 
Scroggins, W. A. (2007). An examination of the additive versus convergent effects of employee perceptions of fit. Journal of Applied Social Psychology, 37(7), 16491649-1665. doi:10.1111/j.1559-1816.2007.00231.x

Sekiguchi, T. (2007). A contingency perspective of the importance of PJ fit and PO fit in employee selection. Joumal of Managerial Psychology, 22(2), 118-131. doi: $10.1108 / 02683940710726384$

Shore, L. M., \& Tetrick, L. E. (1991). A construct validity study of the survey of perceived organizational support. Journal of Applied Psychology, 76(5), 637-637643. doi:10.1037/0021-9010.76.5.637

Society for Industrial Organizational Psychology, Inc (2003). Principle for the validation and Use of Personnel Selection Procedures ( $4^{\text {th }}$ ed.) College Park, MD: Author.

Statistics Canada (2008). Workplace and Employee Survey Compendium 2005, Statistics Canada - Catalogue no. 71-585-XIE, Ottawa, Ontario accessed from http://www5.statcan.gc.ca/bsolc/olc-cel/olc-cel?catno $=71-585-$ X\&lang=eng\&lang=eng. Released Sep 24, 2008. Occasional.

Steel, R. P., \& Griffeth, R. W. (1989). The elusive relationship between perceived employment opportunity and turnover behavior: A methodological or conceptual artifact? Journal of Applied Psychology, 74(6), 846-854. doi:10.1037//00219010.74 .6 .846

Steel, R. P., \& Lounsbury, J. W. (2009). Turnover process models: Review and synthesis of a conceptual literature. Human Resource Management Review, 19(4), 271-282. doi:10.1016/j.hrmr.2009.04.002. 
Syed, F. \& Morrow, Maj R. (2003). Canadian Force Recruiting and Retention Strategies:

Discussion Paper for the NATO Working Group (HFM 107-RTG 037) on Recruiting and Retention. DHRRE.

Tabachnick, B. G., \& Fidell, L. S. (2007). Using multivariate statistics (5th ed.). Boston, MA: Allyn \& Bacon/Pearson Education.

Tak, J. (2011). Relationships between various person-environment fit types and employee withdrawal behavior: A longitudinal study. Journal of Vocational Behavior 78 315-320. doi:10.1016/j.jvb.2010.11.006

Uysal Irak, D. (2010). The role of affectivity in an expanded model of personenvironment fit. Carleton University (Canada). ProQuest Dissertations and Theses, http://search.proquest.com/docview/851889665? accountid=9894

Verquer, M. L., Beehr, T. A., \& Wagner, S. H. (2003). A meta-analysis of relations between person-organization fit and work attitudes. Journal of Vocational Behavior, 63(3), 473-473-489. doi:10.1016/S0001-8791(02)00036-2

Vogel, R. M., \& Feldman, D. C. (2009). Integrating the levels of person-environment fit: The roles of vocational fit and group fit. Journal of Vocational Behavior, 75(1), 6868-81. doi:10.1016/j.jvb.2009.03.007

Wayne, S.J, Shore, L.M., Bommer, W.H., Tetrick, L.E. (2002). The role of fair treatment and rewards in perceptions of organizational support and leader-member exchange. Journal of Applied Psychology, 87, 590-598.

Werbel, J. D., \& Gilliland, S. W. (1999). Person-environment fit in the selection process. US: Elsevier Science/JAI Press. 
Werbel, J. D., \& Johnson, D. J. (2001). The Use of Person-Group Fit for Employment Selection: A Missing Link in Person-Environment Fit. Human Resource Management, 40(3), 227-240. doi:10.1002/hrm.1013

Westerman, J. W., \& Cyr, L.A., (2004). An integrative analysis of person-organization fit theories. International Joumal of Selection and Assessment, 12(3), 252-261. doi: $10.1108 / 13620430710733631$

Wheeler, A. R., Gallagher, V. C., Brouer, R. L., \& Sablynski, C. J. (2007). When personorganization (mis)fit and (dis)satisfaction lead to turnover: The moderating role of perceived job mobility. Journal of Managerial Psychology, 22(2), 203-219. doi: $10.1108 / 02683940710726447$

Wheeler, A. R., Buckley, M. R., Halbesleben, J. R. B., Brouer, R. L., \& Ferris, G. R. (2005). "The elusive criterion of fit" revisited: Toward an integrative theory of multidimensional fit. US: Elsevier Science/JAI Press. doi: 10.1016/S0742$7301(05) 24007-0$

Wyman (2011). Recent trends in Canada's labour force participation rate. Canadian Economic Observer, Vol 24 no12, Section 3. Statistics Canada catalogue number 11-010-X December 2011. Accessed from http://www.statcan.gc.ca/pub/11-010x/2011012/part-partie3-eng.htm. Monthly 


\section{Appendix A}

\section{List of Surveyed Occupations}

\begin{tabular}{l}
\hline \multicolumn{1}{c}{ Army Occupations } \\
\hline 00179 - Artillery Officer \\
00187 - Electrical and Mechanical Engineering Officer \\
00181 - Engineer Officer \\
00180 - Infantry Officer \\
00341 - Signals Officer \\
00008 - Artillery Soldier (Field) \\
00005 - Crewman \\
00327 - Electronic-Optronic Technician \\
00238 - Geomatics Technician \\
00110 - Land Communication and Information Systems Specialist \\
00329 - Signals Operator \\
00129 - Vehicle Technician
\end{tabular}

Navy Occupations

00207 - Maritime Surface and Subsurface Officer

00345 - Marine Systems Engineering Officer

00346 - Naval Engineering Officer

00344 - Naval Combat Systems Engineering Officer

00121 - Marine Engineering Mechanic

00116 - Naval Electronics Technician (Sonar)

00117 - Naval Electronics Technician (Communications)

00118 - Naval Electronics Technician (Radar)

00165 - Steward

\section{Air Force Occupations}

00340 - Communications and Electronics Engineering Officer

00189 - Construction Engineering Officer

00109 - Aerospace Telecommunication and Information Systems Technician

00303 - Electrical Generating Systems Technician

00307 - Construction Technician

Health Services Occupations

00197 - Bioscience Officer

00191 - Dentist

00192 - Health Care Administration Officer

00193 - Hospital Services Officer

00196 - Medical Officer

00195 - Nurse

00194 - Pharmacist

00190 - Physiotherapist

00198 - Social Worker

00155 - Biomedical Electronics Technologist

00335 - Dental Technician

00334 - Medical Technician 
00152 - Medical Laboratory Technologist

00153 - Medical Radiation Technologists

\section{Support Occupations}

00328 - Logistics Officer

00169 - Ammunition Technician

00164 - Cook

00171 - Mobile Support Equipment Operator

00298 - Resource Management Support Clerk

00168 - Supply Technician

00170 - Traffic Technician 


\title{
Appendix B \\ Information/Consent Sheet with Ethics Approval
}

\author{
Canadian Forces Retention Survey
}

Questionnaire

\section{Purpose:}

The retention of highly trained and experienced Canadian Forces (CF) personnel is fundamental to operational capability, military professionalism and efficient personnel management. The purpose of this survey is to obtain the opinion of service members, like you, to explore factors of personnel retention in the $\mathrm{CF}$. At the request of your Branch Advisor, this survey has been initiated by the Director General Military Personnel Research and Analysis (DGMPRA) to determine what your concerns are about your work and the organization. The survey responses will be analyzed in an aggregated format and used for developing retention initiatives.

\section{Your Participation is important:}

- Your participation in completing this questionnaire, or any specific question, is voluntary. However, if the questionnaire is to provide a true picture of the organizational climate, the participation of everyone who receives a questionnaire is very important.

- $\quad$ Recognizing the importance of the questionnaire, the Branch Advisor(s) has authorized completion of this questionnaire during work hours, should you so wish.

- $\quad$ For the results to be useful, it is critical that your answers be honest and accurate in reflecting your beliefs and feelings.

- While the questionnaire may seem lengthy, all components are essential and you will find that most are quick and simple to answer.

- In order for us to get your responses, it is necessary to complete the survey once you start it. Please set aside about 40 to 50 minutes to complete the survey. Thank you for your time.

\section{Ethics and Guarantee of Confidentiality:}

This survey is anonymous; you are not required to record either your name or service number. Further, no demographic information will be used to identify individuals. Prior to releasing any research information in response to request made under the Access to Information Act, the Director of Access to Information and Privacy (DAIP) screens the data to ensure that individual identities are not disclosed. 
Director General Military Personnel Research and Analysis authorizes the administration of this survey within DND/CF in accordance with CANFORGEN 198/08 CMP 084/08 271214Z Oct 08. Authorization number 824/09. The opinions expressed in this document are those of the author and are not necessarily those of the Department of National Defence or the Canadian Forces.

I recognize that:

1. My participation in this survey is voluntary and I can at any time decide not to complete the questionnaire without having to explain why to anyone.

2. There will be no personal consequences to my career or my job whether I decide to participate in this survey or not.

3. The information that I provide will be kept confidential at all times.

If you have any questions or concerns, please email +DGMPRA CF Surveys@CMP DGMPRA@Ottawa-Hull

Thank you very much for your participation! 


\section{Appendix C}

\section{Measures}

\section{Person-Organization Fit}

\begin{tabular}{|c|c|c|c|c|c|c|c|}
\hline \multicolumn{8}{|c|}{$\begin{array}{l}\text { PLEASE INDICATE YOLR DEGREE OF AGREEMENT WITH EACH OF THE FOLLLOWING } \\
\text { STATEMENTS: }\end{array}$} \\
\hline 1 & 2 & 3 & 4 & \multicolumn{3}{|c|}{5} & 6 \\
\hline $\begin{array}{l}\text { STRONGLY } \\
\text { DISAGREE }\end{array}$ & DisaGree & $\begin{array}{l}\text { SOMEWHAT } \\
\text { DISAGREE }\end{array}$ & $\begin{array}{l}\text { SOMEWHAT } \\
\text { AGREE }\end{array}$ & \multicolumn{3}{|c|}{ AGREE } & $\begin{array}{l}\text { STRONGLY } \\
\text { AGREE }\end{array}$ \\
\hline \multicolumn{5}{|c|}{$\begin{array}{l}\text { The CF values, as expressed in military ethos, have a great deal } \\
\text { of personal meaning for me. }\end{array}$} & & 2 & $\begin{array}{llll}3 & 4 & 5 & 6\end{array}$ \\
\hline \multicolumn{5}{|c|}{ I feel like I fit into the $C F$. } & & 2 & \begin{tabular}{|lllll}
3 & 4 & 5 & 6 \\
\end{tabular} \\
\hline \multicolumn{5}{|c|}{ I fit with the CF's culture. } & & 2 & \begin{tabular}{|llll}
3 & 4 & 5 & 6 \\
\end{tabular} \\
\hline
\end{tabular}

\section{Person-Occupation Fit}

\begin{tabular}{|c|c|c|c|c|c|}
\hline \multicolumn{6}{|c|}{$\begin{array}{l}\text { PLEASE INDICATE YOLR DEGREE OF AGREEMENT WITH EACH OF THE FOLLOWING } \\
\text { STATEMENTS: }\end{array}$} \\
\hline 1 & 2 & 3 & \multicolumn{2}{|c|}{4} & 5 \\
\hline $\begin{array}{l}\text { STRO } \\
\text { NGLY } \\
\text { DISAGREE }\end{array}$ & $\begin{array}{l}\text { SOMEWHAT } \\
\text { DISAGREE }\end{array}$ & $\begin{array}{l}\text { NEITHER } \\
\text { AGREE OR } \\
\text { DISAGREE }\end{array}$ & \multicolumn{2}{|c|}{$\begin{array}{l}\text { SOMEWHAT } \\
\text { AGREE }\end{array}$} & $\begin{array}{l}\text { STRONGLY } \\
\text { AGREE }\end{array}$ \\
\hline \multicolumn{4}{|c|}{ My job is a good fit with my skills and interests } & 1 & $\begin{array}{llll}2 & 3 & 4 & 5\end{array}$ \\
\hline \multicolumn{4}{|c|}{ I feel my occupation is still a good fit for me } & & 2345 \\
\hline \multicolumn{4}{|c|}{$\begin{array}{l}\text { I would leave my occupation if given the opportunity to } \\
\text { transfer to a different one }\end{array}$} & 1 & $\begin{array}{lll}3 & 4 & 5\end{array}$ \\
\hline
\end{tabular}

\section{Organizational Commitment}

\begin{tabular}{|c|c|c|c|c|c|c|c|c|c|}
\hline \multicolumn{10}{|c|}{$\begin{array}{l}\text { PLEASE INDICATE YOUR DEGREE OF AGREEMENT WITH EACH OF THE FOLLOWING } \\
\text { STATEMENTS: }\end{array}$} \\
\hline 1 & 2 & 3 & 4 & \multicolumn{3}{|c|}{5} & \multicolumn{3}{|c|}{6} \\
\hline $\begin{array}{l}\text { STRONGLY } \\
\text { DISAGREE }\end{array}$ & DISAGREE & $\begin{array}{l}\text { SOMEWHAT } \\
\text { DISAGREE }\end{array}$ & $\begin{array}{l}\text { SOMEWHAT } \\
\text { AGREE }\end{array}$ & \multicolumn{2}{|c|}{ AGREE } & & \multicolumn{3}{|c|}{$\begin{array}{l}\text { STRONGLY } \\
\text { AGREE }\end{array}$} \\
\hline \multicolumn{10}{|c|}{ AFFECTIVE COMMITMENT } \\
\hline \multicolumn{5}{|c|}{ I would be happy to spend the rest of my career in the CF. } & & & 3 & 45 & \\
\hline \multicolumn{5}{|c|}{ I really feel as if the CF"s problems are my own. } & & 2 & 3 & 45 & 6 \\
\hline \multicolumn{5}{|c|}{ I do not feel like "part of the family" in the CF. } & & 2 & 3 & 45 & 6 \\
\hline \multicolumn{5}{|c|}{ I do not feel "emotionally attached" to the CF. } & & 2 & 3 & 45 & \\
\hline \multicolumn{5}{|c|}{ The CF has a great deal of personal meaning for me. } & & 2 & & 45 & \\
\hline \multicolumn{5}{|c|}{ I do not feel a strong sense of "belonging" to the $\overline{C F}$. } & & 2 & 3 & 45 & \\
\hline \multicolumn{5}{|c|}{ NORMATIVE COMMITMENT } & & 2 & 3 & 45 & \\
\hline \multicolumn{5}{|c|}{ I do not feel any obligation to remain with the $\mathrm{CF}$. } & & 2 & & 45 & \\
\hline \multicolumn{5}{|c|}{$\begin{array}{l}\text { Even if it was to my advantage, I do not feel it would be right to } \\
\text { leave the CF now. }\end{array}$} & & 2 & 3 & 45 & \\
\hline \multicolumn{5}{|c|}{ I would feel guilty if I left the CF now. } & & 2 & 3 & 45 & 56 \\
\hline
\end{tabular}




\begin{tabular}{|c|c|c|c|c|c|c|}
\hline The CF deserves my loyalty. & & 23 & 3 & 4 & 5 & 6 \\
\hline $\begin{array}{l}\text { I would not leave the CF right now because I have a sense of } \\
\text { obligation to the people in my unit. }\end{array}$ & 1 & 23 & 3 & 4 & & 6 \\
\hline I owe a great deal to the CF. & 1 & 23 & 3 & 4 & & 6 \\
\hline CONTINLANCE COMMITMENT & 1 & 2 & 3 & 4 & & 6 \\
\hline $\begin{array}{l}\text { It would be hard for me to leave the CF right now, even if I } \\
\text { wanted to. }\end{array}$ & 1 & 2 & 3 & 4 & & 6 \\
\hline $\begin{array}{l}\text { Too much of my life would be disrupted if I decided to leave the } \\
\text { CF now. }\end{array}$ & 1 & 2 & 3 & 4 & & 6 \\
\hline $\begin{array}{l}\text { Right now, staying with the CF is a matter of necessity as much } \\
\text { as desire. }\end{array}$ & 1 & 2 & 3 & 4 & & 6 \\
\hline I feel that I have too few options to consider leaving the CF. & 1 & 2 & 3 & 4 & & 6 \\
\hline $\begin{array}{l}\text { If I had not already put so much of myself into the CF, I might } \\
\text { consider working elsewhere }\end{array}$ & 1 & 2 & 3 & 4 & & 6 \\
\hline
\end{tabular}

\section{Turnover Intention}

\begin{tabular}{|l|c|c|c|c|}
\hline Do you intend to leave the CF within a year? \\
\hline Definitely Not & Probably Not & Uncertain & Probably & Definitely \\
1 & 2 & 3 & 4 & 5 \\
\hline
\end{tabular}

\section{Psychological Withdrawal}

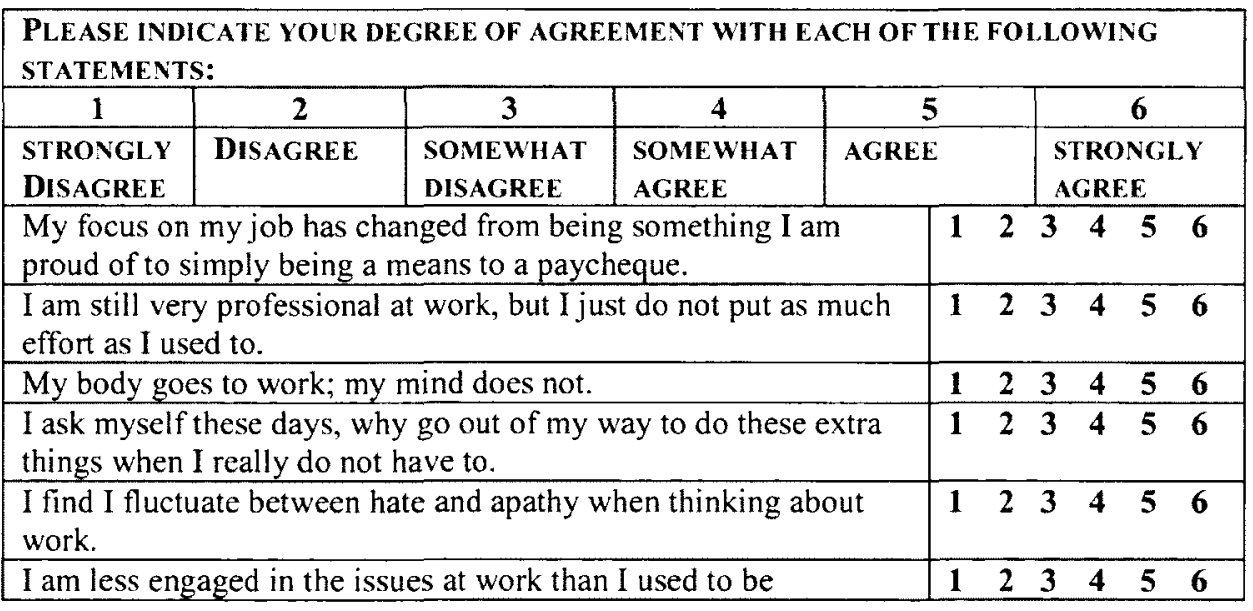




\section{Perceived Organizational Support}

\begin{tabular}{|c|c|c|c|c|c|c|c|c|c|c|}
\hline \multicolumn{11}{|c|}{$\begin{array}{l}\text { PLEASE INDICATE YOLR DEGREE OF AGREEMENT WITH EACH OF THE FOLLOWIYG } \\
\text { STATEMENTS: }\end{array}$} \\
\hline 1 & 2 & 3 & 4 & \multicolumn{3}{|c|}{5} & \multicolumn{4}{|c|}{6} \\
\hline $\begin{array}{l}\text { STRONGLY } \\
\text { DISAGREE }\end{array}$ & DISAGREE & $\begin{array}{l}\text { SOMEWHAT } \\
\text { DISAGREF. }\end{array}$ & $\begin{array}{l}\text { SOMEWHAT } \\
\text { AGREE }\end{array}$ & \multicolumn{3}{|c|}{ AGREE } & \multicolumn{4}{|c|}{$\begin{array}{l}\text { STRONGLY } \\
\text { AGREE }\end{array}$} \\
\hline \multicolumn{5}{|c|}{ Help is available from the CF when I have a problem } & 1 & 2 & 3 & 4 & 5 & \\
\hline \multicolumn{5}{|c|}{ The CF tries to make my job as interesting as possible } & 1 & 2 & 3 & 4 & 5 & 6 \\
\hline \multicolumn{5}{|c|}{ The CF would ignore any complaint by me } & 1 & 2 & 3 & 4 & 5 & 6 \\
\hline \multicolumn{5}{|c|}{ The CF fails to appreciate any extra effort from me } & 1 & 2 & 3 & 4 & 5 & 6 \\
\hline \multicolumn{5}{|c|}{ The CF strongly considers my goals and values } & 1 & 2 & 3 & 4 & 5 & $\underline{6}$ \\
\hline \multicolumn{5}{|c|}{ The CF really cares about my well being } & 1 & 2 & 3 & 4 & 5 & $\overline{6}$ \\
\hline \multicolumn{5}{|c|}{ If given the opportunity, the $C F$ would take advantage of me } & 1 & 2 & 3 & 4 & 5 & 6 \\
\hline \multicolumn{5}{|c|}{ Even if I did the best possible job, the CF would fail to notice me } & 1 & 2 & 3 & 4 & 5 & 6 \\
\hline \multicolumn{5}{|c|}{ The CF would take care of me if I became injured or ill } & 1 & 2 & 3 & 4 & 5 & 6 \\
\hline
\end{tabular}

\section{Perceived Alternatives}

How easy would it be for you to find a good job with another employer?

\begin{tabular}{|c|c|c|c|c|}
\hline Very difficult & Difficult & Easy & Very Easy & Do not know \\
\hline 1 & 2 & 3 & 4 & 5 \\
\hline
\end{tabular}




\section{Appendix D}

\section{Demographic Questions}

I What is your age?

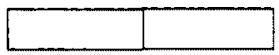

2 What is your gender?

口...Male

口...Female

3 Which environment uniform do you currently wear?

$$
\begin{aligned}
& \square \text { Sea } \\
& \square \text { Land } \\
& \square \text { Air }
\end{aligned}
$$

4 What is your occupation? (Listed as per Appendix A)

5 How many years have you served in the CF: (e.g2 years and 5 months, combined Regular and Reserve Force)?

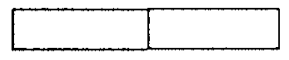

6 What is your rank?

$\square \mathrm{PTET} / \mathrm{OS} / \mathrm{AB}$
$\square \mathrm{PTEB} / \mathrm{OS} / \mathrm{AB}$
$\square \mathrm{Cpl} / \mathrm{LS}$
$\square \mathrm{MCpl} / \mathrm{MS}$
$\square \mathrm{Sgt} / \mathrm{PO} 2$
$\square \mathrm{WO} / \mathrm{PO} 1$
$\square \mathrm{MWO} / \mathrm{CPO} 2$
$\square \mathrm{CWO} / \mathrm{CPO} 1$

\begin{tabular}{ll}
\hline & Ocdt/NCdt \\
$\square$ & $2 \mathrm{Lt} / \mathrm{ASLt}$ \\
$\square$ & $\mathrm{Lt} / \mathrm{SLt}$ \\
$\square$ & $\mathrm{Capt} / \mathrm{Lt}(\mathrm{N})$ \\
$\square$ & $\mathrm{Maj} / \mathrm{LCdr}$ \\
$\square$ & $\mathrm{LCol} / \mathrm{Cdr}$ \\
$\square$ & $\mathrm{Col} / \mathrm{Capt}(\mathrm{N})$ \\
$\square$ & $\mathrm{Gen} / \mathrm{Flag}$ Offr
\end{tabular}

8 What is your first official language?

ㅁ. English

F French 
9 What is your highest level of education?

a Some high school

- High school graduate (including GED)

- Some college (including CEGEP)

College graduate (including CEGEP)

a Some university

U Undergraduate degree

G Graduate degree courses

$\square$ Graduate degree

11 What is your marital status?

口 Married / Common Law / Partner

(a) Single

a Separated / Divorced

$\square$ Widowed 


\section{Appendix E}

\section{Civilian Equivalence for Surveyed Occupations}

\begin{tabular}{|c|c|}
\hline \multicolumn{2}{|l|}{ Army Occupations } \\
\hline Officer & $\begin{array}{l}\text { Civilian } \\
\text { Equivalence }\end{array}$ \\
\hline 00179 Artillery Officer & 1 \\
\hline $\begin{array}{l}00187 \text { Electrical and Mechanical Engineering } \\
\text { Officer }\end{array}$ & 2 \\
\hline 00181 Engineer Officer & 2 \\
\hline 00180 Infantry Officer & 1 \\
\hline 00341 Signals Officer & 1 \\
\hline \multicolumn{2}{|l|}{ Noncommissioned } \\
\hline 00008 Artillery Soldier (Field) & 1 \\
\hline 00005 Crewman & 1 \\
\hline 00327 Electronic-Optronic Technician & 2 \\
\hline 00238 Geomatics Technician & 2 \\
\hline $\begin{array}{l}00110 \text { Land Communication and Information } \\
\text { Systems Specialist }\end{array}$ & $2^{4}$ \\
\hline 00329 Signals Operator & 1 \\
\hline 00129 Vehicle Technician & 2 \\
\hline \multicolumn{2}{|l|}{ Navy Occupations } \\
\hline \multicolumn{2}{|l|}{ Officer } \\
\hline 00207 Maritime Surface and Subsurface Officer & 1 \\
\hline 00345 Marine Systems Engineering Officer & 1 \\
\hline 00346 Naval Engineering Officer & 1 \\
\hline 00344 Naval Combat Systems Engineering Officer & 1 \\
\hline \multicolumn{2}{|l|}{ Noncommissioned } \\
\hline 00121 Marine Engineering Mechanic & 2 \\
\hline 00116 Naval Electronics Technician (Sonar) & $2^{5}$ \\
\hline $\begin{array}{l}00117 \begin{array}{l}\text { Naval Electronics Technician } \\
\text { (Communications) }\end{array}\end{array}$ & 2 \\
\hline 00118 Naval Electronics Technician (Radar) & 2 \\
\hline 00165 Steward & 2 \\
\hline
\end{tabular}

${ }^{4}$ Occupation renamed to Army Communication Systems Specialist

${ }^{5}$ Naval Electronics, Sonar, Communications and Radar technicians combined and renamed Weapons Engineering Technicians. 


\begin{tabular}{|c|c|c|}
\hline \multicolumn{3}{|c|}{ Air Force Occupations } \\
\hline Officer & & $\begin{array}{l}\text { Civilian } \\
\text { Equivalence }\end{array}$ \\
\hline & $\begin{array}{l}00340 \text { Communications and Electronics } \\
\text { Engineering Officer }\end{array}$ & 1 \\
\hline & 00189 Construction Engineering Officer & 2 \\
\hline \multicolumn{3}{|c|}{ Noncommissioned } \\
\hline & $\begin{array}{l}00109 \text { Aerospace Telecommunication and } \\
\text { Information Systems Technician }\end{array}$ & 2 \\
\hline & $0030 \quad$ Electrical Generating Systems Technician & 2 \\
\hline & 00307 Construction Technician & 2 \\
\hline \multicolumn{3}{|c|}{ Health Services Occupations } \\
\hline \multicolumn{3}{|l|}{ Officer } \\
\hline & 00197 Bioscience Officer & 1 \\
\hline & 00191 Dentist & 2 \\
\hline & 00192 Health Care Administration Officer & 2 \\
\hline & 00193 Hospital Services Officer & 2 \\
\hline & 00196 Medical Officer & 2 \\
\hline & 00195 Nurse & 2 \\
\hline & 00194 Pharmacist & 2 \\
\hline & 00190 Physiotherapist & 2 \\
\hline & 00198 Social Worker & 2 \\
\hline \multicolumn{3}{|c|}{ Noncommissioned } \\
\hline & 00155 Biomedical Electronics Technologist & 2 \\
\hline & 00335 Dental Technician & 2 \\
\hline & 00334 Medical Technician & 2 \\
\hline & 00152 Medical Laboratory Technologist & 2 \\
\hline & 00153 Medical Radiation Technologists & 2 \\
\hline \multicolumn{3}{|c|}{ Support Occupations } \\
\hline \multicolumn{3}{|l|}{ Officer } \\
\hline & 00328 Logistics Officer & 1 \\
\hline \multicolumn{3}{|c|}{ Noncommissioned } \\
\hline & 00169 Ammunition Technician & 2 \\
\hline & 00164 Cook & 2 \\
\hline & 00171 Mobile Support Equipment Operator & 2 \\
\hline & 00298 Resource Management Support Clerk & 2 \\
\hline & 00168 Supply Technician & 2 \\
\hline & 00170 Traffic Technician & 2 \\
\hline
\end{tabular}

Note: Coding Legend 1 = no related civilian occupations, $2=$ one or more related civilian occupations. Information derived from www. forces.gc.ca fact sheets. 


\section{Appendix F}

Gender and Occupation Distribution for Officers

\begin{tabular}{|c|c|c|c|c|c|c|}
\hline \multirow[t]{2}{*}{ Occupations } & \multirow[t]{2}{*}{$\mathrm{N}$} & \multirow[t]{2}{*}{$\%$} & \multicolumn{2}{|c|}{ Males } & \multicolumn{2}{|c|}{ Females } \\
\hline & & & $N$ & $\%$ & $\mathrm{~N}$ & $\%$ \\
\hline Artillery & 188 & 3.1 & 184 & 97.4 & 4 & 2.1 \\
\hline $\begin{array}{l}\text { Electrical and Mechanical } \\
\text { Engineering }\end{array}$ & 166 & 2.7 & 156 & 94.0 & 10 & 6.0 \\
\hline Engineer & 135 & 2.2 & 129 & 95.6 & 6 & 4.4 \\
\hline Infantry & 184 & 3.0 & 178 & 96.7 & 5 & 2.7 \\
\hline Signals & 194 & 3.1 & 180 & 92.8 & 14 & 7.2 \\
\hline $\begin{array}{l}\text { Maritime Surface and } \\
\text { Subsurface }\end{array}$ & 176 & 2.8 & 140 & 79.5 & 36 & 20.5 \\
\hline $\begin{array}{l}\text { Marine Systems } \\
\text { Engineering }\end{array}$ & 97 & 1.6 & 82 & 84.5 & 15 & 15.5 \\
\hline Naval Engineering & 29 & .5 & 29 & 100 & 0 & 0.0 \\
\hline $\begin{array}{l}\text { Naval Combat Systems } \\
\text { Engineering }\end{array}$ & 102 & 1.7 & 95 & 93.1 & 7 & 6.9 \\
\hline $\begin{array}{l}\text { Communications and } \\
\text { Electronics Engineering }\end{array}$ & 164 & 2.7 & 134 & 81.7 & 30 & 18.3 \\
\hline Engineering & 135 & 2.2 & 111 & 82.2 & 24 & 17.8 \\
\hline Bioscience & 21 & .3 & 16 & 76.2 & 5 & 23.8 \\
\hline Dentist & 66 & 1.1 & 40 & 60.6 & 26 & 39.4 \\
\hline $\begin{array}{l}\text { Health Care } \\
\text { Administration }\end{array}$ & 51 & .8 & 30 & 58.8 & 21 & 41.2 \\
\hline Hospital Services Officer & 30 & .5 & 21 & 70.0 & 9 & 30.0 \\
\hline Medical Officer & 72 & 1.2 & 47 & 65.3 & 23 & 31.9 \\
\hline Nurse & 69 & 1.1 & 18 & 26.1 & 51 & 73.9 \\
\hline Pharmacist & 24 & .4 & 13 & 54.2 & 10 & 41.7 \\
\hline Physiotherapist & 8 & .1 & 6 & 75.0 & 25 & 2.5 \\
\hline Social Worker & 19 & .3 & 6 & 31.6 & 13 & 68.4 \\
\hline Logistics Officer & 570 & 9.2 & 382 & 67.0 & 188 & 33.0 \\
\hline Total Officer & 2501 & 40.5 & 1915 & 79.8 & 479 & 20.0 \\
\hline
\end{tabular}




\section{Appendix G}

\section{Gender and Occupation Distribution for Noncommissioned Members}

\begin{tabular}{|c|c|c|c|c|c|c|}
\hline Occupations & $\mathrm{N}$ & $\%$ & \multicolumn{2}{|c|}{ Males } & \multicolumn{2}{|c|}{ Females } \\
\hline & & & $\mathrm{N}$ & $\%$ & $\mathrm{~N}$ & $\%$ \\
\hline Artillery Soldier (Field) & 84 & 1.4 & 78 & 92.9 & 6 & 7.1 \\
\hline Crewman & 134 & 2.2 & 129 & 96.3 & 5 & 3.7 \\
\hline Electronic-Optronic Technician & 114 & 1.8 & 107 & 93.9 & 6 & 5.3 \\
\hline Geomatics Technician & 57 & .9 & 45 & 78.9 & 11 & 19.3 \\
\hline $\begin{array}{l}\text { Land Communication and } \\
\text { Information Systems Specialist }\end{array}$ & 259 & 4.2 & 234 & 90.3 & 22 & 8.5 \\
\hline Signals Operator & 275 & 4.5 & 245 & 89.1 & 29 & 10.5 \\
\hline Vehicle Technician & 111 & 1.8 & 103 & 92.8 & 7 & 6.3 \\
\hline $\begin{array}{l}\text { 00121 - Marine Engineering } \\
\text { Mechanic }\end{array}$ & 22 & 0.4 & 18 & 81.8 & 4 & 18.2 \\
\hline $\begin{array}{l}\text { 00116- Naval Electronics } \\
\text { Technician (Sonar) }\end{array}$ & 36 & 0.6 & 34 & 94.4 & 2 & 5.6 \\
\hline $\begin{array}{l}00117 \text { - Naval Electronics } \\
\text { Technician (Communications) }\end{array}$ & 59 & 1.0 & 58 & 98.3 & 1 & 1.7 \\
\hline $\begin{array}{l}00118 \text { - Naval Electronics } \\
\text { Technician (Radar) }\end{array}$ & 79 & 1.3 & 75 & 94.9 & 3 & 3.38 \\
\hline $\begin{array}{l}00165 \text { - Steward } \\
00109 \text { - Aerospace }\end{array}$ & 54 & .9 & 47 & 87.0 & 7 & 13.0 \\
\hline $\begin{array}{l}\text { Telecommunication and } \\
\text { Information Systems Technician }\end{array}$ & 228 & 3.7 & 200 & 87.7 & 25 & 11.0 \\
\hline $\begin{array}{l}00303 \text { - Electrical Generating } \\
\text { Systems Technician }\end{array}$ & 63 & 1.0 & 61 & 61.8 & 2 & 3.2 \\
\hline 00307 - Construction Technician & 78 & 1.3 & 78 & 100.0 & 0 & 0.0 \\
\hline $\begin{array}{l}\text { 00155-Biomedical Electronics } \\
\text { Technologist }\end{array}$ & 6 & .1 & 5 & 83.3 & 1 & 16.7 \\
\hline 00335 - Dental Technician & 60 & 1.0 & 13 & 21.7 & 47 & 78.3 \\
\hline 00334 - Medical Technician & 207 & 3.3 & 122 & 58.9 & 84 & 40.6 \\
\hline $\begin{array}{l}00152 \text { - Medical Laboratory } \\
\text { Technologist }\end{array}$ & 11 & .2 & 5 & 45.5 & 6 & 54.5 \\
\hline $\begin{array}{l}\text { 00153 - Medical Radiation } \\
\text { Technologists }\end{array}$ & 10 & .2 & 5 & 50.0 & 5 & 50.0 \\
\hline 00169 - Ammunition Technician & 64 & 1.0 & 60 & 93.8 & 4 & 6.3 \\
\hline $00164-$ Cook & 165 & 2.7 & 140 & 84.8 & 25 & 15.2 \\
\hline $\begin{array}{l}\text { 00171 - Mobile Support } \\
\text { Equipment Operator }\end{array}$ & 240 & 3.9 & 208 & 86.7 & 31 & 12.9 \\
\hline $\begin{array}{l}00298 \text { - Resource Management } \\
\text { Support Clerk }\end{array}$ & 633 & 10.2 & 289 & 45.7 & 342 & 54.0 \\
\hline 00168 - Supply Technician & 491 & 7.9 & 354 & 72.1 & 133 & 27.1 \\
\hline 00170 - Traffic Technician & 140 & 2.3 & 105 & 75.0 & 35 & 25.0 \\
\hline $\begin{array}{l}\text { Total Noncommissioned } \\
\text { Members }\end{array}$ & 3680 & 59.5 & 900 & 76.7 & 863 & 22.8 \\
\hline
\end{tabular}




\section{Appendix H}

\section{Summary Tables for Correlations, Means and Standard Deviations for Cross Validation}

\section{Table 14}

Correlations, Means, and Standard Deviations - $20 \%$ Sample

\begin{tabular}{|c|c|c|c|c|c|c|c|c|c|c|c|c|}
\hline Variables & 1 & 2 & 3 & 4 & 5 & 6 & 7 & 8 & 9 & 10 & 11 & 12 \\
\hline \multicolumn{13}{|l|}{1 Gender $^{\mathrm{a}}$} \\
\hline 2 Years of Service & $-.21^{* *}$ & & & & & & & & & & & \\
\hline 3 Education & $.08^{*}$ & $-.10^{* *}$ & & & & & & & & & & \\
\hline 4 Affective Commitment & -.03 & $.11^{* *}$ & .03 & & & & & & & & & \\
\hline 5 Continuance Commitment & .02 & -.06 & $-.17^{* *}$ & .03 & & & & & & & & \\
\hline 6 Normative Commitment & .03 & .02 & -.01 & $.63^{* *}$ & $.23^{* *}$ & & & & & & & \\
\hline 7 Perceived Organization Support & -.01 & $.08^{*}$ & -.02 & $.56^{* *}$ & -.03 & $.55^{* *}$ & & & & & & \\
\hline 8 Psychological Withdrawal & .01 & $-.09^{*}$ & -.07 & $-.60^{* *}$ & $.13^{* *}$ & $-.48^{* *}$ & $-.57^{* *}$ & & & & & \\
\hline 9 Person-Organization Fit & -.03 & $.14^{* *}$ & .00 & $.71^{* *}$ & -.01 & $.56^{* *}$ & $.53^{* *}$ & $-.58^{* *}$ & & & & \\
\hline 10 Person-Occupation Fit & -.01 & $.11^{* *}$ & .04 & $.42^{* *}$ & $-.09^{*}$ & $.36^{* *}$ & $.39^{* *}$ & $-.54^{* *}$ & $.41^{* *}$ & & & \\
\hline 11 Turnover Intention & -.02 & $.18^{* *}$ & $-.09^{*}$ & $-.35^{* *}$ & $-.24^{* *}$ & $-.38^{* *}$ & $-.25^{* *}$ & $.31^{* *}$ & $-.30^{* *}$ & $-.23^{* *}$ & & \\
\hline 12 Perceived Job Alternatives & .06 & .03 & .03 & .04 & $-.08^{*}$ & .04 & .03 & -.05 & .04 & .03 & -.01 & \\
\hline 13 Civilian Equivalence ${ }^{b}$ & & .04 & $.37^{* *}$ & .07 & -.05 & .03 & .02 & -.03 & .04 & -.03 & -.07 & .00 \\
\hline 14 Rank $^{c}$ & & .01 & $.77^{* *}$ & .04 & $-.15^{* *}$ & -.00 & .01 & -.05 & .01 & .06 & -.07 & .02 \\
\hline Mean & & 17.75 & 4.33 & 4.34 & 3.32 & 3.42 & 3.86 & 2.70 & 4.70 & 3.71 & 1.83 & 3.67 \\
\hline $\mathrm{SD}$ & & 9.01 & 1.13 & .96 & 1.09 & 1.03 & .91 & 1.27 & .92 & .98 & 1.16 & .95 \\
\hline
\end{tabular}

Notes: $N=1266-1270^{\mathrm{a}}$ Gender (Males $=0$, Females $\left.=1\right)^{\mathrm{b}} \mathrm{Civilian}$ Equivalence $(\text { no equivalence }=0 \text {, equivalence }=1)^{\mathrm{c}} \mathrm{Rank}$ (Noncommissioned member $=0$ Officer $=1$ )

$* p<.01 . * * p<.0001$. 


\section{Table 15}

\section{Correlations, Means, and Standard Deviations - 20\% Sample for Noncommissioned Members and Officers}

\begin{tabular}{|c|c|c|c|c|c|c|c|c|c|c|c|c|c|c|c|c|c|}
\hline & $\mathrm{M}$ & SD & 1 & 2 & 3 & $\overline{4}$ & 5 & $\overline{6}$ & 7 & 8 & $\overline{9}$ & 10 & $\pi$ & 12 & 13 & $\bar{M}$ & SD \\
\hline 1 Gender & 1.23 & 0.42 & & $-.19^{* *}$ & .06 & -.07 & .00 & .01 & .07 & .05 & -.06 & .02 & .00 & .07 & & 1.20 & 0.40 \\
\hline ervice & 17.66 & 9.02 & $-.21^{* *}$ & & $-.10^{*}$ & $.10^{*}$ & -.02 & .04 & -.03 & .02 & $.12^{* *}$ & .05 & $.22^{* *}$ & .04 & .07 & 17.88 & 9.01 \\
\hline 3 Education & 3.00 & 1.34 & $.23^{*}$ & $-.22^{* *}$ & & .02 & $-.19^{* *}$ & .02 & .01 & $-.16^{* *}$ & .06 & $.12^{* *}$ & -.05 & .08 & $-.09^{*}$ & 6.37 & 1.34 \\
\hline 4 Affective Commitment & 4.31 & 0.98 & -.01 & $.12^{* *}$ & -.04 & & -.02 & $.61^{* *}$ & $.50^{* *}$ & $-.57^{* *}$ & $.70^{* *}$ & $.45^{* *}$ & $-.32^{* *}$ & .04 & $.10^{\circ}$ & 4.40 & 0.93 \\
\hline 5 Continua & 3.45 & 1.08 & .03 & $-.09^{*}$ & -.02 & .07 & & $.19^{* *}$ & -.08 & $.17^{* *}$ & -.04 & $-.14^{* *}$ & $-.22^{* *}$ & $-.10^{\circ}$ & $.12^{*}$ & 3.13 & 1.07 \\
\hline 6 Normative Commitment & 3.42 & 1.05 & .06 & .01 & -.03 & $.65^{* *}$ & $.25^{* *}$ & & $.51^{* *}$ & $-.47^{* *}$ & $.55^{* *}$ & $.41^{* *}$ & $-.35^{* *}$ & .04 & .07 & 3.42 & 1.02 \\
\hline 7 Organizat & 3.85 & 0.93 & .02 & $.14^{* *}$ & -.06 & $.60^{\prime *}$ & -.01 & $.58^{* *}$ & & $-.52^{* *}$ & $.51^{* *}$ & $.38^{* *}$ & $-.22^{* *}$ & .01 & .08 & 3.86 & 0.89 \\
\hline 8 Psychological Withdrawal & 2.75 & 1.27 & -.02 & $-.15^{* *}$ & .03 & $-.62^{* *}$ & $.10^{*}$ & $-.50^{* *}$ & $-.60^{* *}$ & & $-.58^{* *}$ & $-.57^{* *}$ & $.29^{* *}$ & -.05 & -.06 & 2.61 & 1.26 \\
\hline 9 Person-Orgat & 4.68 & 0.94 & -.02 & $.15^{* *}$ & -.06 & $.72^{* *}$ & .01 & $.57^{* *}$ & $.55^{* *}$ & $-.59^{* *}$ & & $.48^{* *}$ & $-.25^{* *}$ & .04 & .05 & 4.71 & 0.88 \\
\hline 10 Person-Occupation Fit & 3.67 & 0.98 & -.01 & $.15^{* *}$ & $-.11^{*}$ & $.40^{* *}$ & -.05 & $.33^{* *}$ & $.40^{* *}$ & $-.51^{* *}$ & $.37^{* *}$ & & $-.27^{* *}$ & .03 & -.01 & 3.79 & 0.96 \\
\hline 11 Turnover Intention & 1.90 & 1.18 & -.04 & $.17^{* *}$ & -.05 & $-.37^{* *}$ & $-.27^{* *}$ & $-.40^{* *}$ & $-.27^{* *}$ & $.32^{* *}$ & $-.32^{* *}$ & $-.20^{* *}$ & & .03 & -.07 & 1.73 & 1.11 \\
\hline 12 Perceived Job Alternatives & 3.66 & 1.00 & .06 & .02 & -.01 & .04 & -.07 & .03 & .05 & -.05 & .04 & .02 & -.03 & & .01 & 3.70 & 0.86 \\
\hline 13 Civilian Equivalence & 1.13 & 0.34 & & .02 & $-.11^{*}$ & .01 & -.03 & .00 & -.02 & .04 & .03 & $-.14^{\prime \prime}$ & -.01 & -.03 & & 1.67 & 0.47 \\
\hline
\end{tabular}

Notes $V=769$ Noncommissioned members correlations shown below the diagonal, $N=497$ officers correlations shown above the diagonal Means and standard deviations for noncommissioned members displayed on the left side of the table Officer means and standard deviations are displayed on the right.

${ }^{*} p .05,{ }^{* *} p \ldots, 01,{ }^{* *} p<0001$. 
Appendix I

Summary Tables for Multiple Regression Analyses for Cross Validation Sample

Table 16 Cross Validation of Direct Effects of Person Occupation and Person Organization Fit

\begin{tabular}{|c|c|c|c|c|c|c|c|c|c|c|c|c|}
\hline & \multicolumn{6}{|c|}{ Noncommissioned Members } & \multicolumn{6}{|c|}{ Officers } \\
\hline & $B$ & $S E B$ & $\beta$ & $s r^{2}$ & $R^{2}$ & $f^{2}$ & $B$ & $S E B$ & $B$ & $s r^{2}$ & $R^{2}$ & $f^{2}$ \\
\hline Affective Commitment & & & & & $.54 * *$ & 1.17 & & & & & $.50^{* *}$ & 1.00 \\
\hline Years of Service & .00 & .00 & .01 & .00 & & & .00 & .00 & .01 & .00 & & \\
\hline Gender & -.00 & .06 & -.00 & .00 & & & -.03 & .08 & -.02 & .00 & & \\
\hline Education & .02 & .02 & .02 & .00 & & & -.03 & .02 & -.04 & .00 & & \\
\hline P-Org & $.70^{* *}$ & .03 & .67 & .38 & & & $.66^{* *}$ & .04 & .62 & .30 & & \\
\hline $\mathrm{P}-\mathrm{Occ}$ & $.15^{* *}$ & .03 & .15 & .02 & & & $.15^{* *}$ & .04 & .16 & .02 & & \\
\hline Normative Commitment & & & & & $.34 * *$ & .52 & & & & & $.32^{* *}$ & .47 \\
\hline Years of Service & -.01 & .00 & -.08 & .00 & & & -.00 & .00 & -.04 & .00 & & \\
\hline Gender & .13 & .08 & .05 & .00 & & & .05 & .10 & .02 & .00 & & \\
\hline Education & -.01 & .02 & -.01 & .00 & & & -.03 & .03 & -.04 & .00 & & \\
\hline P-Org & .59 & .04 & .52 & .24 & & & $.52 * *$ & .05 & .45 & .16 & & \\
\hline P-Occ & .15 & .03 & .14 & .02 & & & $.20^{* *}$ & .05 & .19 & .03 & & \\
\hline Turnover Intention & & & & & $.16^{* *}$ & .19 & & & & & $.15^{* *}$ & .18 \\
\hline Years of Service & $.03 * *$ & .01 & .23 & .05 & & & $.03 * *$ & .00 & .26 & .06 & & \\
\hline Gender & .03 & .01 & .01 & .00 & & & .10 & .12 & .04 & .00 & & \\
\hline Education & -.03 & .03 & -.03 & .00 & & & .01 & .06 & .01 & .00 & & \\
\hline P-Org & -.39 & .05 & -.31 & .08 & & & $-.22 * *$ & .06 & -.17 & .02 & & \\
\hline P-Occ & $-.14 *$ & .04 & -.12 & .01 & & & $-.22 * *$ & .06 & -.19 & .03 & & \\
\hline Psychological Withdrawal & & & & & $.45^{* *}$ & .82 & & & & & $.45^{* *}$ & .82 \\
\hline Years of Service & -.01 & .00 & -.05 & .00 & & & .01 & .01 & .08 & .00 & & \\
\hline Gender & -.10 & .09 & -.03 & .00 & & & .12 & .11 & .04 & .00 & & \\
\hline Education & -.04 & .03 & -.04 & .00 & & & -.07 & .03 & -.08 & .00 & & \\
\hline P-Org & -.62 & .04 & -.46 & .18 & & & $-.57^{* *}$ & .06 & -.40 & .12 & & \\
\hline $\mathrm{P}-\mathrm{Occ}$ & -.45 & .04 & -.35 & .10 & & & $-.48 * *$ & .05 & -.37 & .10 & & \\
\hline
\end{tabular}

Notes:,$V=765$ noncommissioned members. 495 Officers P-Org =Person-Organization Fit, P-Occ Fit = Person-Occupation fit

${ }^{*} p=01,{ }^{* *} p .0001$. 


\section{Table 17}

Cross Validation of Moderating Effects of Perceived Organizational Support on Affective Commitment

\begin{tabular}{|c|c|c|c|c|c|c|c|c|c|c|c|c|c|c|}
\hline \multirow{3}{*}{$\begin{array}{l}\text { Step and Variable } \\
\text { Step } 1\end{array}$} & \multicolumn{6}{|c|}{$\begin{array}{l}\text { Noncommissioned Members } \\
99 \% \mathrm{CI} \text { for } B\end{array}$} & \multirow[b]{2}{*}{$f^{2}$} & \multicolumn{7}{|c|}{$\begin{array}{l}\text { Officers } \\
99 \% \mathrm{Cl} \text { for } B\end{array}$} \\
\hline & $B$ & $S E B$ & $L L$ & $U L$ & $R^{2}$ & $\Delta R^{2}$ & & $B$ & $S E B$ & $L L$ & $U L$ & $R^{2}$ & $\Lambda R^{2}$ & $f^{2}$ \\
\hline & & & & & $.12^{*}$ & & .02 & & & & & .01 & & .01 \\
\hline Years of Service & $.01^{*}$ & .00 & .00 & .02 & & & & .01 & .00 & -.00 & .02 & & & \\
\hline Gender & .04 & .09 & -.18 & .27 & & & & -.01 & .11 & -.40 & .18 & & & \\
\hline Education & .02 & .02 & -.08 & .06 & & & & .02 & .03 & -.06 & .10 & & & \\
\hline Step 2 & & & & & $.59^{* *}$ & $.57^{* *}$ & 1.38 & & & & & $.52^{* *}$ & $.51^{* *}$ & 1.08 \\
\hline Years of Service & -.00 & .00 & -.01 & .01 & & & & .00 & .00 & -.01 & .01 & & & \\
\hline Gender & -.03 & .06 & -.17 & .12 & & & & -.01 & .07 & -.20 & .18 & & & \\
\hline Education & .02 & .02 & -.03 & .06 & & & & -.02 & .07 & -.08 & .04 & & & \\
\hline P-Org & $.57 * *$ & .03 & .49 & .64 & & & & $.58 * *$ & .04 & .47 & .68 & & & \\
\hline $\mathrm{P}-\mathrm{Occ}$ & $.10^{* *}$ & .03 & .03 & .17 & & & & $.12^{*}$ & .04 & .03 & .21 & & & \\
\hline POS & $.27^{* *}$ & .03 & .20 & .35 & & & & $.18^{* *}$ & .04 & .08 & .28 & & & \\
\hline Step 3 & & & & & .59 & .00 & .00 & & & & & .52 & .00 & .00 \\
\hline Years of Service & -.00 & .00 & -.01 & .01 & & & & .00 & .00 & -.01 & .01 & & & \\
\hline Gender & -.03 & .06 & -.18 & .12 & & & & -.01 & .07 & -.20 & .18 & & & \\
\hline Education & .02 & .02 & -.03 & .07 & & & & -.02 & .02 & -.07 & .04 & & & \\
\hline P-Org & $.56 * *$ & .03 & .48 & .64 & & & & $.57^{* *}$ & .04 & .46 & .69 & & & \\
\hline $\mathrm{P}-\mathrm{Occ}$ & .10 & .03 & .03 & .17 & & & & $.12^{*}$ & .04 & .02 & .21 & & & \\
\hline POS & $.28 * *$ & .03 & .20 & .36 & & & & $.18 * *$ & .04 & .08 & .29 & & & \\
\hline P-Org Fit X POS & -.03 & .03 & -.10 & .03 & & & & -.01 & .04 & -.10 & .09 & & & \\
\hline P-Occ Fit X POS & .04 & .03 & -.04 & .10 & & & & -.02 & .04 & -.12 & .08 & & & \\
\hline
\end{tabular}




\section{Table 18}

\section{Cross Validation of Moderating Effects of Perceived Organizational Support on Normative Commitment}

\begin{tabular}{|c|c|c|c|c|c|c|c|c|c|c|c|c|c|c|}
\hline \multirow[b]{2}{*}{$\begin{array}{l}\text { Step and Variable } \\
\text { Step I }\end{array}$} & \multicolumn{5}{|c|}{$\begin{array}{c}\text { Noncommissioned Members } \\
99 \% \mathrm{Cl} \text { for } \\
B\end{array}$} & \multirow[b]{2}{*}{$\Delta R^{2}$} & \multirow[b]{2}{*}{$\begin{array}{l}f^{2} \\
.01\end{array}$} & \multicolumn{7}{|c|}{$\begin{array}{l}\text { Officers } \\
99 \% \mathrm{Cl} \text { for } \mathrm{B}\end{array}$} \\
\hline & $B$ & $S E B$ & $L L$ & $U L$ & $\begin{array}{l}R^{2} \\
.01\end{array}$ & & & $B$ & $S E B$ & $L L$ & $U L$ & $\begin{array}{l}R^{2} \\
.00\end{array}$ & $\Delta R^{2}$ & $\begin{array}{l}f^{2} \\
.00\end{array}$ \\
\hline Years of Service & .00 & .00 & -.01 & .01 & & & & .00 & .01 & -.01 & .02 & & & \\
\hline Gender & .17 & .09 & -.08 & .41 & & & & .00 & .12 & -.30 & .30 & & & \\
\hline Education & -.03 & .03 & -.11 & .05 & & & & .01 & .03 & -.07 & .10 & & & \\
\hline Step 2 & & & & & $.44^{* *}$ & $.43^{* *}$ & .77 & & & & & $.38^{* *}$ & $.38 * *$ & .60 \\
\hline Years of Service & $-.01 *$ & .00 & -.02 & -.00 & & & & .00 & .00 & -.01 & .01 & & & \\
\hline Gender & .09 & .07 & -.10 & .27 & & & & .09 & .09 & -.15 & .32 & & & \\
\hline Education & -.01 & .02 & -.06 & .05 & & & & -.02 & .03 & -.09 & .05 & & & \\
\hline P-Org & $.40^{* *}$ & .04 & .30 & .49 & & & & $.38 * *$ & .05 & .24 & .51 & & & \\
\hline P-Occ & .06 & .03 & -.02 & .15 & & & & $.14^{*}$ & .04 & .03 & .25 & & & \\
\hline POS & $.42 * *$ & .04 & .33 & .52 & & & & $.33 * *$ & .05 & .21 & .45 & & & \\
\hline Step 3 & & & & & .44 & .003 & .00 & & & & & .38 & .00 & .00 \\
\hline Years of Service & $-.01 *$ & .00 & -.10 & -.00 & & & & .00 & .00 & -.01 & .01 & & & \\
\hline Gender & .09 & .07 & -.09 & .27 & & & & .10 & .09 & -.14 & .33 & & & \\
\hline Education & -.01 & .02 & -.06 & .05 & & & & -.02 & .03 & -.08 & .05 & & & \\
\hline P-Org & $.40^{* *}$ & .04 & .30 & .50 & & & & $.35 * *$ & .06 & .21 & .50 & & & \\
\hline $\mathrm{P}-\mathrm{Occ}$ & .08 & .03 & -.01 & .16 & & & & $.15^{*}$ & .04 & .03 & .26 & & & \\
\hline POS & $.42 * *$ & .04 & .32 & .52 & & & & $.33 * *$ & .05 & .20 & .45 & & & \\
\hline P-Org Fit X POS & .01 & .03 & -.08 & .01 & & & & -.05 & .05 & -.17 & .07 & & & \\
\hline P-Occ Fit X POS & .02 & .03 & -.04 & .14 & & & & .02 & .05 & -.11 & .14 & & & \\
\hline
\end{tabular}


Table 19

Cross Validation of Moderators on Turnover Intentions for Noncommissioned Members $99 \% \mathrm{CI}$ for $B$

\begin{tabular}{|c|c|c|c|c|c|c|c|}
\hline \multirow[b]{2}{*}{ Step and Variable } & & & & & & & \\
\hline & $B$ & $S E B$ & $L L$ & $U L$ & $R^{2}$ & $\Delta R^{2}$ & $f^{2}$ \\
\hline Step 1 & & & & & $.03 * *$ & & .03 \\
\hline Years of Service & $.02 * *$ & .01 & .01 & .04 & & & \\
\hline Gender & .01 & .11 & -.26 & .28 & & & \\
\hline Education & -.01 & .03 & -.09 & .08 & & & \\
\hline Step 2 & & & & & $.24^{* *}$ & .21 & .28 \\
\hline Years of Service & $.03 * *$ & .00 & .02 & .04 & & & \\
\hline Gender & .06 & .01 & -.18 & .30 & & & \\
\hline Education & -.04 & .03 & -.12 & .03 & & & \\
\hline P-Org & $-.30 * *$ & .05 & -.42 & -.16 & & & \\
\hline P-Occ & $-.13 * *$ & .04 & -.24 & -.02 & & & \\
\hline POS & $-.17 * *$ & .05 & -.30 & -.04 & & & \\
\hline PAlt & -.04 & .04 & -.13 & .06 & & & \\
\hline $\mathrm{CC}$ & $-.28 * *$ & .04 & -.37 & -.19 & & & \\
\hline Civ Equiv & -.11 & .11 & -.40 & .19 & & & \\
\hline Step 3 & & & & & .26 & .02 & .03 \\
\hline Years of Service & $.03^{* *}$ & .00 & .02 & .04 & & & \\
\hline Gender & .07 & .09 & -.17 & .31 & & & \\
\hline Education & -.04 & .03 & -.11 & .04 & & & \\
\hline P-Org & -.33 & .16 & -.73 & .08 & & & \\
\hline $\mathrm{P}-\mathrm{Occ}$ & -.06 & .15 & -.46 & .33 & & & \\
\hline POS & $-.18 *$ & .05 & -.31 & -.14 & & & \\
\hline PAlt & -.03 & .04 & -.13 & .06 & & & \\
\hline $\mathrm{CC}$ & $-.27 * *$ & .04 & -.36 & -.17 & & & \\
\hline Civ Equiv & -.12 & .122 & -.44 & .20 & & & \\
\hline P-Org X POS & .04 & .04 & -.08 & .15 & & & \\
\hline P-Org X PAlt & -.05 & .05 & -.17 & .07 & & & \\
\hline P-Org X CC & $.12 *$ & .04 & .02 & .21 & & & \\
\hline P-Org X Civ Equiv & .05 & .13 & -.30 & .40 & & & \\
\hline P-Occ X POS & -.04 & .05 & -.15 & .08 & & & \\
\hline P-Occ Fit X PAlt & -.03 & .04 & -.13 & .08 & & & \\
\hline P-Occ Fit X CC & -.08 & .04 & -.17 & .03 & & & \\
\hline P-Occ Fit X Civ Equiv & -.06 & .13 & -.39 & .27 & & & \\
\hline
\end{tabular}

Notes: $N=764$ POS = Perceived Organizational Support, P-Org = Person-organization fit, P-Occ $=$ PersonOccupation Fit, PAlt $=$ Perceived Job Alternatives, $\mathrm{CC}=$ Continuance Commitment, Civ Equiv $=$ Civilian Equivalence.

${ }^{*} p<.01,{ }^{* *} p<.0001$. 
Table 20

Cross Validation of Moderators on Psychological Withdrawal for Noncommissioned Members

\begin{tabular}{|c|c|c|c|c|c|c|c|}
\hline \multirow[b]{2}{*}{ Step and Variable } & \multicolumn{6}{|c|}{$99 \%$ CI for $B$} & \multirow[b]{2}{*}{$f^{2}$} \\
\hline & $B$ & $S E B$ & $L L$ & $U L$ & $R^{2}$ & $\Delta R^{2}$ & \\
\hline \multicolumn{8}{|l|}{ Step 1} \\
\hline Years of Service & $-.02 * *$ & .01 & -.04 & -.01 & $.02 * *$ & & .02 \\
\hline Gender & -.17 & .11 & -.46 & .13 & & & \\
\hline Education & .01 & .04 & -.08 & .10 & & & \\
\hline Step 2 & & & & & $.53^{* *}$ & .51 & 1.07 \\
\hline Years of Service & -.00 & .00 & -.01 & .01 & & & \\
\hline Gender & -.06 & .08 & -.27 & .15 & & & \\
\hline Education & -.03 & .03 & -.10 & .03 & & & \\
\hline P-Org & $-.42 * *$ & .04 & -.53 & -.31 & & & \\
\hline $\mathrm{P}-\mathrm{Occ}$ & $-.35^{* *}$ & .04 &.- .44 & -.25 & & & \\
\hline POS & $-.45^{* *}$ & .04 & -.57 & -.34 & & & \\
\hline PAlt & -.01 & .03 & -.10 & .07 & & & \\
\hline $\mathrm{CC}$ & $.10^{* *}$ & .03 & .02 & .18 & & & \\
\hline Civ Equiv & .01 & .10 & -.24 & .26 & & & \\
\hline Step 3 & & & & & .53 & .00 & .00 \\
\hline Years of Service & .00 & .00 & -.01 & .01 & & & \\
\hline Gender & -.06 & .08 & -.27 & .03 & & & \\
\hline Education & -.03 & .03 & -.09 & .15 & & & \\
\hline P-Org & $-.42 *$ & .13 & -.76 & -.08 & & & \\
\hline P-Occ & $-.34^{*}$ & .13 & -.66 & -.01 & & & \\
\hline POS & $-.46^{* *}$ & .04 & -.58 & -.35 & & & \\
\hline PAlt & -.02 & .03 & -.06 & .06 & & & \\
\hline $\mathrm{CC}$ & $.10^{*}$ & .03 & .03 & .18 & & & \\
\hline Civ Equiv & .01 & .10 & -.26 & .28 & & & \\
\hline P-Org Fit X POS & .04 & .04 & -.05 & .14 & & & \\
\hline P-Org Fit X PAlt & .03 & .04 & -.07 & .13 & & & \\
\hline P-Org Fit X CC &. .00 & .04 & -.08 & .07 & & & \\
\hline P-Org Fit X Civ Equiv & .01 & .11 & -.29 & .30 & & & \\
\hline P-Occ X POS & -.04 & .04 & -.14 & .06 & & & \\
\hline P-Occ Fit X PAlt & -.07 & .03 & .15 & .02 & & & \\
\hline P-Occ Fit X CC & .01 & .03 & -.08 & .09 & & & \\
\hline P-Occ Fit X Civ EQuiv & -.01 & .11 & -.30 & .27 & & & \\
\hline
\end{tabular}

Notes: $N=764$ POS = Perceived Organizational Support, P-Org = Person-organization fit, P-Occ = PersonOccupation Fit, $\mathrm{PAlt}=$ Perceived Job Alternatives, $\mathrm{CC}=$ Continuance Commitment, $\mathrm{Civ}$ Equiv $=$ Civilian Equivalence.

${ }^{*} p<.01,{ }^{* *} p<.0001$ 
Table 21

Cross Validation of Moderators on Turnover Intention for Officers

\begin{tabular}{|c|c|c|c|c|c|c|c|}
\hline \multirow[b]{2}{*}{ Step and Variable } & \multicolumn{6}{|c|}{$99 \%$ CI for $B$} & \multirow[b]{2}{*}{$f^{2}$} \\
\hline & $B$ & $S E B$ & $L L$ & $U L$ & $R^{2}$ & $\Delta R^{2}$ & \\
\hline Step 1 & & & & & $.05^{* *}$ & & .05 \\
\hline Years of Service & $.03^{* *}$ & .01 & .01 & .04 & & & \\
\hline Gender & .12 & .12 & -.20 & .44 & & & \\
\hline Education & -.02 & .04 & -.11 & .07 & & & \\
\hline Step 2 & & & & & $.22^{* *}$ & .17 & .22 \\
\hline Years of Service & $.03^{* *}$ & .01 & .02 & .04 & & & \\
\hline Gender & .07 & .11 & -.22 & .36 & & & \\
\hline Education & -.04 & .03 & -.12 & .05 & & & \\
\hline P-Org & $-.17^{*}$ & .06 & -.33 & -.01 & & & \\
\hline P-Occ & $-.25 * *$ & .05 & -.39 & -.11 & & & \\
\hline POS & -.09 & .06 & -.24 & .07 & & & \\
\hline PAlt & .01 & .05 & -.13 & .14 & & & \\
\hline $\mathrm{CC}$ & $-.27 * *$ & .04 & -.38 & -.16 & & & \\
\hline Civ Equiv & -.10 & .11 & -.35 & .15 & & & \\
\hline Step 3 & & & & & .23 & .01 & .01 \\
\hline Years of Service & $.03^{* *}$ & .02 & .02 & .04 & & & \\
\hline Gender & .07 & .11 & -.22 & .37 & & & \\
\hline Education & -.04 & .03 & -.12 & .05 & & & \\
\hline P-Org & -.01 & .22 & -.63 & .48 & & & \\
\hline $\mathrm{P}-\mathrm{Occ}$ & -.06 & .20 & -.58 & .45 & & & \\
\hline POS & -.08 & .06 & -.23 & .08 & & & \\
\hline PAlt & .00 & .05 & -.14 & .14 & & & \\
\hline $\mathrm{CC}$ & $-.27^{* *}$ & .04 & -.39 & -.16 & & & \\
\hline Civ Equiv & -.09 & .10 & -.34 & .16 & & & \\
\hline P-Org X POS & -.01 & .06 & -.16 & .14 & & & \\
\hline P-Org X PAlt &. .09 & .07 & -.27 & .10 & & & \\
\hline P-Org X CC & -.06 & .05 & -.19 & .08 & & & \\
\hline P-Org X Civ Equiv & -.06 & .12 & -.38 & .25 & & & \\
\hline P-Occ X POS & .01 & .06 & -.16 & .15 & & & \\
\hline P-Occ Fit X PAlt & -.02 & .06 & -.17 & .13 & & & \\
\hline P-Occ Fit X CC & -.05 & .05 & -.08 & .18 & & & \\
\hline P-Occ Fit X Civ Equiv & -.12 & .11 & -.41 & .18 & & & \\
\hline
\end{tabular}

Notes: $N=495$ POS = Perceived Organizational Support, P-Org = Person-organization fit, P-Occ $=$ PersonOccupation Fit, PAlt $=$ Perceived Job Alternatives, $\mathrm{CC}=$ Continuance Commitment, Civ Equiv $=$ Civilian Equivalence.

${ }^{*} p<.01,{ }^{* *} p<.0001$. 
Table 22

Cross Validation of Moderators on Psychological Withdrawal for Officers

\begin{tabular}{|c|c|c|c|c|c|c|c|}
\hline \multirow[b]{2}{*}{ Step and Variable } & \multicolumn{6}{|c|}{$99 \%$ CI for $B$} & \multirow[b]{2}{*}{$f^{2}$} \\
\hline & $B$ & $S E B$ & $L L$ & $U L$ & $R^{2}$ & $\Delta R^{2}$ & \\
\hline Step 1 & & & & & $.03^{* *}$ & & .03 \\
\hline Years of Service & .00 & .01 & -.01 & .02 & & & \\
\hline Gender & .17 & .14 & -.20 & .54 & & & \\
\hline Education & $-.14^{*}$ & .04 & -.25 & -.04 & & & \\
\hline Step 2 & & & & & $.50^{* *}$ & .47 & .95 \\
\hline Years of Service & .01 & .01 & -.00 & .02 & & & \\
\hline Gender & .07 & .10 & -.20 & .34 & & & \\
\hline Education & -.07 & .03 & -.15 & .01 & & & \\
\hline P-Org & $-.43 * *$ & .06 & -.58 & -.28 & & & \\
\hline $\mathrm{P}-\mathrm{Occ}$ & $-.41^{* *}$ & .05 & -.54 & -.28 & & & \\
\hline POS & $-.33 * *$ & .05 & -.47 & -.19 & & & \\
\hline PAlt & -.03 & .05 & -.15 & .10 & & & \\
\hline $\mathrm{CC}$ & $.10^{*}$ & .04 & .00 & .20 & & & \\
\hline Civ Equiv & -.12 & .09 & -.35 & .10 & & & \\
\hline Step 3 & & & & & .51 & .01 & .01 \\
\hline Years of Service & .01 & .01 & -.01 & .02 & & & \\
\hline Gender & .07 & .10 & -.27 & .01 & & & \\
\hline Education & -.07 & .03 & -.09 & .34 & & & \\
\hline P-Org & -.22 & .20 & -.76 & .29 & & & \\
\hline P-Occ & $-.51^{*}$ & .18 & -.66 & -.05 & & & \\
\hline POS & $-.33 * *$ & .05 & -.58 & -.18 & & & \\
\hline PAlt & .01 & .05 & -.06 & .13 & & & \\
\hline $\mathrm{CC}$ & $.10^{*}$ & .04 & .03 & .21 & & & \\
\hline Civ Equiv & -.12 & .09 & -.26 & .10 & & & \\
\hline P-Org Fit X POS & -.05 & .05 & -.05 & .08 & & & \\
\hline P-Org Fit X PAlt & -.05 & .06 & -.07 & .11 & & & \\
\hline P-Org Fit X CC & .00 & .05 & -.08 & .12 & & & \\
\hline P-Org Fit X Civ Equiv & -.15 & .11 & -.29 & .14 & & & \\
\hline P-Occ X POS & .01 & .05 & -.14 & .15 & & & \\
\hline P-Occ Fit X PAlt & $.17 *$ & .05 & .15 & .30 & & & \\
\hline P-Occ Fit X CC & .01 & .05 & -.08 & .12 & & & \\
\hline P-Occ Fit X Civ EQuiv & .07 & .10 & -.30 & .34 & & & \\
\hline
\end{tabular}

Notes: $N=495$ POS = Perceived Organizational Support, P-Org = Person-organization fit, P-Occ $=$ PersonOccupation Fit, PAlt $=$ Perceived Job Alternatives, $\mathrm{CC}=$ Continuance Commitment, Civ Equiv $=$ Civilian Equivalence.

${ }^{*} p<.01,{ }^{* *} p<.0001$ 


\section{Appendix $\mathbf{J}$}

\section{Figures for Significant Moderator Effects for Cross Validation Sample}

Figure 6

Moderator Effects of Continuance Commitment on Turnover Intention for Noncommissioned Members.

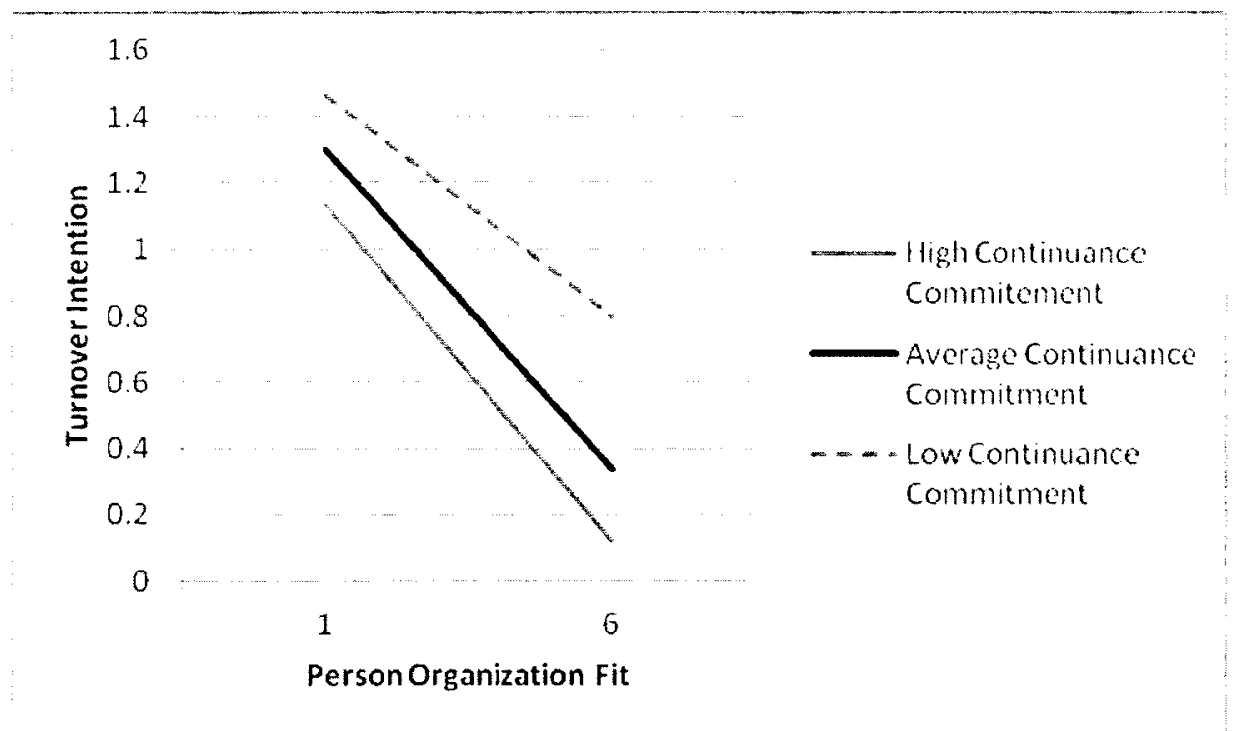

Figure 6. Interaction graph depicting the moderating effect of continuance commitment on the association between person-organization fit and turnover intention for noncommissioned members 


\section{Figure 7}

\section{Moderator Effects of Perceived Job Alternatives on Psychological Withdrawal for}

\section{Noncommissioned Members}

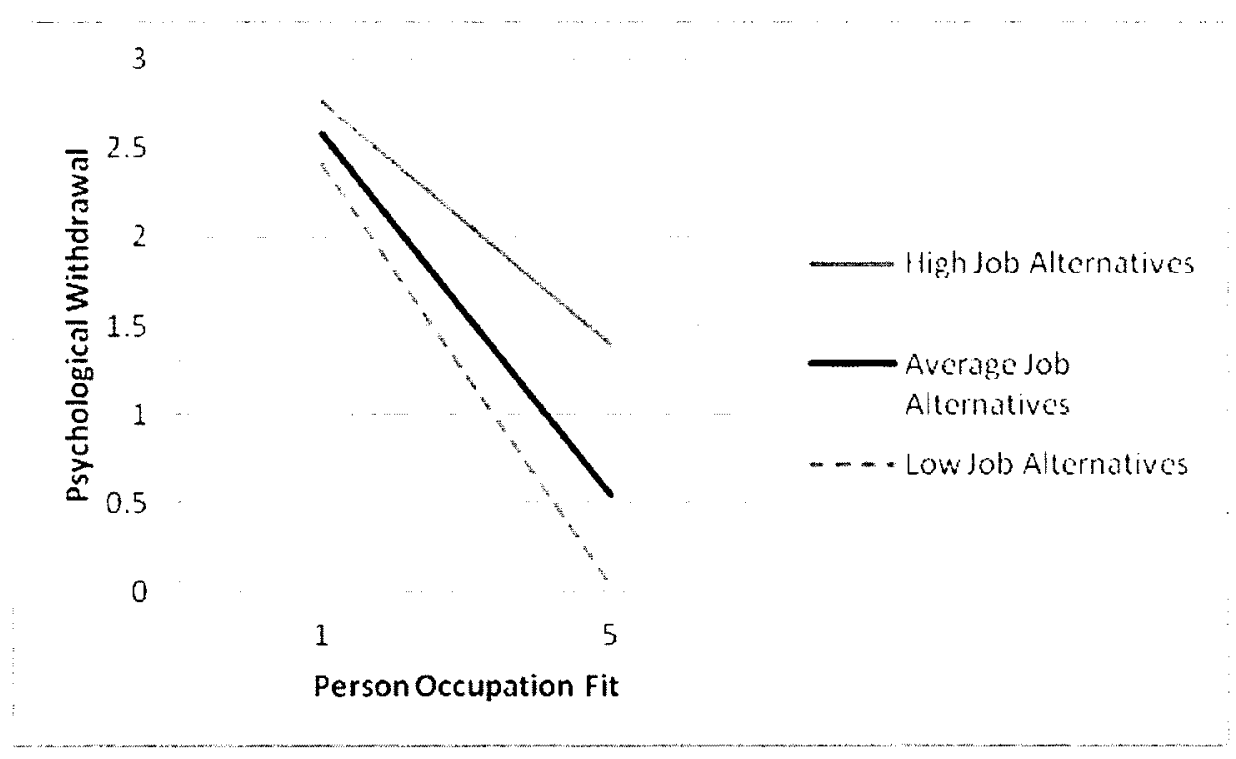

Figure 7. Interaction graph depicting the moderating effect of perceived job alternative on the association between person-occupation fit and psychological withdrawal for officers 